OPERATIONAL PLANNING OF FIXED-ROUTE

AND DEMAND-RESPONSIVE BUS SYSTEMS IN GREATER LAFAYETTE AREA

SEPTEMBER 1973 - NUMBER 22

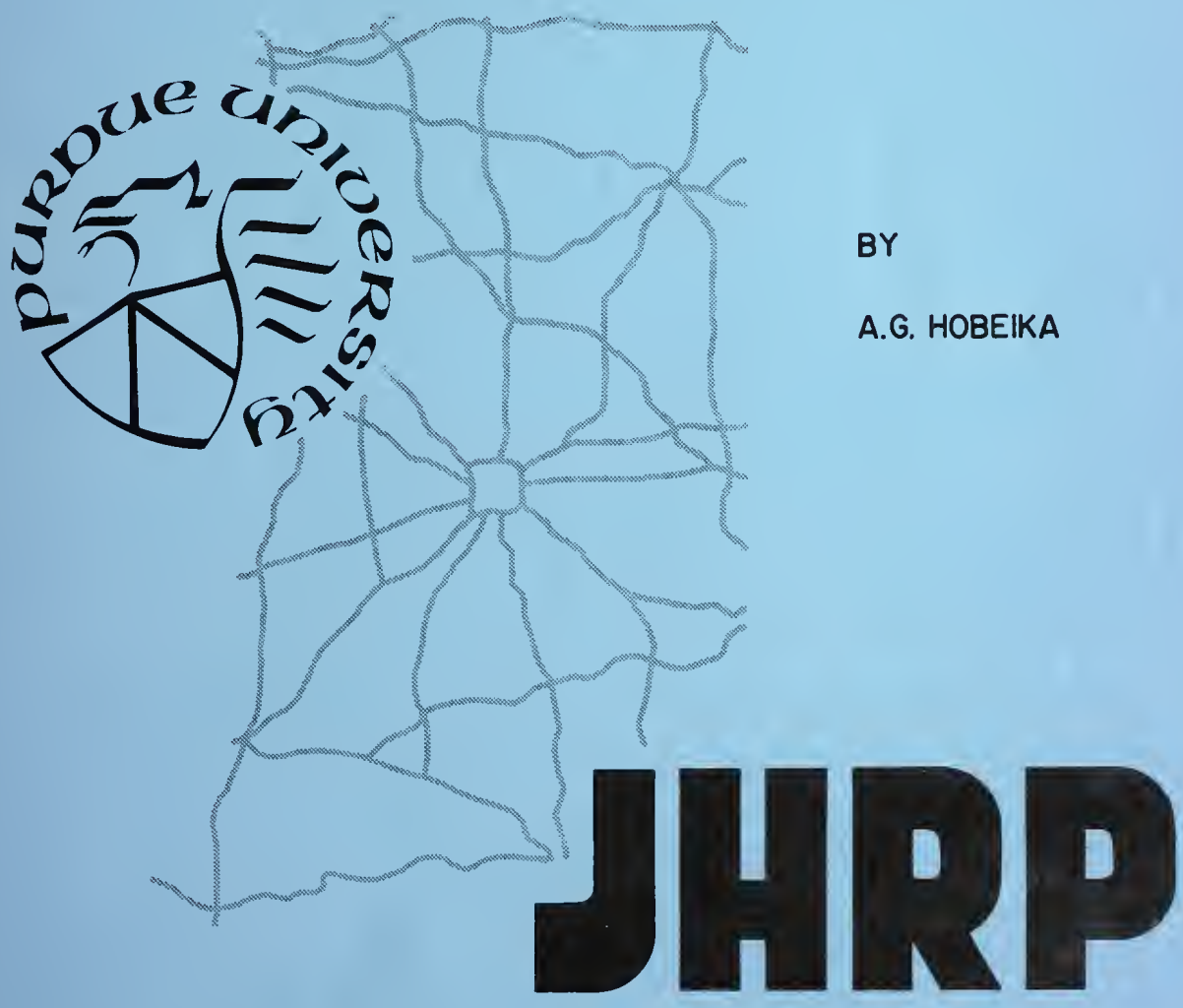

JOINT HIGHWAY RESEARCH PROJECT PURDUE UNIVERSITY AND INDIANA STATE HIGHWAY COMMISSION 

OPERATIONAL PLANNING OF FIXED-ROUTE AND DEMAND-RESPONSIVE BUS SYSTEMS IN GREATER LAFAYETTE AREA

T0: J. F. McLaughlin, Director Joint Highway Research Project

FROM: H. L. Michael, Associate Director Joint Highway Research Project
September 14,1973

Project: $\quad C-36-740$

File: $3-9-4$

Attached is a Ftnal Report titled "Operational Planning of Fixed-Route and Demand-Responsive Bus Systems in Greater Lafayette Area" which has been authored by Mr. Antoine G. Hobeika under the direction of Professor G. T. Satteriy of our staff. This research was sponsored by the school of Civil Engineering in cooperation with the Greater Lafayette community in the planning of flxed-route and demand-responsive bus systems for the communtty. The fixed route system has been 1 mplemented and the demand-responsive system is now planned for implementation in early 1974. Mr. Hobeika also used the research report as his thesis for the Ph.D. degree.

Although the research was not sponsored by the Indiana State Highway Commission, it is presented to the JHRP Board in line with our policy of making available to its members as information related research conducted by the School of Civil Engineering.

Respectfully submitted,

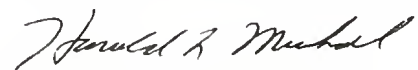

Harold L. Michael Associate Director

$H L M: m s$

CC: W. L. Dolch

R. L. Eskew

G. D. Gibson

W. H. Goetz

M. J. Gutzwiller

G. K. Hallock
R. H. Harrell

M. L. Hayes

C. W. Lovell

G. W. Marks

R. D. Miles

G. T. Satterly
C. F. Scholer

M. B. Scott

J. A. Spooner

N. W. Steinkamp

H. R. J. Walsh

E. J. Yoder 
Digitized by the Internet Archive in 2011 with funding from

LYRASIS members and Sloan Foundation; Indiana Department of Transportation 


\title{
Final Report \\ OPERATIONAL PLANNING OF FIXED-ROUTE AND DEMAND-RESPONSIVE BUS SYSTEMS IN GREATER LAFAYETTE AREA
}

\author{
by \\ Antoine G. Hobelka \\ Graduate Instructor in Research \\ Joint Highway Research Project \\ Project No.: C-36-74D \\ File No.: $3-9-4$
}

This research was sponsored by the School of Civil Engineering.

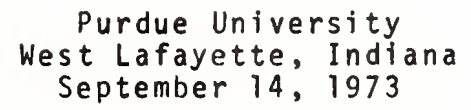


"If there is technological advance without social advance, there is almost automatically an increase in human misery."

\author{
Michael Harrington \\ "The Other America". - 1962
}




\section{ACKNOWLEDGMENTS}

The author wishes to express his appreciation to Professor Gilbert T. Satterly for his counsel during the entire course of this study. He also wishes to express his appreciation of Professor Satterly's and Professor Michael's critical review of the manuscript.

The author wishes to thank the School of Civil Engineering, Purdue University and the Joint Highway Research Project of Purdue University for the financial assistance which made this research possible.

The author would also like to express his thanks to the staff of Greater Lafayette Public Transportation Corporation and of Greater Lafayette Transportation and Development study for their assistance in collecting the data; to Mr. Marcel Zobrak, Urban Mass Transportation Administration, and to Dr. Frank Tung, Transportation System Centre, Department of Transportation, for providing the Dial-A-Ride computer simualtion package; to Mrs. Linda Muench for typing the correspondence in the data collection phase; and to Mrs. Marian Sipes who typed the final manuscript. 
TABLE OF CONTENTS

$\underline{\text { Page }}$

LIST OF TABLES ........................... vii

LIST OF FIGURES. . . . . . . . . . . . viii

ABSTRACT . . . . . . . . . . . . . $x i$

CHAPTER 1: INTRODUCTION ............... 1

Urban Transportation Problems . . . . . . . 1

Problem Statement.......... . . 7

Purpose and Scope of study. . . . . . . . 10

CHAPTER 2: RELATEO WORKS. .......... . 12

Fixed-Route Bus Systems . . . . . . . . 12

Demand-Responsive Bus System. . . . . . . 18

CHAPTER 3: CONCEPTUALIZATION OF OPERATIONAL

PLANMING OF BUS SYSTEMS IN SMALL URBAN AREAS. • 23

Pandom Routes and Fixed Routes. . . . . . 23

Short-Distance Public Transportation. . . . 27

operational Planning. ........... 31

CHAPTER 4: AREA CHARACTERISTICS ........ 36

Greater Lafayette Area. . . . . . . . . 36

Non-Demographic Characteristics..... 39

Analys is Zones........... . . 39

Existing Land Uses........ . . 39

Existing Street Network. . . . . . . 44

Demographic Characteristics. . . . . . . 47

Population and Employment Distribution . 47

Car Ownership and Housing Unit Values. . 49

CHAPTER 5: THE FIXED-ROUTE BUS SYSTEM . . . . . 54

Public Transportation Prior to April 1973 . . . 54

History. . . . . . . . . . 54

0ld Bus Service.......... . 56 
TABLE OF CONTENTS (Continued)

Page

Characteristics of Transft Riders... . 62

Travel Data............. 64

Economic Condition ......... 67

Conclusions Regarding the 01d Bus Service. 69

Development of the New Fixed-Route Bus System. 70

objectives.......... . . 70

Guidelines for Route Development. . . 70

Fixed-Route Selection Procedures . . . . 74

Alternate System Concepts. . . . . . 78

Analys is of the Selected System. . . . 85

CHAPTER 6: THE DEMAND-RESPONSIVE BUS SYSTEM . . . 95

Introduction. . . . . . . . . . . 95

Operational Characteristics of Dial-A-Ride. . 96

How It Works........ . 9 96

Problems Encountered in the operation

of Dial-A-Ride.......... 99

Area Size. . . . . . . . . . . 101

Demand Level .. . . . . . . . . 102

Scheduling Algorithm of the Dial-A-Ride System. 104

Introduction . . . . . . . . . . 104

Algorithmic Considerations . . . . . 105

Statement of the Problem . . . . . . 107

Algorithm Design........ . . 109

Computer simulation of the Dial-A-Ride System. 116

Introduction .......... 116

Objective of the Simulation Model. . . 117

The Model............ . 117

Simulation Experiments. . . . . . . . . 122

Area Characteristics. . . . . . . 127

Demand Characteristics...... . 132

Vehicle Characteristics. . . . . . 138

Run Characteristics. . . . . . . . 139

The Simulation Results......... . . 139

Number of Vehicles......... 140

Level of Service......... . . 143

Trip Length. . . . . . . . . . . 152

CHAPTER 7: COST ANALYSIS. . . . . . . . 156

Introduction. ............. . . 156

Analysis of the Resuits of the Two Bus systems. 157

Cost Analysis of the Fixed-Route System . . . 159

Cost Analysis of the Demand-Responsive System. 161 
Page

CHAPTER 8: CONCLUSIONS AND RECOMMENDATIONS. . . . 165

Conclusions............. . . 165

Recommendations for Further Research. . . . 167

Recommendations for Implementation..... . 168

LIST OF REFERENCES ............. 170

General References. . . . . . . . . 173

APPENDICES . . . . . . . . . . . . 175

Appendix A. . . . . . . . . . . 175

Appendix B. . . . . . . . . . . . . 179

Appendix C................ . 188

Appendix D. . . . . . . . . . . . . 199

VITA . . . . . . . . . . . . 209 


\section{LIST OF TABLES}

Table

Page

5-1 Timetable of the 01d Bus Routes...... 59

5-2 The Selected Route Timetables. . . . . . 88

6-1 Provisional Route........... 113

6-2 Node Insertion ........... 114

6-3 Values of Demand Level and Number of

Buses Used in the Simulation Experiments . . 126

Appendix

Table

A-1 Traffic Zone Cumulative Frequencies of

Containing Origins and Destinations. . . . 176

A-2 Level of Service of the Fixed-Route

Bus System.............. 177

B-1 A Sample of Input Data........ 180

B-2 A Sample output of the Computer

Simulation Runs. . . . . . . . . . . 183

C-1 Demographic Characteristics of the

Simulation Zones........... . 190

C-2 Simulation Zone Coordinates and Their

Relative Probabilities of Containing

Origins and Destinations....... . 192

D-1 Mean Level of Service, Vehicle

Productivity, and Percent Time Vehicle Unassigned for the Different Simulation Runs............... 200

D-2 Maximum and Mean Service Times for the Different Simulation Runs. . . . . . . 203

D-3 Mean Level of Service By Trip Length . . . 206 
LIST OF FIGURES

Figure

Page

2-1 The Main Subsystems of Public

3-1 Routing and Scheduling Schematic For

Public Transport System. . . . . . . . 26

3-2 Characteristics of Short-Distance

Public Transportation. . . . . . . . 28

3-3 Transportation Patterns and Travel

Desire Patterns........... . . 30

3-4 The Design Planning Process. . . . . . . 34

4-1 Population Growth of the Lafayette

Standard Metropolitan Statistical Area... 38

4-2 Traffic Analysis Zones.......... 40

4-3 Existing Land Uses . . . . . . . . 4 42

4-4 Major and Minor Arterial Streets . . . . . 45

4-5 Number of Housing Units and Population

Distribution by Traffic Zones....... 48

4-6 Employment Distribution by Traffic Zones. . 50

4-7 Car Ownership by Census Tracts . . . . . . 51

4-8 Housing Unit Values. . . . . . . . . 52

5-1 Bus Routes of the 01 d System...... . . 57

5-2 Route Coverage of the 01d Bus System (1/4

Mile on Each Side of Route)........ 60

5-3 Characteristics of Transit Riders. . . . . 63

5-4 Hourly Transit Trip Distribution . . . . . 65 
LIST OF FIGURES (Continued)

Figure

Page

5-5 Net Taxable Income - Greater Lafayette

Bus Company. ............. 68

5-6 Route Concept A. . ......... 80

5-7 Route Concept B............ 82

5-8 Route Concept $C$ (The Selected System). . . 84

5-9 Bus Route Coverage ( $1 / 4$ Mile on Each

Side of Route)............ . 90

5-10 Bus Route Coverage ( $1 / 8$ Mile on Each

Side of Route)............ . 91

6-1 The Dial-A-Ride Concept. ....... 97

6-2 Node Insertion Process ......... 112

6-3 Relation Among the Different Parameters

of the Simulation Model. . . . . . . 124

6-4 Relationship Between the Aerial and

Actual Distance............ . 131

6-5 Effect of Service Constraints on the

Normalized Mean and Maximum Waiting Time. . 133

6-6 Effect of Service Constraints on the Normalized Mean and Maximum Travel Time. . 134

6-7 Effect of Service Constraints on the Normalized Mean and Maximum Total Time . . 135

6-8 Effect of Demand Level on Number of Vehicles.............. 141

6-9 Effect of Demand Level on Vehicle Productivity............ . 142

6-10 Effect of Demand on Mean Level of Service. . 144

6-11 Effect of Demand Level on Mean and Maximum Service Times. . . . . . . . . 145

6-12 Effect of Demand Level on Percent Time Vehicle Unassigned.......... 146 


\section{LIST OF FIGURES (Continued)}

Figure

Page

6-13 Effect of Number of Vehicles on Mean

Level of Service.......... . 149

6-14 Effect of Number of Vehicles on Mean and Maximum Service Times. . . . . . . 150

6-15 Effect of Number of Vehicles on the Percent Time Vehicle Unassigned. . . . . 151

6-16 Effect of Number of Vehicles on Mean Level of Service by Trip Length. ..... 153

6-17 Effect of Demand Level on Mean Level of Service by Trip Length. . . . . . . 154

Appendix

Figure

A-1 Desire Lines of Travel of the FixedRoute Simulation.......... 178

C-1 Dial-A-Ride Simulation Zones . . . . . 189

C-2 Desire Lines of Travel of Simulation Run Number 1.............. 195

C-3 Desire Lines of Travel of Simulation Run Number 2.............. 196

C-4 Desire Lines of Travel of Simulation Run Number 3............... . 197

C-5 Desire Lines of Travel of Simulation Run Number 4.............. 198 
ABSTRACT

Hobeika, Antoine George, Ph.D., Purdue University, August, 1973. Operational Planning of Fixed-Route and DemandResponsive Bus Systems in Greater Lafayette Area. Major Professor: Gilbert T. Satterly, Jr.

Many small urban areas in the United States are trying to revive their bus public transportation. Some of them are intending to implement, in addition to the conventional bus system, a new bus system that has close attributes to the automobile, a demand-responsive system known as DialA-Ride. The Greater Lafayette Area in Indiana, is one of these small urban areas. This research suggests the proper combination of two bus modes, the fixed-route and the demand-responsive bus systems, that best serves the various demand levels at a level of service required by the customer, using Greater Lafayette Area as a case study. A simplified procedure was developed to design the fixed route of the bus system of the Greater Lafayet te Area. Fifteen buses of 25 to 30 passenger seats running at half hour headways are needed to provide a mean level of service of 2.3 to 2.5 times the mean auto travel time. The level of service was measured by the total time spent by the users on the bus system. 
Computer simulation was used to duplicate the operations of the Dial-A-Ride system in real environment. The system operates on many-to-many basis (many origins to many destinations) with computer dispatching. The number of small buses needed to satisfy the demand levels of 30 calls per hour to 150 calls per hour had been investigated for different levels of service.

Cost comparisons of the two systems provided the feasible operation of the two bus modes for various demand levels under the same level of service. The results show that the fixed-route system best serves the high demands, demands that are greater than 90 persons per hour. The Dial-A-Ride system best serves the lower demands, demands of 90 calls per hour and less.

Ho generalization of the results could be reached at this point in time, except for small urban areas similar in size and in structure to Greater Lafayette Area. 
CHAPTER 1: INTRODUCTION

\section{Urban Transportation Problems}

Scientific and technological developments have profoundly altered man's instltutions, his life style, and his aspirations in the last several generations. The technological developments brought about by the transport industries were the main forces behind these changes. This research concentrated mainly on intra-urban passenger transportation and its role as an urban-shaping force. Movement of goods, though equally important, was beyond the scope of this study.

According to Lyle C. Fitch, American cities, which originally were closely clustered around oceans or riverports, have been conditioned as to development, shape and life by a series of transportation technological developments. Fitch describes the four major transportation developments as follows:

First was the railroad, which freed industry and commerce from exclusive dependence on ports, linked cities with hinterlands and other cities. The railroad encouraged suburban towns to develop along radial lines from the city core.

A second major technolgoical development was the high speed elevator which spread cities into the third dimension. It made possible great increases in 1 and-use densities, and created problems of integrating horizontal and vertical movement. 
Third was the motor vehicle; it loosened the bonds which historically had tied many activities to the central city and transformed drastically the city-suburban structure and its functions.

Fourth was the airplane; though it is not a significant intra-urban transportation mode, it has had several important urban-shaping effects. Air transportation links many urban residents more closely to the outside world in ways that affect their working and living patterns. Large city airports tend to become major subcentres because they are large employers themselves and because they attract many different types of economic activity (4).*

In spite of all the technological developments, the transportation system is one of the many things which presently seem to be growing no better in urban regions. The transportation system offers nearly a mile of street or road for every square mile of 1 and and yet, provides no relief from time-consuming, and wasteful congestion.

The transportation system lays out new freeways to accommodate the increase in number of cars in growing cities and suburbs, and in doing so disrupts the neighborhood, damages the countryside, and fouls the air with exhaust from automobiles. In addition, the transportation system could not find a way to prevent the death of 50,000 people each year on highways and streets. * Numbers in parentheses refer to entries in the List of
References. 
These pressing problems in the transportation system were so apparent in the last decade that they required action from the presidents of the United States.

President John F. Kennedy was the first president to send a special message to Congress on the subject of transportation. In his message, "The Transportation System of Our Nation," on April 5, 1962, he comments on the urban transportation problems as follows:

Our national welfare therefore requires the provision of good urban transportation, with the properly balanced use of private vehicles and modern mass transport to help shape, as well as serve, urban growth (12).

President Lyndon B. Johnson, in his message "Transportation for America" to the congress on March 2, 1966, summarizes the shortcomings of the transportation system:

America today lacks a coordinated transportation system that permits travellers and goods to move conveniently and efficiently from one means of transportation to another, using the best characteristics of each (11).

President Richard M. Nixon, in a proclamation on March 31, 1971, said:

We are now entering into a new era in transportation, an era in which our national mobility will demand the continued conquest of time and space; yet, our national conscience will not longer permit irreparable damage to our land, our environment, or the social fabric of our communities. It is in this light that transportation faces its challenge of the future.

To meet that challenge, we will need a wholly. balanced transportation system - a system that provides our citizens with the ability to choose the most efficient means of 
transportation at the least possible cost to themselves and to the environment. I ask for the help of all citizens in achleving this goal (16).

A coordinated and balanced transportation system seems to be the answer to the transport problems in American cities. But many experts do not fully support this answer. On one side, the environmentalists and the ecologists think that the American public and the automobile are in a life and death struggle. According to ecologist Kenneth P. Cantor:

The car is robbing the American people of their land, air, minds, and their very lifes. It is becoming increasingly clear that the solution of the transportation-automobile problem is of high priority if we are to come to terms with the environment and with ourselves (2).

A. Q. Howbray, in his book Road to Ruin, asks to take the streets away from the private automobile in American cities and give them back to the people. He considers that such a step would be judged insane by the society, but he believes that it must be taken someday to save the lives of the people:

Population grows, asphalt spreads, and land diminishes, and there is a finite end to it al1. Long before the 1 imit is reached, the environment will have become utterly hostile to human life (14).

on the other side, the road and auto advocates consider that the backbone of the economic growth of the United States is the vast networks of highways and 
Interstate roads. A study financed by American Association of State Highway Officials (A.A.S.H.O.) shows clearly that:

The automobile is by far the most important mode of travel to the American household. . . Nearly all change in family situations and community developments tend to increase the use of the automobile, leading to the conclusion that the automobile will become even more important in the years ahead.

There appears to be close 'ego-involvement' with the automobile as a way of life.

The attitude toward existing public transportation service and facllities tend to be generally negative than positive (15).

The report concludes that "highways will be the dominant force and a major transportation mode in all areas of the United States for years to come."

The transportation mode that will be dominant in the future remains a matter of considerable debate. However, many experts feel that a proper mix of the different transportation modes would attempt to solve the transport problem in most American cities. The ideal, of course, would be to have each of the general modes - private transport and mass transport - do the job that it does best. Private transport, known for its extreme flexibility, comfort, speed, and privacy will probably remain the type of transportation most desirable and most economical for both individual and society as a whole for a wide variety of trips involving metropolitan areas. Where many persons must use the same space at the same time, mass transport, because of its economical use of space and its ability to 
handle large numbers of people, is generally deemed to have the advantage as far as the effective use of spaceresources is concerned $(20)$. At the same time, public transport is a necessity for those people who cannot, or choose not, to drive to achieve their travel needs.

Clearly there is a need for the proper combination of facilities and hardware in the transport systems. How this proper combination can be achieved is still a matter of discussion and research among the experts in the field of transportation.

The first step taken by the federal government to assist in achieving a balanced transportation system was initiated through the passage of the legislation of The Urban Mass Transportation Act of 1964. The legislation was signed into law by President Johnson on July 9, 1964. The program provides federal grants to assist public agencies and local bodies in providing capital facilities and equipment for use in public transportation service in urban areas. The legislation allows the federal government to contribute up to two-thirds of the cost of new equipment and facilities. The other one-third of the cost must be provided by local funds. The legislation specified that a continuing program of comprehensive planning is necessary in any given city or metropolitan area in order for it to qualify for the capital grants. This financial incentive reinforces the new federal policy of coordinating transport 
programs with other aspects of urban development.

Federal money is also available through the 1964 Act to Research, Development and Demonstration Projects which "will assist in the reduction of urban transportation needs, the improvement of mass transportation service, or the contribution of such services toward meeting total urban transportation needs at minimum cost" (22). The 1966 Amendments to the Urban Mass Transportation Act of 1964 made federal money also available, on a matching basis, for the technical studies that are required before application for a federal capital grant can be initiated. Aid was also provided for a new program of managementtraining grants, thus recognizing the vital need to improve the caliber of management in the mass-transit field. Aid programs to colleges and universities were also provided for research and training to foster comprehensive studies on urban transportation problems.

\section{Problem Statement}

Public transportation in the Greater Lafayette Area of Indiana prior to April 1973, gives a typical example of the decline of transit operations in small cities. With the advent of the automobile, people were no longer restricted to walking distances or specific transit routes. The automobile gave them total flexibility in movement and in choice of residence. This dependence upon the 
automobile led to urban sprawl, and to the dispersion of urban activities, resulting in an increase of spatial separation between people and activities.

The past and existing transit systems, being structured mainly to serve the downtown area or central business district, were unable to meet the basic change in the demand structure for movement in the city. Loss of patronage to the transit system resulted, and people became more and more dependent on the automobile to satisfy their travel needs. This continuous decline in transit patronage resulted in continuous decrease in passenger revenues, and coupled with continuous increase in operating costs, resulted in a transit system that is not economically viable. Being economically infeasible, combined with the inability of transit management to modify the system to meet public demand, resulted in curtailment in the transit routes, and finally to its abandonment to public ownership. The deterioration of public transportation has left a portion of urban citizens at a disadvantage in achieving their travel needs. The group of citizens that are dependent upon public transportation for movement include: 1) the elderly who cannot or choose not to drive; 2) the young; 3) the secondary worker and the housewife with no automobile available for their tripmaking; and 4) the poor. Depriving these people of complete mobility limits their social, 
economic, and cultural opportunities and makes the quality of their urban life miserable in comparison with the other more mobile groups of the community.

The city of Lafayette agreed to the assumption of the public transportation system in the Greater Lafayette Area in July 1970. The elected officials of the two cities then formed a Mass Transit Authority which took over the operation of the bus system in the latter part of 1971.

When the Authority took over the operation, it found that there was no equipment that could be termed safe for operation. The newest bus was at least twenty years old and there were at least three breakdowns a day on the routes. The bus system was composed of six buses operating on four fixed routes. According to a study done in November 1970 , the ridership on the system amounted to less than a thousand persons on the average day. Most of these riders were captive riders. That is to say the riders had no other alternative for making their trip. Very few, if any, of the ridership desired to use public transportation in the Greater Lafayette Area. They simply had no other means of transportation.

This attitude toward the existing bus system is explainable by the fact that most of the riders were discontented with the level of service provided and with the condition of equipment. 
The city officials recognizing the plight they were in, directed the Mass Transit Authority to implement a new bus system in the city. The Mass Transit Authority agreed to buy 16 new middle size buses to operate on fixed routes during the peak hours, and 10 small buses to operate on dynamic and flexible routes on the off-peak hours using the demand-responsive bus concept, usually known as Dial-A-Ride. To obtain the money needed to rebuild the system the Authority applied for the federal money available for the two-thirds of the capital investments provided by the Urban Mass Transportation Act of 1964. The local matching money was obtained from general obligation bonds bought by the local banks and will be repaid by means of general tax revenues.

\section{Purpose and Scope of the Study}

The main purpose of this study was to investigate the proper combination of fixed-route and demand-responsive bus systems that would best serve different demand levels at a required or given level of service. In achieving this purpose four objectives were developed.

The first objective was to develop a methodology for the design of the fixed-routes of a bus system in a small urban area. This methodology was used to develop the fixed-routes of the Greater Lafayette Area bus system, using the number of buses available for 
service. Fifteen buses, following the recommendation of the Greater Lafayette Bus Transit Study were available for the new service. Factors needed for the design such as the characteristics of the Greater Lafayette Area and of the old bus system were also included in the analysis.

The second objective was to predict the number of buses required to provide a demand-responsive bus system in off-peak periods in the Greater Lafayette Area. The system as planned will operate on many-to-many basis (many origins to many destinations) with computerized dispatching. This was studied for different demand levels and various levels of service required by the customers. Computer simulation was used to duplicate the real world environment, to evaluate the system, and to arrive at some operating decisions for real performance.

The third objective was to make cost comparisons between the two bus systems and to find out which system would be cheaper to implement for the different demand levels. The cost elements of each system were also identified. The costs were divided into capital costs and operating costs.

The fourth and last function was to evaluate the proper combination of the two systems. 
CHAPTER 2: RELATED WORKS

\section{Fixed-Route Bus System}

Public transportation may be divided into four main subsystems: the demand subsystem, the management and control subsystem, the operative subsystem, and the physical subsystem. This division is depicted graphically in Figure 2-1.

The demand subsystem is the most important function of the mass transit industry because it determines the success as well as the failure of the system. One of the main objectives of transit management is to monitor the attitudes of the public with respect to the service, to find out means of attracting the non-user and to forecast the future demand. Extensive research has been done in the area of demand evaluation and demand forecasting for public transports. Estimates for the future demand for public transportation have been incorporated as part of the continuing comprehensive transportation planning process for urban areas. The main consideration is to find out how many of the total generated trips for a certain study area will go by public mass transit or by private automobile. The name given to the models that 


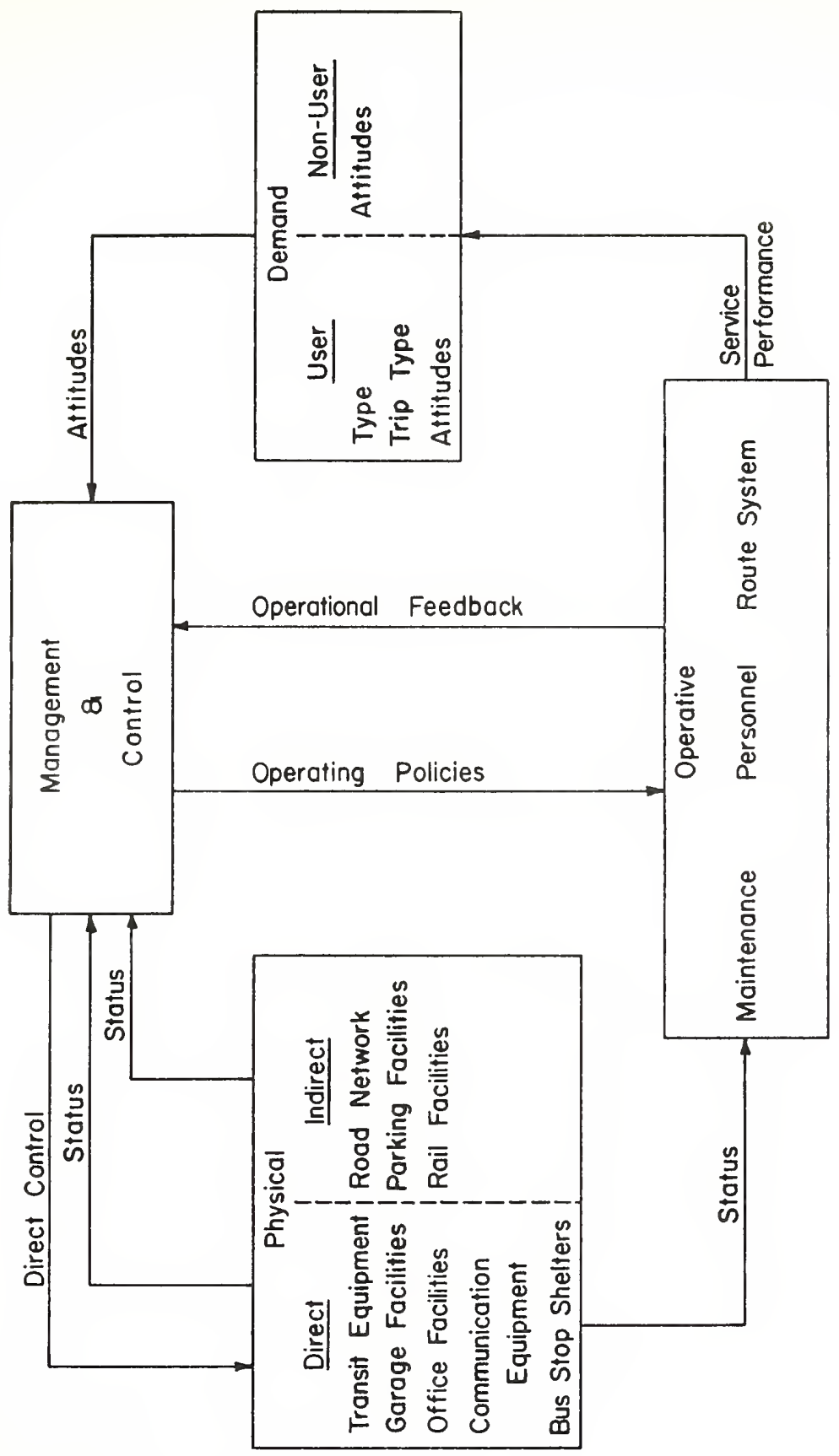

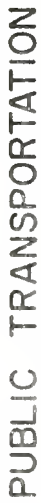

능

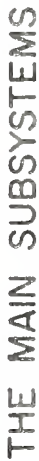

స

$\frac{w}{\frac{U}{9}}$ 
have been developed to estimate the future intra-city travel demand by alternative modes of transportation is "modal split." These models have used different factors in determining the "modal split." However, the significant factors could be grouped into three major categories: 1) characteristics of the trip, 2) characteristics of the trip-maker, 3) characteristics of the transportation system (3).

In this study, no attempt was made to estimate the demand for public transportation at a future date for Lafayette, Indiana. It is considered that any survey analysis of the public attitudes with the existing deteriorated bus system would lead to biased conclusions. Instead, a range of values of the feasible demand set was considered in the design of the demand-responsive bus system. The fixed-route bus system is considered to be inelastic to low demand volumes usually existent in small urban areas, with respect to the route's development. It is rather affected by the demand distribution which was used in developing the fixed routes of the bus system. Little attention has been given to the management and control subsystem of public transportation. A handbook for small cities on mass transit management (23) had been published by the Institute for Urban Transportation, Indiana University, Broomington, Indiana. The aim of the handbook is to provide information for the management of 
small transit systems particularly found in smaller cities in the United States. It emphasizes that management should provide a service quality that meets the consumer needs and desires at a cost carefully calculated and controlled, rather than to provide a minimum of servide at the lowest possible cost. The MITRE Corporation under the sponsorship of the Office of Research, Development, and Demonstration, Urban Transportation Administration, had developed a Run Cutting and Scheduling (RUCUS) computer package (18) to assist the management of large transport systems in sheet development, vehicle scheduling, and driver run cutting. Rescheduling of transit property, which occurs two to four times a year, requires the revision of timetables based on ridership patterns and then the reallocation of transit company resources vehicles and drivers - to the revised time tables. Computerization of these activities would save extensive amounts of time spent on these tasks by the experienced people of the scheduling department. This research did not discuss the management and control function of the transit system because it is outside the scope of its study.

The physical subsystem has been receiving a great deal of attention lately, especially in large urban areas. Improvements in the design of transit equipment, communication equipment, and transfer facilities are very carefully studied and extensive research is still going on 
in this area. The Chicago Transit Authority had developed a communication and surveillance system to control the proper headways between buses and to eliminate unnecessary delays at the different routes of the bus system. Traffic management for bus priority treatments (13) has been increasingly studied and implemented throughout the world. Its aim is to improve the service quality of bus transit bringing rapid transit to many large communities. These priority treatments include reserved bus lanes on downtown city streets, special bus streets, contra-flow bus lanes on expressways, special bus lanes on freeways, special bus ramps for express bus service, metered freeway ramps with bypass lanes provided for buses and many others. They are mainly found or proposed in large American cities. The greater Lafayette Area will not require in the near future these specialized treatments due to the dimensions of its area, the dimensions of its traffic volume and the dimensions of its bus use.

The operative subsystem is one area which has remained relatively untouched. The system-wide configuration of bus routes, which is the working skeleton of the transit system, has received 1 ittle study. The bus routes are being developed on a qualitative basis, using a number of routing and operating criteria to judge the route network. Computer simulation has been used to evaluate the operation of a specific bus route after it has been designed and 
implemented. Nfter the actual demand on the bus-route has been gathered, sensitivity analysis through computer simulation would allow the modification of the schedules and initial timetables to achieve the desired quality of service required by the consumers. Testing of alternative route configurations through computer simulation to choose the optimum system had been investigated (24). It was found to be ineffective, requiring an extensive amount of computer time and offering no better results than qualitative evaluation. A man-computer interactive graphic system, (17) developed at the University of Washington, was applied to a series of experiments designed to identify the characteristics of high-performance bus rapid transit (BRT) systems for CBD-bound clientele which reside in a generalized suburban corridor. A man-computer interaction for bus-route problem solving could lead to valuable, efficient exploration of the different feasible solutions for large transit systems. This research used the systems analys is approach to develop the different bus-route configurations. It included the definition of the system objectives, the determination of its evaluating criteria, the development and testing of the different route alternatives, and the choice of the best system. 


\section{Demand-Responsive Bus System}

In contrast to fixed-route bus system, a substantial amount of research has been completed on demand-responsive bus systems. The new concept was initially studied by a group of students at the Massachusetts Institute of Technology while taking an interdepartmental course in the design of an integrated, evolutionary urban transportation system (7). The concept was named "The Genie System." The Genie System made use of low capacity vehicles operating without a fixed route or fixed schedule in suburban areas (low and medium density.) Both route and schedule for all vehicles are decided by a computer reviewing the instantaneous state of demand. This sytem was designed to provide a level of service almost up to the taxi standard (door-to-door service) but with cost greatly reduced by using multi-passenger vehicles. The scope of the Genie system had been limited to the many-toone, one-to-many problems.

The new concept had received a great deal of attention and acceptance among transportation researchers in universities and in private industries. At Northwestern University a group of graduate students had investigated the feasibility of door-to-door bus service to both dispersed origins and destinations (many-to-many problem) through computer simulation. The simulation model of their demand-scheduled bus system (DSB) (18) assumed a model city 
With equally spaced, parallel streets where the buses travel either east or west on the grid before travelling north or south. The decision rules, which assign passengers to the buses, were developed to make the assigning and scheduling process as close to optimal as possible.

In addition, separate research of the system had been developed by the Westinghouse Air Brake Company (WABCO), General Motors Research Laboratory (GMRL), and Ford Transportation Research and Planning Office. This illustrates the interest of the private industries in the new concept. In all the research, computer simulation had been used to evaluate such systems and to arrive at some operating decisions for a real performance or demonstration project. Each group working in this area had proposed somewhat different algorithms for the routing and scheduling of vehicles. As the success of a demand-responsive system might well be within the routing and scheduling ability, a critical review was made of the different routing and scheduling algorithms, highlighting their differences, similarities, and possible limitations (10).

The Transportation Research Department of General Motors Research Laboratories had also conducted a number of research studies to evaluate the technical and economic feasibility and the potential social and political acceptance of such a system within the environment of a 
selected case study community. The Transportation Research and Planning Office of Ford Motor Company had done similar research in the area and is acting as technical advisor to certain demonstration experiments, such as the Ann Arbor, Michigan, Dial-A-Ride experiment.

The most extensive research done in this area is the one carried out lately by the several academic departments and the special laboratories of Massachusetts Institute of Technology. The work was initially sponsored through the U.S. Department of Housing and Urban Development and later supported by the U.S. Department of Transportation. About seventy people at M.I.T. were involved in the project. The project was concerned with the evaluation, planning, design, and implementation of demand-responsive "Dial-ARide" transportation systems. Around eighteen reports were published to discuss the different research concepts.

This study used the computer simulation package developed at M.I.T. for the design of a Dial-A-Ride system. It is considered at present to be the best available computer simulation of such a system. In addition, it was accessible to the author, and it was easy to adopt to the computer hardware of Purdue University. The use of the simulation model for the design of the Greater Lafayette Area "Dial-A-Ride" system will be discussed in detail in chapter six of this study. 
The Dial-A-Ride system has been carried from the concept stage into practical application over the past few years. Several Dial-A-Ride systems have been operating in North America and Europe. Some of them are listed below:

A demand-responsive bus service was first tried in North America in 1964 in Peoria, Illinois, as a weekday subscriber service to take workers from their homes to a factory in the morning and back again at night.

In 1969, in Mansfield, a town of 60,000 in Ohio, the private transit operator experimented with a "Dial-A-Ride" service linking a residential neighborhood to the town's business district. Via a radio-telephone hook-up, passengers whose homes were off the regular route could arrange to be picked up by dialing directly through to the bus driver, who doubled as a dispatcher.

In July, 1970, the Ontario Government introduced a Dial-A-Bus experiment in Bay Ridges, a residential community of 15,000 , as a feeder system for the GO Transit commuter rail line. Dial-A-Bus has succeeded there not only as a feeder system, but also as this community's first internal public transit system.

The experiment in Regina, Saskatchewan's capital city, was a joint effort by municipal, provincial and federal governments. The city has a population of 145,000 and a typical low density of 5,000 persons per square mile. 
Dial-A-Bus was introduced in 1971 to replace some bus lines where sagging patronage was creating large deficits.

The United States Department of Transportation, Urban Mass Transportation Administration and the New Jersey Department of Transportation, who is the demonstration sponsor, has approved a Dial-A-Ride project for Haddonfield, New Jersey, a suburb of Philadelphia. The service started on February 19, 1972. It provides service from any place to any place within the service area, (many-to-many). It operates 24 hours a day, 7 days a week, and 365 days a year. The control system is operated manually, but it is hoped that it will utlimately become computer-controlled. The Mitre Corporation is evaluating the demonstration from the service standpoint. 
CHAPTER 3: CONCEPTUALIZATION OF OPERATIONAL PLANNING OF BUS SYSTEMS IN SMALL URBAN AREAS

\section{Random Routes and Fixed Routes}

A transportation system in an urban area is divided into two main subsystems, private and public transportation. Private transportation can be described as a random-routes system. With the existing street network in most urban areas, a traveller going from point $A$ to point $B$ may randomly choose his route from among many possible alternative combination of links to reach his destination. He is not constrained to a fixed rail or a road bed and he has the ability to change or reverse his direction according to his wish at any point on the system.

Public transportation, on the contrary, is identified as a fixed-route system. The user has limited alternatives to travel from point $A$ to point $B$ in the urban community. The vehicle is usually constrained to a fixed rail, track, or road bed. It operates on fixed schedules and stops at definite points on the route. The user is not able to change his direction as long as he is riding the same vehicle. His desired line of travel is constrained by the desired lines of travel of other users. 
Comparing the two systems, without looking to the side effects, the private system stands out as being more flexible, less time consuming, and more tailored to the desires of its users than the public system. In short, private transportation provides a better service to its users.

Researchers and professionals in the field of public transportation, in addition to their contribution to the conventional fixed-route public transfort systems, started looking for new concepts that might provide some of the advantages of the random-route system. Some of these new concepts are the dual-mode system, the personalized rapid transit, the moving sidewalks, and the demand-responstve bus system - usually known as Dial-A-Ride system. One of the most promising new concepts is the Dial-A-Ride system because it does not require a huge capital investment as do the other concepts, and the technology needed for its implementation is available.

The demand-responsive bus system operates essentially like a shared taxi service. Taxi service, which is in the domain of public transportation, is the closest to the random-route system. It offers a door-to-door service, and the customer has the perogative to go from any point A to any point $B$ in the urban area. The taxi, however, is expensive to the customer, requires many drivers, and its vehicle productivity is low. A demand-responsive bus 
system would have a greater vehicle productivity ( 8 to 20 passengers per hour) depending on the demand level and area size while it offers the same door-to-door service. As with the taxi service, the customer calls the dispatching centre asking for service and gives both his origin and his destination. A vehicle is assigned, either by the dispatcher or through the help of a digital computer, to pick up the customer. After the customer boards the vehicle, he will be taken to his desired destination. While on route, the vehicle will make minor detours to pick up and drop off other passengers. Figure 3-1 shows the routing and scheduling spectrum of the Dial = A-Ride regime with respect to the other conventional public transport systems (5).

In its most sophisticated state, the many-to-many Dial-A-Ride overlaps with the taxi regime. The only important differences are the shared riding, slightly longer travel time, and lower fares. However, there is a large spectrum of potential Dial-A-Ride systems that offer substantially less than full taxi service. These are commonly referred to as many-to-one and many-to-few systems. Many-to-one indicates a focal point for the service such as a town centre, rapid transit station, airport, medical complex, or other major activity centres. The many-to-few concept is an expanded system in which between two or more focal points can be serviced. 


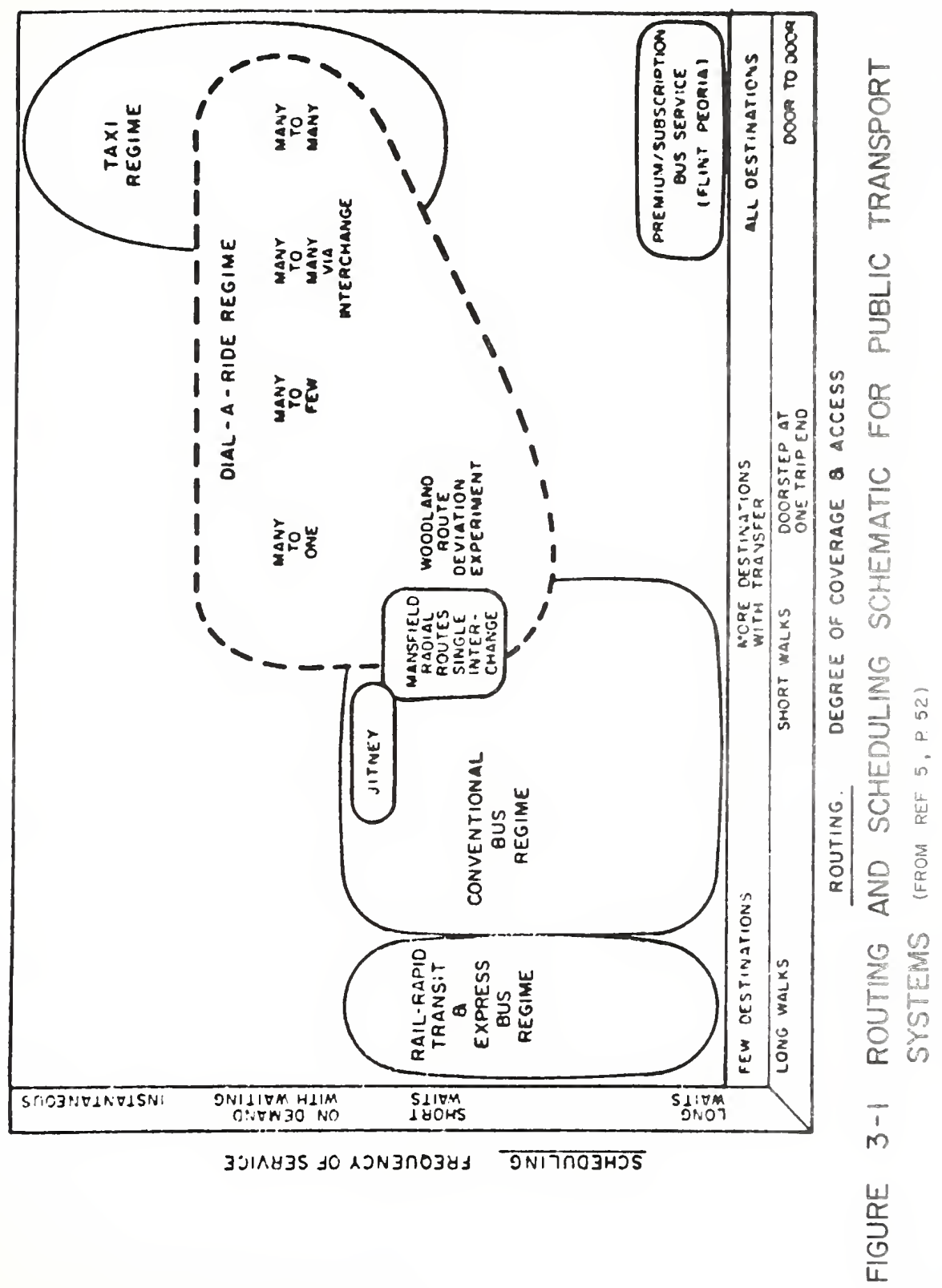




\section{Short-Distance Public Transportation}

In order to assess the potential markets for the feasible application of the Dial-A-Ride concept, a brief look on the components of short-distance public transportation is necessary. Short-distance transportation characterizes the intra-city movement, as opposed to longdistance transportation which characterizes the inter-city movements. All modes of short-distance transportation have three main features in common: collection, line-haur, and distribution. In the random-route system, cars are collected by the collectors and arterial streets, hauled by the freeways, and distributed by the arterial streets.

The same concept applies for the movement of people by the different modes of public transportation. Figure $3-2$ shows the characteristics of each of the three features of short-distance public transportation and the different feasible public modes to serve each of them. The rist does not include all the possible modes and concepts in public transportation since the main aim in this exhibit is to describe the feasible application of the Dial-A-Ride concept.

From Figure 3-2 it can be seen that demand-responsive bus system best serves the collection and distribution spheres of public transportation. It can operate as a line-haul collector and feeder and as a distributor to high activity centres such as shopping centres, airports, 


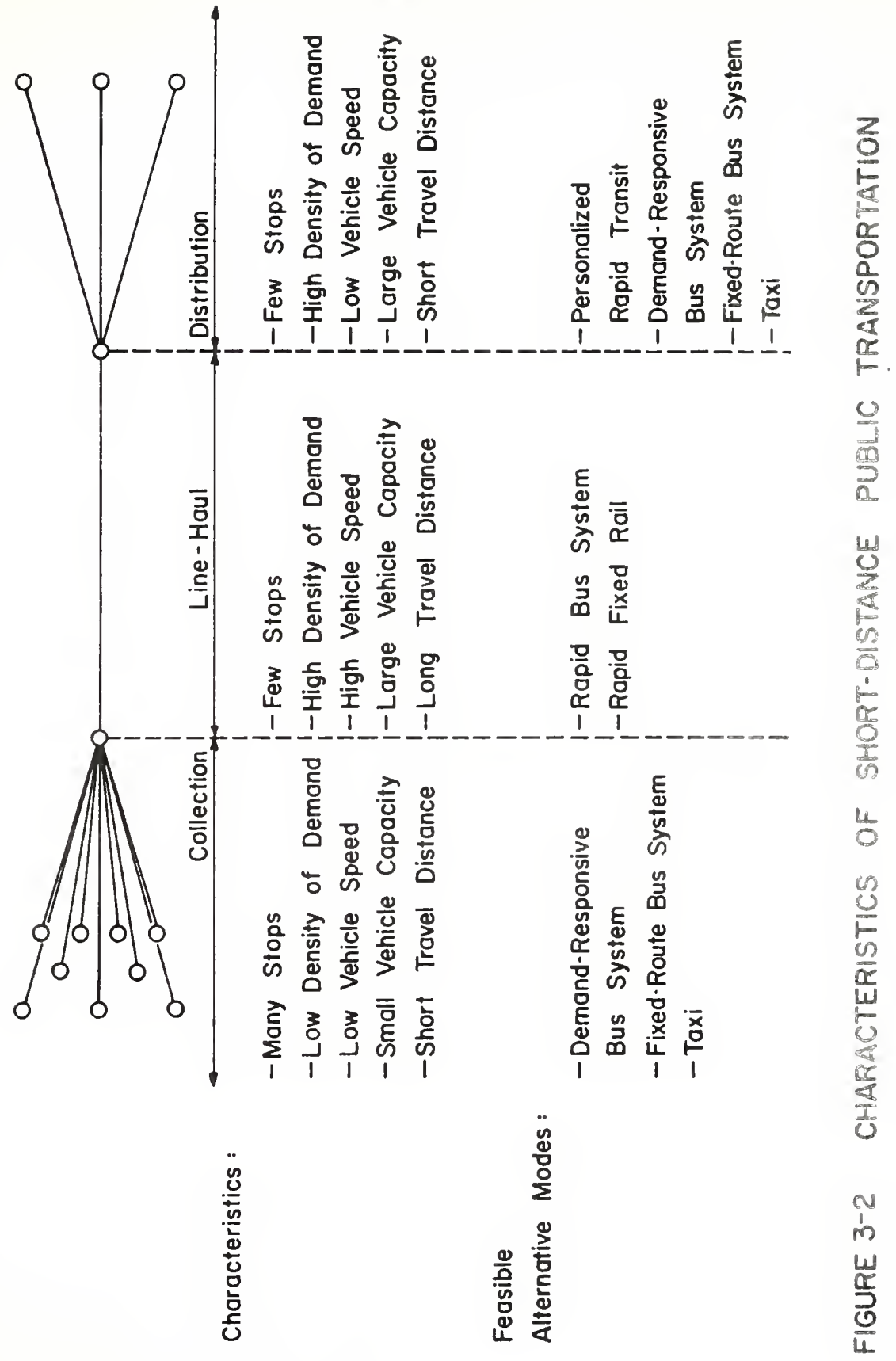


medical complexes, and others. In small cities and new towns, where the line-haul movement does not exist and the collection and distribution operations are close to each other, the Dial-A-Ride concept would provide a feasible public transportation alternative.

From Figure 3-2 it is also shown that other public transportation modes such as the fixed-route bus system and the taxi could provide a competitive alternative for the demand-responsive bus system in the same market areas. A brief discussion of the characteristics of each of the three modes is presented to outline the differences in their transportation role. Figure $3-3$ shows the transportation patterns and the travel desire patterns of the three modes (23).

The three factors that determine the best operative mode are the demand level, the area size, and the level of service demanded by the customers. Taxi, as mentioned before, provides the best level of service to the customers, and the demand-responsive bus system provides a better service than the fixed-route bus system. This is irrespective of the demand level and the size of the service areas. At high demand level and large area size, the taxi would operate at a lower efficiency than the fixed-route bus system. It would have to make a lot of $B$ to $C$ type trips as shown in Figure 3-3, in which the taxi would be empty for a sizeable portion of the operating 
a. Dial-A-Ride Route and Possenger Desire Lines

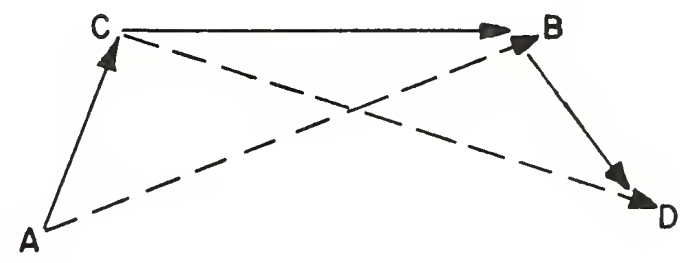

b. Conventional Bus Route and Passenger Desire Lines

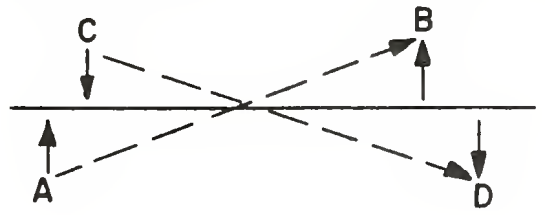

c. Taxi Route and Possenger Desire Lines

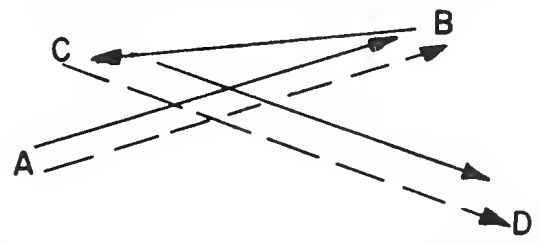

FIGURE 3-3 TRANSPORTATION PATTERNS AND

TRAVEL DESIRE PATTERNS (FROM REF. 23, P.1-2) 
time. Thus, it would produce a low vehicle productivity compared to the fixed-route bus system. Similarly, the demand-responstve bus system, under these conditions, would have to make a long circuitous route A-B-C-D etc., which would limit its ability to pick up other customers on the way in order to secure the service guarantees of its boarding passengers. Therefore, the fixed-route bus system best serves the high demand level and the large area size. The taxi, however, best serves the low demand level and the small area size. Their low vehicle productivity best fits such kind of an operation and, due to their less sophisticated control system, they might produce lower costs than the demand-responsive bus system and the fixed-route bus system. The demand-responsive bus system best serves the medium demand level and area size. This will be analyzed and studied in detail in Chapter 6 .

\section{Operational Planning}

The two bus modes, the fixed-route and the demandresponsive systems as discussed earlier provide a feasible alternative for bus public transportation in small urban areas. They best serve different demand levels and different area size. However for a defined service area the demand level for public transportation varies at different times of the day. It increases sharply at certain times, usually during the home-to-work and work-to- 
home travel periods, and it decreases and levels off at other periods. The proper application of each of the two modes to best serve the various demand levels remains a problem to the transit planners. No real analysis and experimentation has been done to find out the proper combination of the two modes. Most of the Dial-A-Ride experiments have been done either in separate service areas that do not include a fixed-route bus system or it has been implemented to serve part of an area that is already covered by a fixed-route bus system. This study investigated the application of a fixed-route bus system during the peak periods, and the (many-to-many) Dial-ARide system during the off-peak periods in Greater Lafayette Area. The number of buses required by each mode to operate at a certain level of service was determined. Consequentiy the cost analys is of the two systems determined the feasibility of their operation. Emphasis was also placed on the operational planning used to achieve this analysis.

Operational planning of bus systems has received little attention by transit planners. Little is found in the literature on how to design the system after it has been conceived. This study developed a methodology for the design of fixed routes of bus systems in small urban areas. Although each study area has its own characteristics that would require special design elements, general design 
procedures can be developed to apply to most small urban areas.

The planning process used to design the two bus systems is outlined in Figure $3-4$.

The demographic and non-demographic characteristics of the study area were studied first. They play an important role in the design of the two bus systems. They constrain as well as shape the development of the two systems. The physical function determines the origins and the destinations of demand in space. The demand function was considered independent of the operative function and no attempt was made to explore the effect of different operating policies on demand level. A demand value was chosen out of all possible values of the demand set and various levels of service were investigated to meet that demand. The operative function was divided into three elements,operational objective, criteria and system design. The operational objectives outlined the operational policies of the system. The criteria provided the framework for the evaluation of the different system designs with respect to the operational objectives.

The cost function depends mainly on the operative function of the system although there are some cost elements which are independent, such as terminal land cost, facilities costs, management costs, etc. In this case, the cost function was considered as a by-product of 


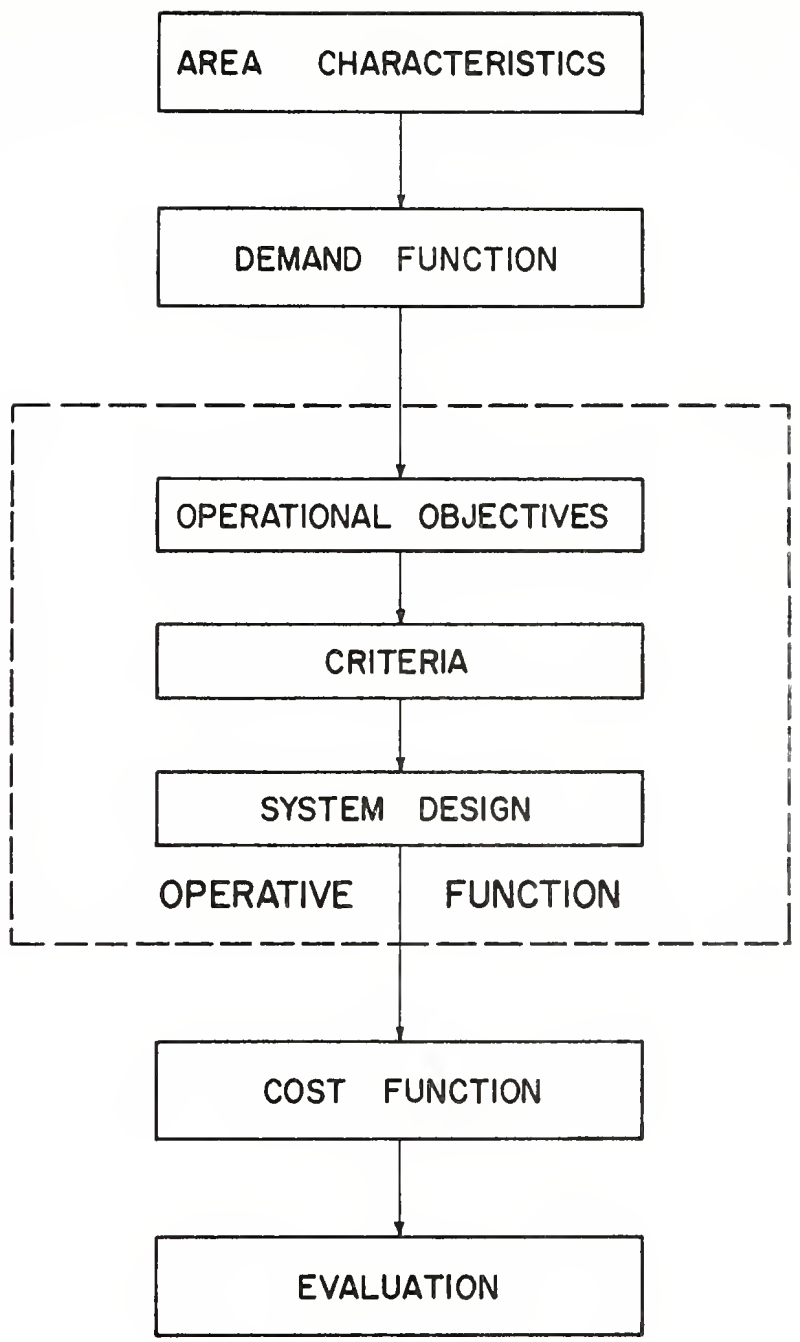

FIGURE 3-4 THE DESIGN PLANNING PROCESS 
an operative function satisfying a certain demand and not as the initial set which constrains the operative function. The reason that this approach was adopted in this research lies in the marketing analysis of public transportation. The concept is to determine the costs needed to provide a certain level of service rather than to determine the level of service that could be provided for a certain cost. This is because the consumer may not use the product at the level of service offered, no matter what the initial cost is. The last process included the evaluation of the two bus systems. It determined the best feasible operation of each mode. 
CHAPTER 4: AREA CHARACTERISTICS

This chapter presents the demographic and non demographic characteristics of the Greater Lafayette Area. The data is obtained mainly from the Greater Lafayette Area Transportation and Development Study. Available data in the census Reports of 1970 has also been used.

\section{Greater Lafayette Area}

The Greater Lafayette Area is a small metropolis made up of two core cities, Lafayette and West Lafayette. Lafayette was first platted in 1826 and was incorporated as a city in 1856. West Lafayette was organized in 1866 under the name of Chauncey and become the town of West Lafayette in the late 1880's and was incorporated as a city in 1924.

Lafayette and West Lafayette are located in the northwest section of Indiana in approximately the geographical centre of Tippecanoe County. The two cities are separated by the Wabash River, and they are linked together by four bridges.

The Greater Lafayette Area is located a third of the way from Indianapolis to Chicago on Interstate 65. It is served by three railroads, the Norfolk and Western, Penn- 
Central, and the $L \& N$. One of the rallpax passenger routes makes stops in Lafayette; Chicago-Cincinnati; and Chicago-Miami. Two airlines, Allegheny, and Air Wisconsin serve the area from Purdue Airport.

The population of the Lafayette Standard Metropolitan Statistical Area (which includes all of Tippecanoe County) was 109,378 in 1970 and is projected to 150,000 by 1990 (9). It has been a rapidly growing area since 1940 as shown in Figure 4-1.

About 42,000 people are employed in the area. Eighteen and a half percent of them are employed in manufacturing industries. Fifty-three and a half percent are employed in white-collar occupations and 27.5 percent work with the government. The median income of the families in the SMSA is $\$ 10,120$. The mean income is $\$ 11,048$ and the mean income per family member is $\$ 3,273$. The percentage of persons 25 years old and over who completed 4 years of high school or more is 67.7 percent.

The Greater Lafayette Area is becoming an important banking and financial centre. The assets of the full service banks amount to $\$ 235,000,000$. It also provides good commercial activities and it has a good number of shopping centers.

Overall planning for the metropolitan area is under study. The Area Plan Commission is preparing a comprehensive land use, and transportation plan for the Greater Lafayette Area. 


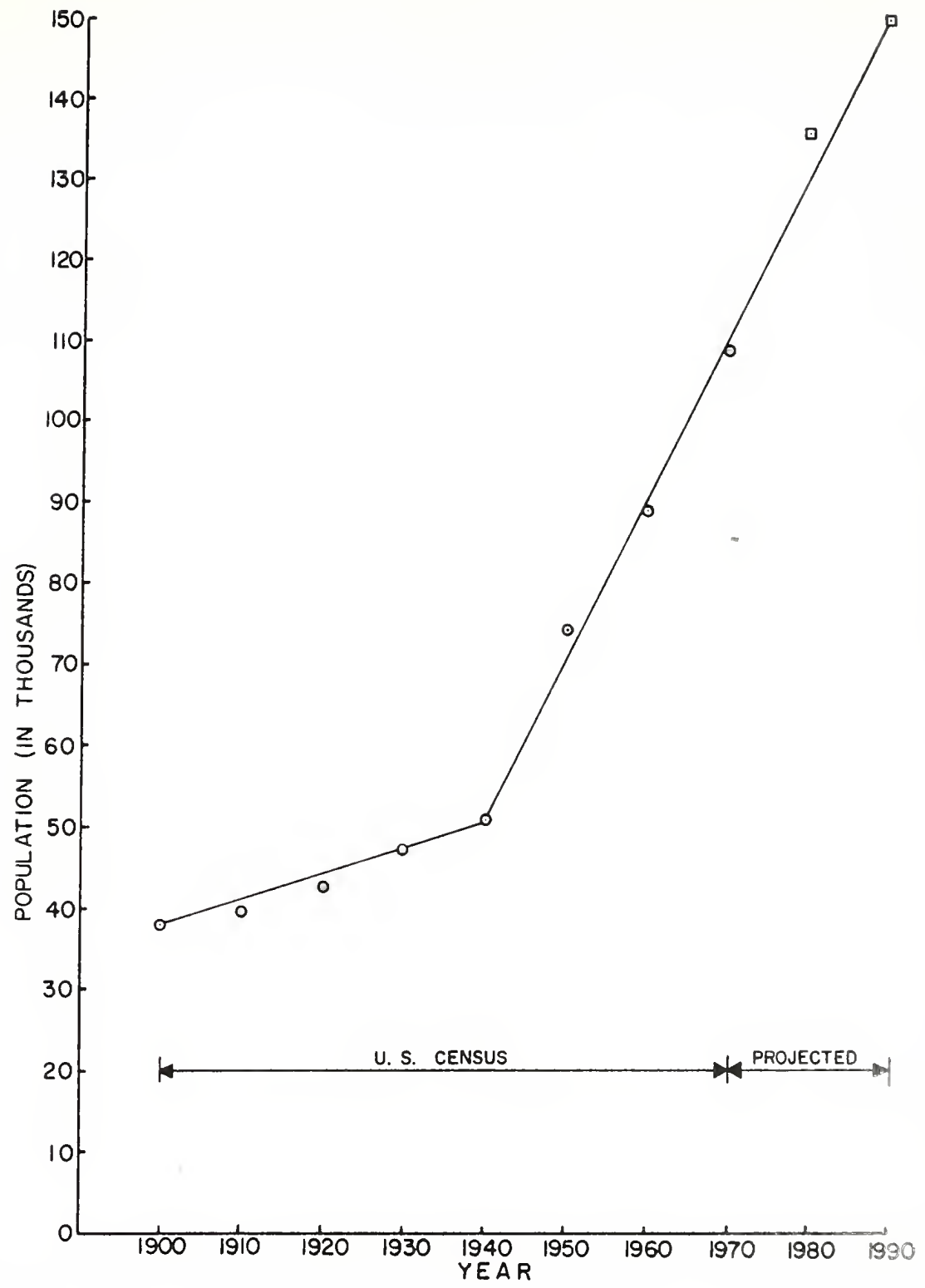

FIGURE 4-1 POPULATION GROWTH OF THE LAFAYETTE STANDARD METROPOLITAN STATISTICAL AREA (FROM REF. 9, P. 3) 


\section{Non-Demographic Characteristics}

\section{Analysis Zones}

To be able to describe on an aggregated basis the demographic and non-demographic data of the study area a system of zones has to be established.

The zones used in this study are the traffic zones al ready established by the Greater Lafayette Area Transportation and Development Study. They were used because most of the collected data was furnished by the Transportation Study, and it was compiled on that level. In addition, census tracts of Lafayette and West Lafayette were used to display some data obtained from the census reports.

The traffic zones map is shown in Figure 4-2. Not all the traffic zones established by the Transportation Study were used since they cover an area much larger than the bus system could possibly cover with the short-range planning. However, the 92 traffic zones that were chosen cover the urbanized areas of Lafayette and West Lafayette and the surrounding area.

\section{Existing Land Uses}

An inventory of existing land uses is a prerequisite of any transportation study, because it gives the distribution of people and economic activities over the urban landscape. A knowledge of this distribution would 


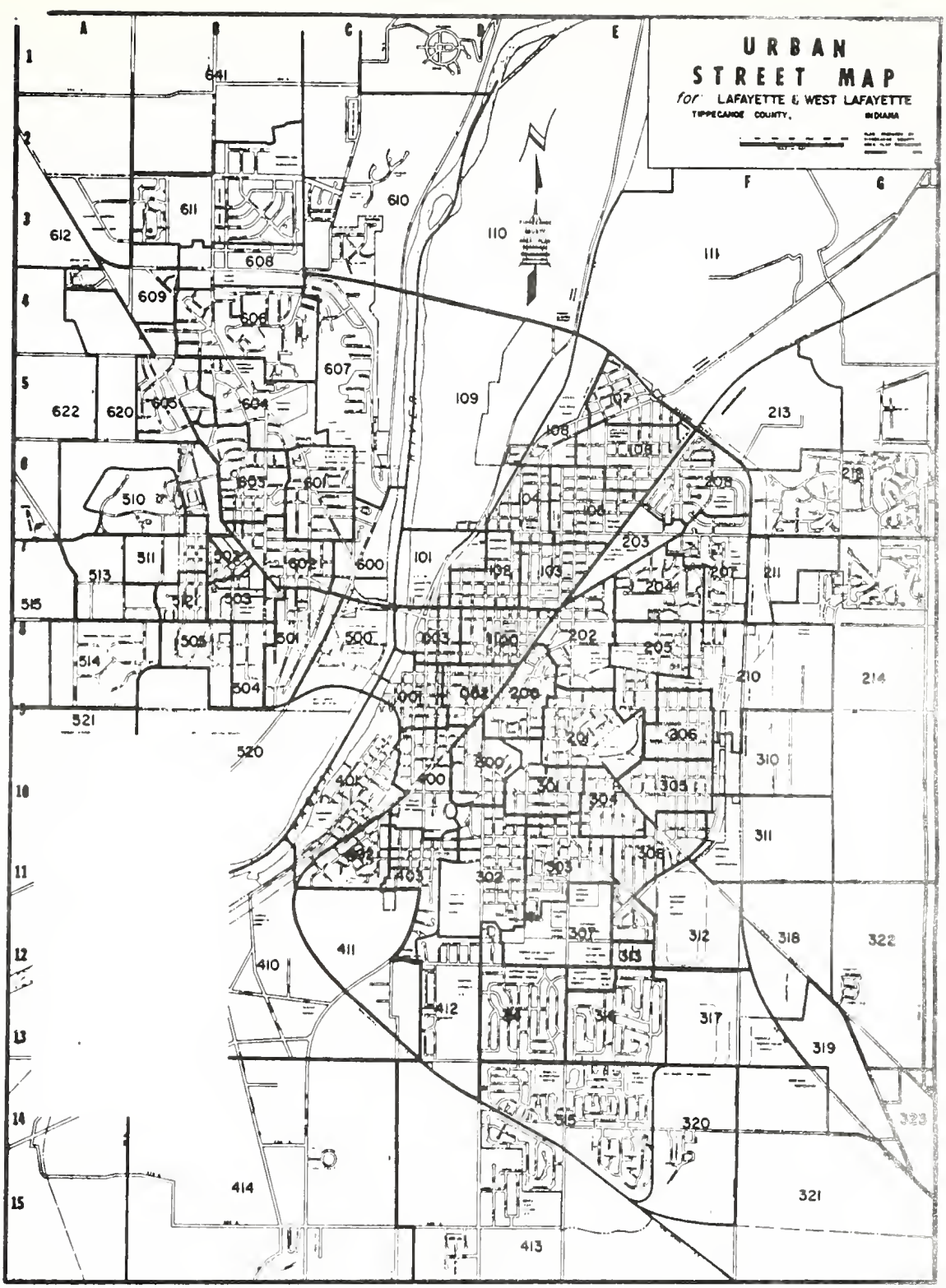

FIGURE 4-2 TRAFFIC ANALYSIS ZONES 
help in determining the origins, the destinations and the linkages of travel. The land use data was obtained from the Greater Lafayette Area Transportation and Development Study.

The existing land use pattern within the Greater Lafayette Area is shown in Figure 4-3. It is divided into five generalized categories - residential, commercial. industrial, public buildings and schools, and golf courses, cemeteries, and parks playgrounds.

Single family residential development takes up the majority of residentially developed land in the communities. The direction of residential growth has been primarily to the north of West Lafayette and to the east and south of Lafayette.

The major concentration of high density residential development is located in West Lafayette, surrounding the Purdue University campus. Other locations of relatively high density residential development are apartments and townhouses along the Sagamore Parkway of West Lafayette.

The number of housing units in each traffic zone is shown in Figure 4-5. This number would reflect on the residential density within each zone compared to other zones.

Although the area's manufacturing base is small, it is diversified and is located in several areas, but mainly in the city of Lafayette. The main manufacturing area is 


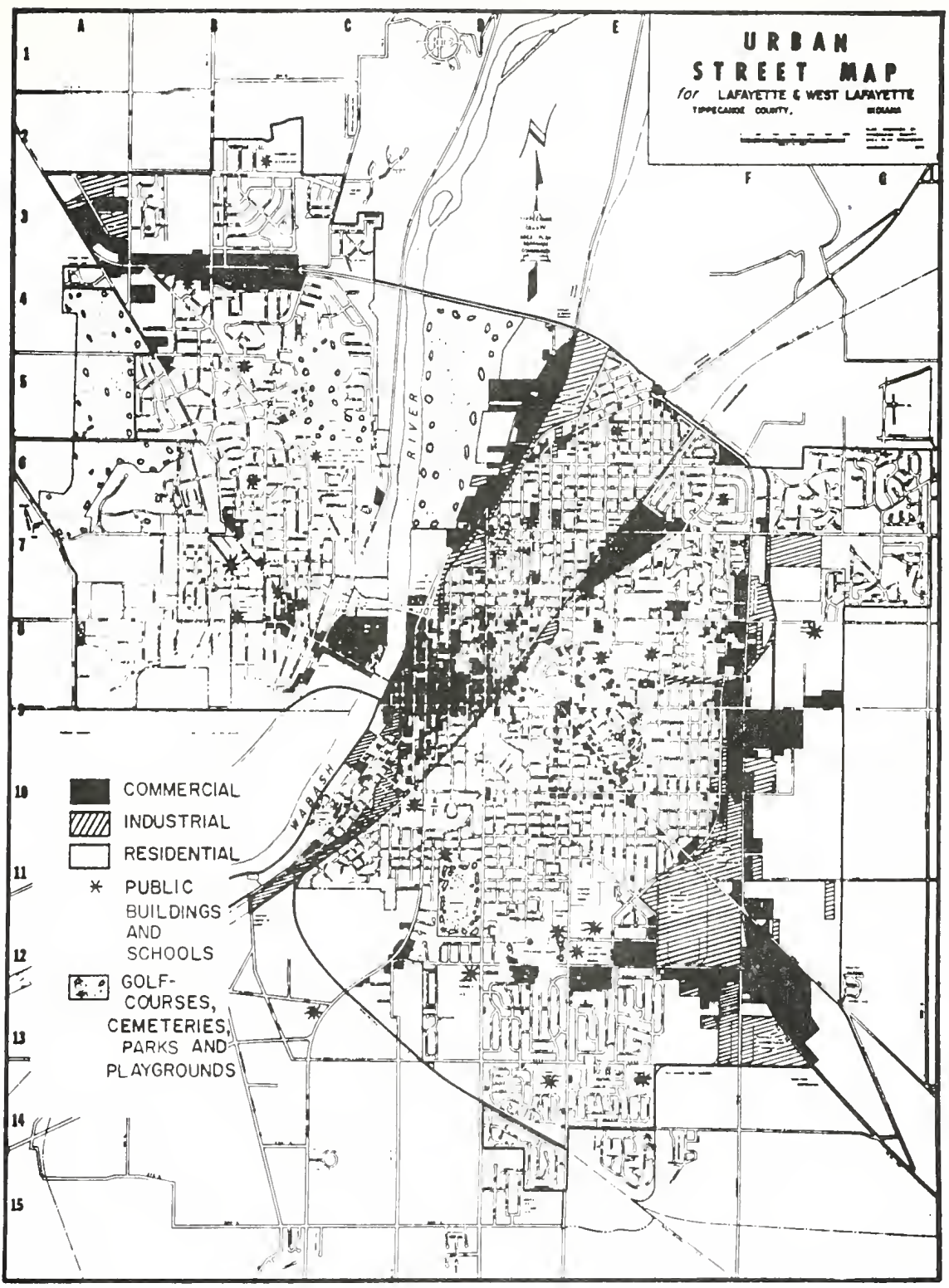

FIGURE 4-3 EXISTING LAND USES 
located in the southeast of Lafayette near Sagamore Parkway in the zone numbers $311,312,317$ and 320 . Major industries such as Alcoa, National Homes, General Fọds, Fairffeld Manufacturing, Berger Steel, and Anheuser-Busch are located in this area. The other industrial areas are located near the east bank of the Wabash River along the canal road in the north and the Wabash Avenue in the south. They include such industries as Duncan Electric, Monon Shops, Ralston-Purina, Eli Lilly and some other number of small industries.

The city of West Lafayette includes a number of small industries, most of which are located in the Purdue Industrial Park which is in the northwest part of the city.

There are five major retailing areas in the community of Greater Lafayette Area. Three areas are in the city of Lafayette and two areas are in the city of West Lafayette. In Lafayette they consist of the Central Eusiness District in the downtown area, the commercial strip in the south on Teal Road until it reaches Sagamore Parkway where K-Mart, T-Way and the new shopping mall are located, and the Market Square area in the northeast on Elmwood Avenue.

In the city of West Lafayette the two major commercial strips occur on State Road in the south near Purdue University and on Sagamore Parkway in the north.

Purdue University is located on the west side of the community but it is not incorporated within the city limits 
of West Lafayette. The University accounts for a major part of the area use of services, a fact pointing to the importance of the University in the economy of the area. Agricultural land surrounds the community on all sides. The land is flat or gently rolling and generally offers no major problems for development.

\section{Existing Street Network}

A knowledge of the existing physical characteristics of the street system is necessary in the evaluation and determination of the posstble flxed routes of the bus system. No detailed investigation and analysis of the street network is required since the main objectives of this inventory is to find out the possible streets on which the bus could run, rather than finding the inefficiencies and the inadequacies of the system, which is outside the scope of this study.

The major and minor arterials of the study area are shown in Figure 4-4. The map was taken from the Greater Lafayette Area Transportation and Development Study. The streets were classified mainly on their functional and traffic volume properties.

The existing system is a reasonably well defined grid system, mainly in the city of Lafayette. The major arterials are approximately one mile apart except in the central areas where the spacing is much closer. Several 


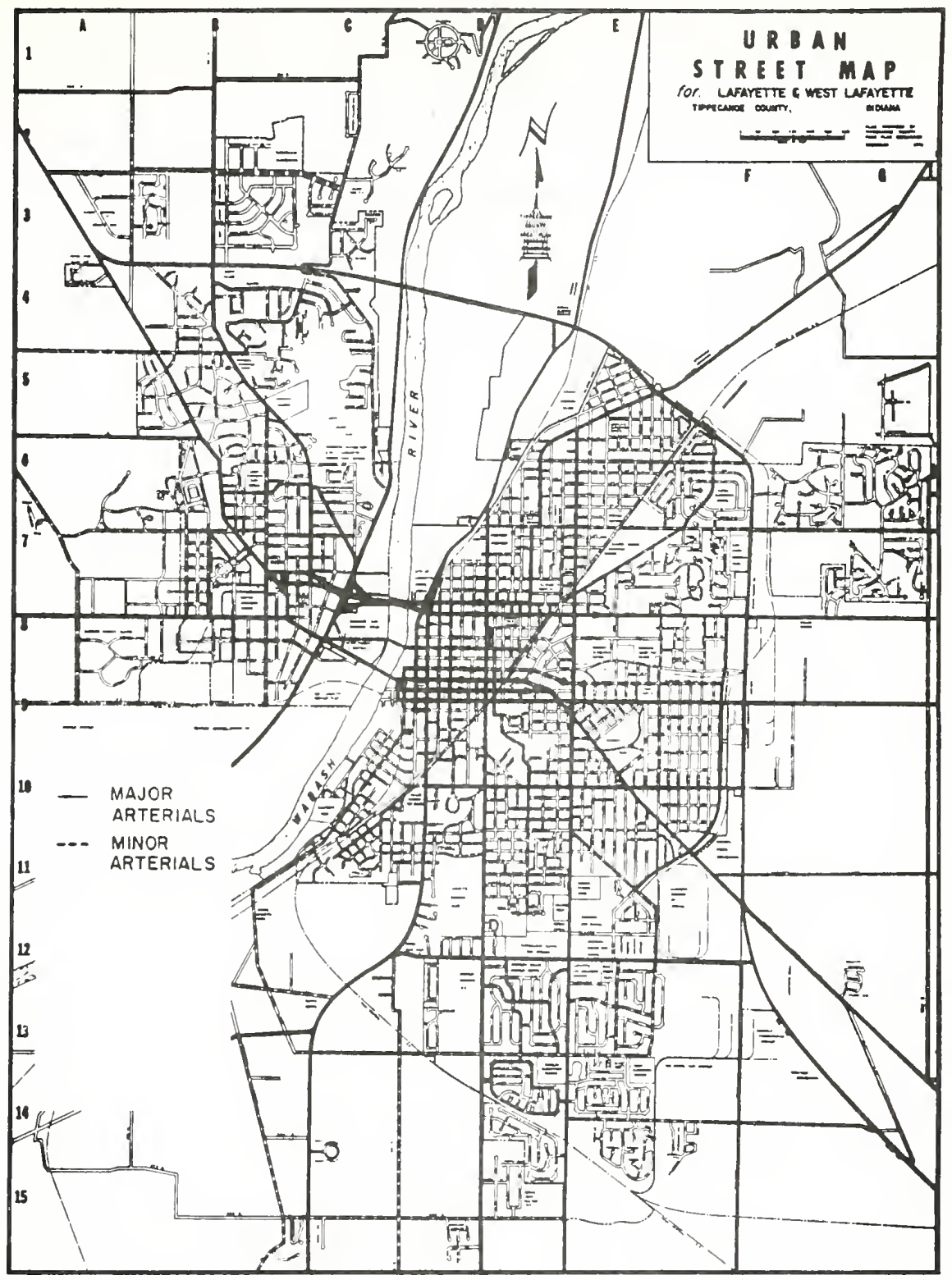

FIGURE 4-4 MAJOR AND MINOR ARTERIAL STREETS 
major streets are continuous throughout the length and width of the existing developed area. The major arterials that connect the two cities are State Road 26, Northwestern Avenue and Union Street over Harrison Bridge, and Sagamore Parkway. In a north-south direction, in the city of Lafayette, three major arterials are continuous, Canal Road and State Road 43, 9 th Street, and 18 th Srteet. Other major arterials are Main Street, Kossuth Street, and Teal Road in Lafayette, and Salisbury and River Road in West Lafayette. In the city of Lafayette, the railroad tracks cross most of the major and minor arterials at grade. Conflict of movement, therefore, occurs in different parts of the city at different times of the day. It creates delays and it might prevent the buses from meeting their assigned schedules. This problem does not exist in the city of West Lafayette, and major traffic delays are absent except when a big activity is taking place on Purdue Campus, such as football games on Saturday afternoons during the fall semester, which occur 5 to 6 times a year. In developing the fixed routes for the bus system consideration was mainly given to major and minor arterials as possible routes, except in some residential areas where better service was justified and the width of the street is large enough to accommodate the bus. 


\section{Demographic Characteristics}

\section{Population and Employment Distribution}

The population and employment distribution describes the intensity of use of urban landscape. In addition, they give the locations of work and residency and the possible linkages of travel between the two places during the peak periods.

The population data was obtained from the 1970 Census Reports on the block level. It was separated and compiled on the zonal level by the author. The zones which lie outside the census tracts developed for the cities of West Lafayette and Lafayette have no population data at present.

The population distribution is shown in Figure 4-5. The map shows four numerical figures in each zone. The first figure gives the number of housing units in that zone. The second figure indicates the number of total population in that zone. The third figure gives the number of people below the age of 18 , and the fourth figure gives the number of people 62 years old or more. The division of population into the two categories of young and old would help in defining that segment of the society, usually called captive riders, that might depend on public transportation for most of their travel. 


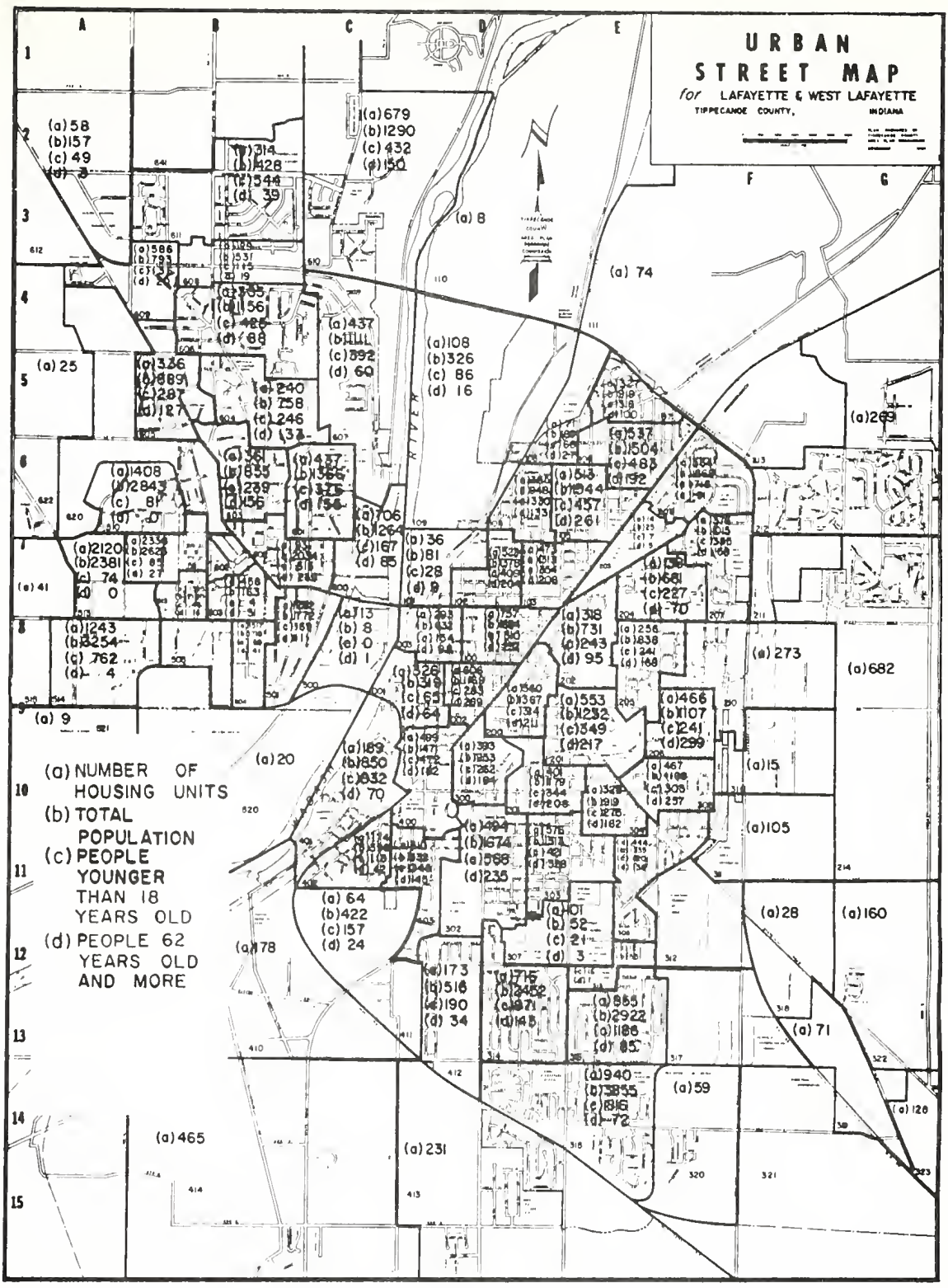

FIGURE 4-5 NUMBER OF HOUSING UNITS AND POPULATION DISTRIBUTION BY TRAFFIC ZONES 
The information on employment distribution was gathered from the land use inventory of Greater Lafayette Area Transportation and Development Study. The major sector of employment is in services, where Purdue University forms the major part. The other sectors are manufacturing, retail trade and transportation. The map showing the employment distribution is Figure 4-6.

\section{Car Ownership and Housing Unit Values}

The car ownership distribution and the housing unit values were collected as indicators of the economic characteristics of the population in the study area. These indicators may reflect on the low economic areas in the community, where car ownership and housing values might be low.

The car ownership data was gathered from the Census Reports, which is aggregated on the census tracts level. Each census tract contains the number of housing units, and the number of households owning one car, two cars, three cars or more, and none. The distribution of car ownership per census tract is shown in Figure 4-7.

The map showing the housing unit values was obtained from the Greater Lafayette Area Transportation and Develpment study. This is displayed in Figure 4-8.

There are areas of generally substandard housing in the city of Lafayette. These areas coincide with areas of 


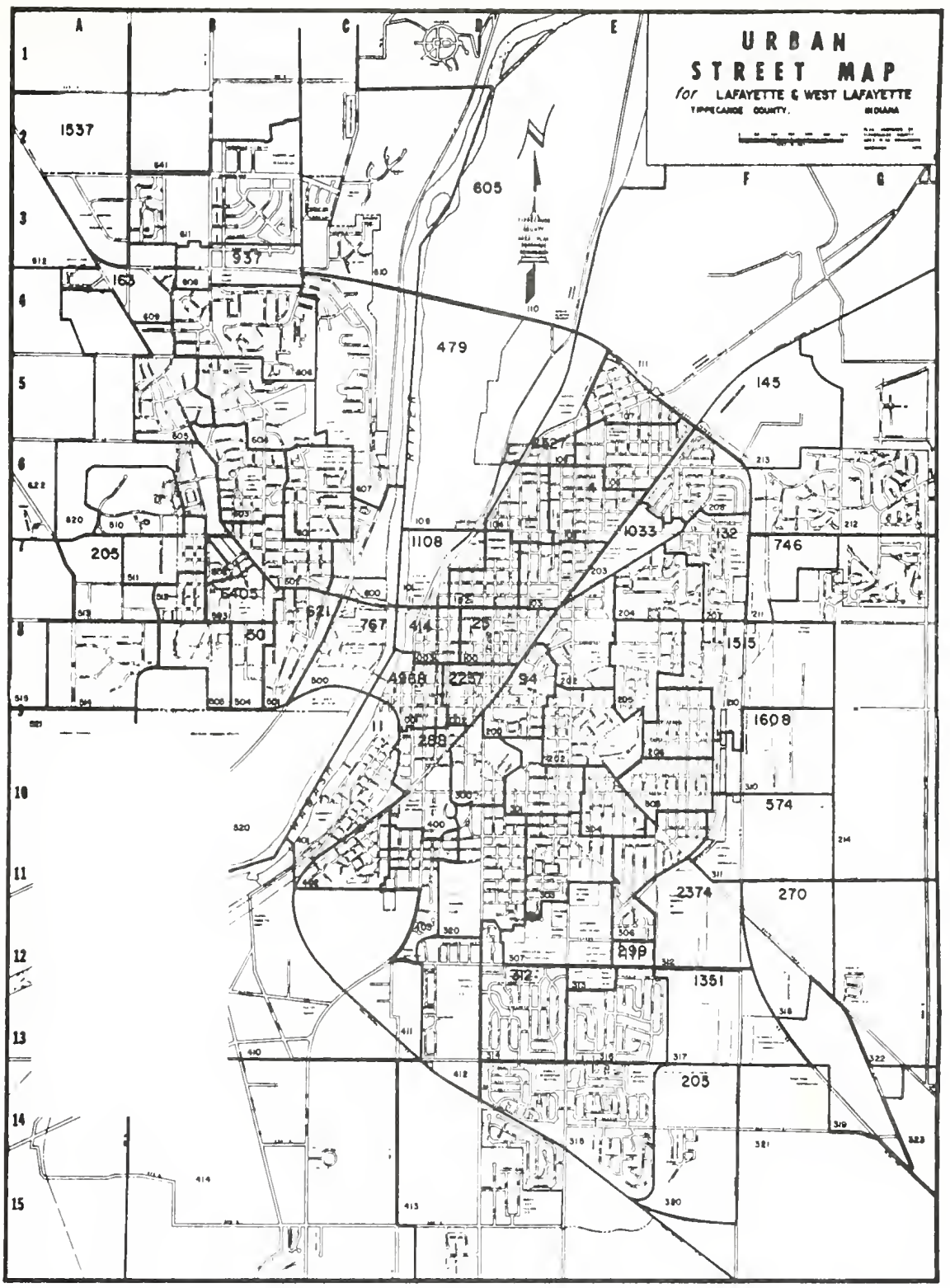

FIGURE 4-6 EMPLOYMENT DISTRIBUTION BY TRAFFIC ZONES 


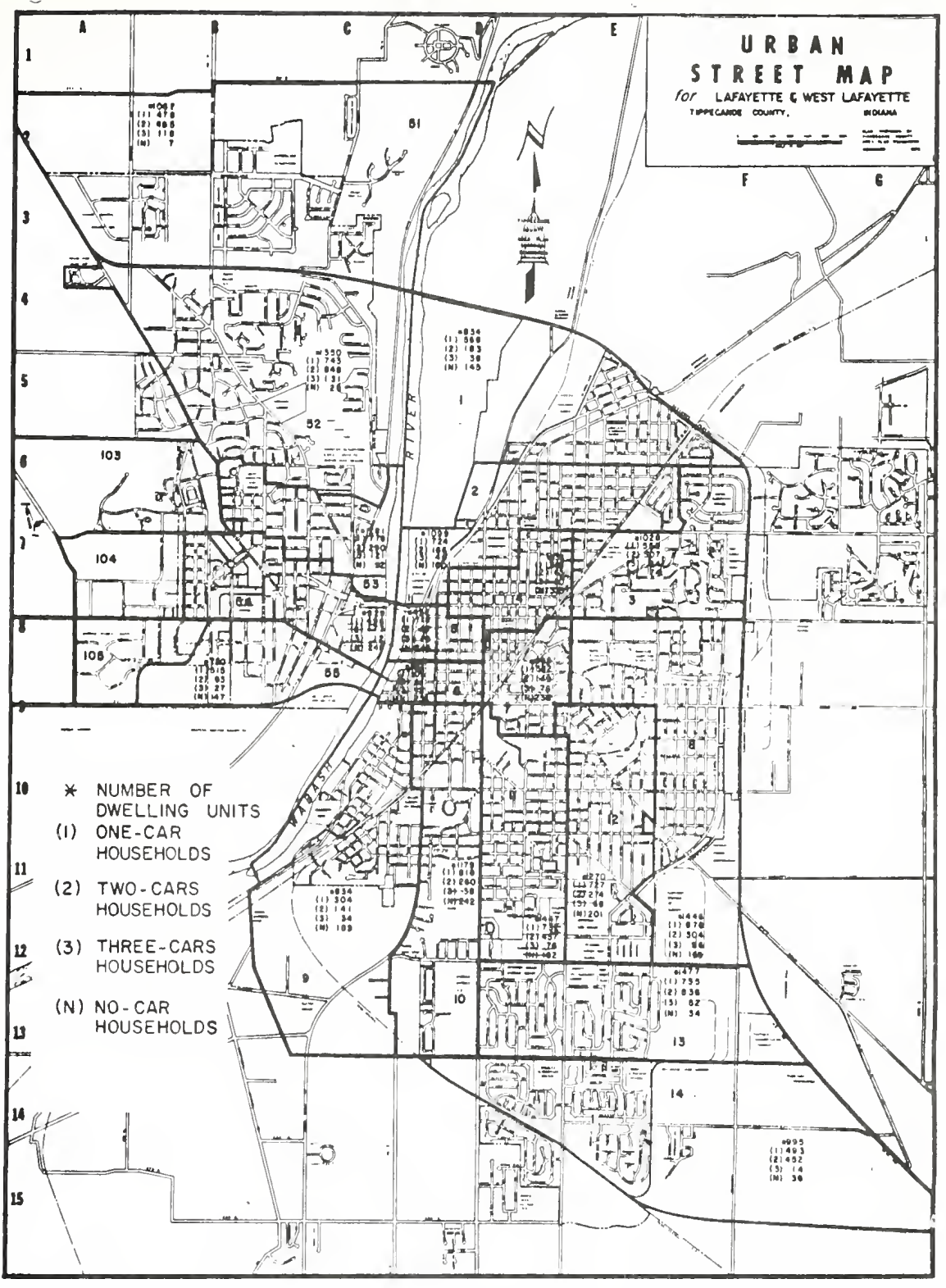

FIGURE 4-7 CAR OWNERSHIP BY CENSUS TRACTS 


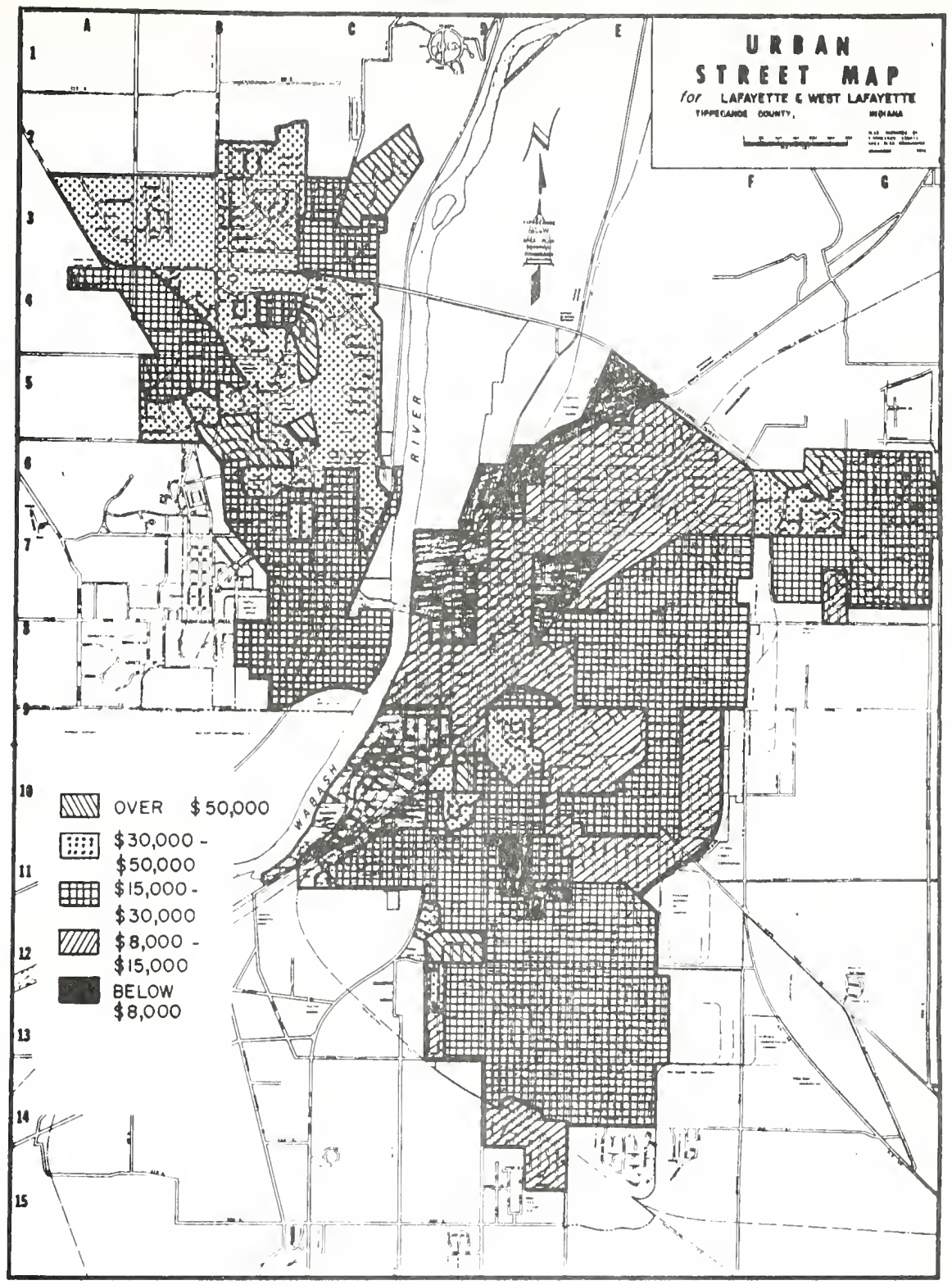

FIGURE4-8 HOUSING UNIT VALUES 
10w car ownership. They are located near the east bank of the Mabash River, along the Canal Road and Monon Avenue in the north, and along the Wabash River in the south. Another area that shows low economic characteristics is the residential strip around St. Elizabeth's Hospital on the west side of the railroad tracks.

The city of West Lafayette, in general, exhibits more car ownership per dwelling unit and better housing values than the city of Lafayette.

The houses belonging to Purdue University have not been included in the appraisal developed by the Transportation Study. The car ownership of people living on the University grounds has also not been collected by the Census Bureau, since they lie outside the census tracts developed for the city of West Lafayette. 
CHAPTER 5: THE FIXED ROUTE BUS SYSTEM

The purpose of this chapter is to develop the fixedroutes of the new bus system of Greater Lafayette Area. Analysis of the bus system prior to April 1973 is presented first to help identify the previous conditions.

\section{Public Transportation Prior to April 1973}

\section{History}

The history of public transportation in Greater Lafayette Area started in the year 1869, shortly after the Civil War. It consisted of a mule drawn railway type system and it only lasted for a few years.

A more extensive system was initiated in the year 1884. This system was composed of mule drawn street cars. It prospered in this form until August 1888, at which time the Sprig Company of Richmond, Virginia electrified the system. The electric street cars began by serving the central business district, then later extended the rails to serve Purdue University. Another route was initfated in June 1893 to serve the Soldier's Home through Happy Hollow, but it was later on abandoned due to maintenance problems. The average speed of the electric street cars 
was about 15 m.p.h., but on the State street hill the speed would drop to $5 \mathrm{~m} . \mathrm{p} . \mathrm{h}$. The electric trolley was also used to tow coal cars to Soldier's Home from a Monon line spur connection near Battleground.

The first motorized bus started its operation on January 27,1925 . It was owned and operated by the state of Indiana to provide service from the trolley line on North River Road to Soldier's Home on the top of the hill, to replace the discontinuance of the street car line. This bus remained in service until 1941 .

In March 1940, new 27 passenger buses were purchased to supplement the street cars, and two months later the buses took over the entire public transportation service. The last street car to operate was on the Salisbury-Monon Shops line and the date was May 11, 1940.

The bus system continued to operate under various owners until July 1970. At this time, the local government took the responsibility of operating the system.

The above discussion shows that public transportation played an important role in the development of Greater Lafayette Area. For over 100 years, there has been some form of public transportation available to the people of the area. As new technology and new concepts come into existence, they were incorporated in the public transportation system to provide a better service to the people in the community. 


\section{0ld Bus Service}

Routes: The route configuration of the Lafayette bus transit system in operation during the year 1972 was designed to provide direct access to the central business district (CBD), with four bus routes operating into the downtown area (see figure 5-1). The four bus routes were joined together in the CBD so as to provide through service to opposite sections of the two cities. Three of the bus routes served the city of West Lafayette and Purdue Campus. It was possible to transfer between all routes. A common transfer point existed at the Courthouse in the downtown area.

Most routes operated on one-way loops at the out-ofdowntown-part of the route. The policy of utilizing long one way loop created hardships for some passengers since they made circuitous, time-consuming trips to reach their destinations. This inconvenience discourages transit usage. Schedules: Headway, the interval of time between buses on each route, and a measure of level of service, receives the most attention of transit users as well as by transit operators. The schedules provided a headway of one hour on two routes (South Street - Salisbury, Kossuth - Purdue) and thirty minutes on two routes (Monon Shops - University, Fairpark - Union). Because of the almost identical routes east of the CBD, for the Kossuth - Purdue, and the South Salisbury, thirty minutes headways were provided in that area. 


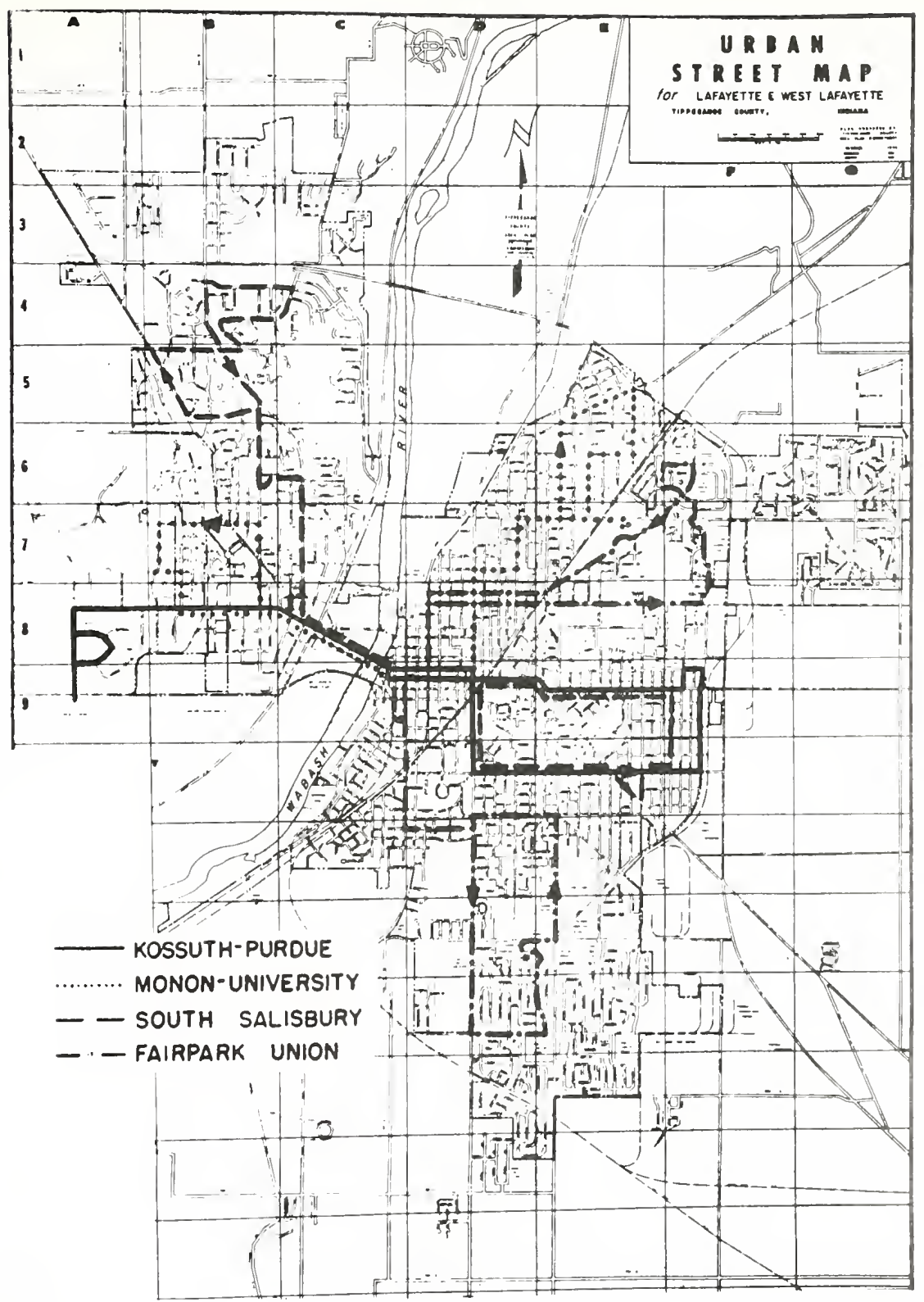

FIGURE 5-I BUS ROUTES OF THE OLD SYSTEM 
There was no service provided on sundays and on holidays. In the evenings, due to relatively low volume of passengers being carried by the system, the service was discontinued at different times on different routes as shown in Table 5-1.

Coverage: One measure of the level of transit service available is the portion of the city within walking distance of a transit line. Figure 5-2 shows the area within approximately five minutes walking distance, i.e., one quarter of a mile from any bus line. The quarter mile standard is commonly used in the transit industry but is useful only in determining whether or not an area is served. Studies nationwide have indicated that relatively few transit users walk from areas beyond the quarter-mile limit.

The area coverage of each of the bus routes is described below:

Fairpark-Union was essentially a north-south route of the city of Lafayette. It served the Tecumseh Addition, Jefferson Square Shopping Center, and portions of the northeast Lafayette residential area. Two buses were used on this route, thereby providing half-hour headways.

Monon Shops-University served the northwest residential area of Lafayette, Market Square shopping centre, the downtown area and Purdue University. Two buses were used on this route also, thereby achieving half-hour headways. 


\section{TABLE 5-1 TIMETABLE OF THE OLD BUS ROUTES}

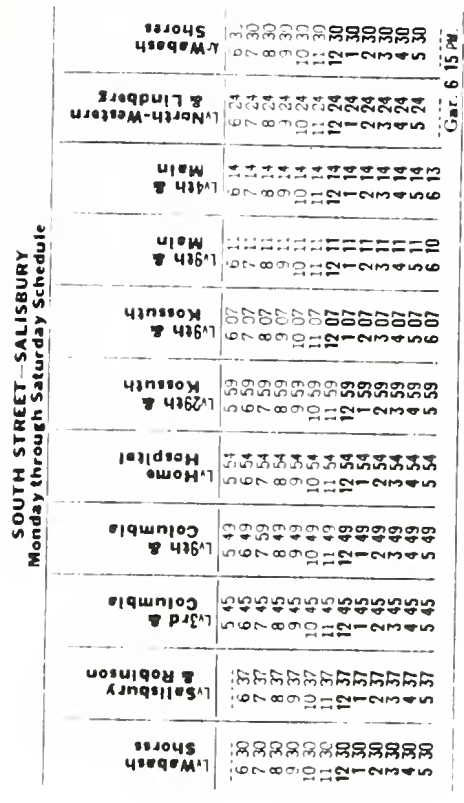

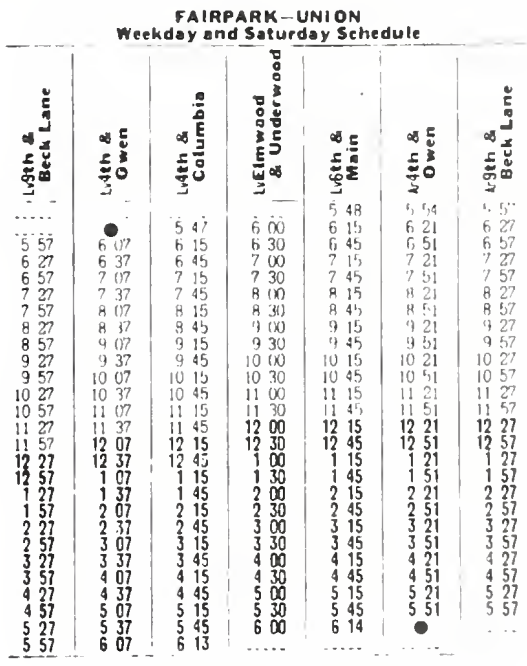

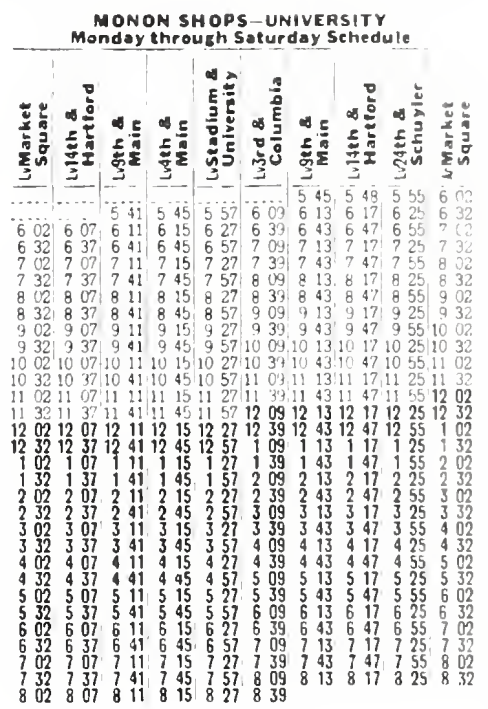

NO SUNDAY OR HOLIDAY SERVICE 


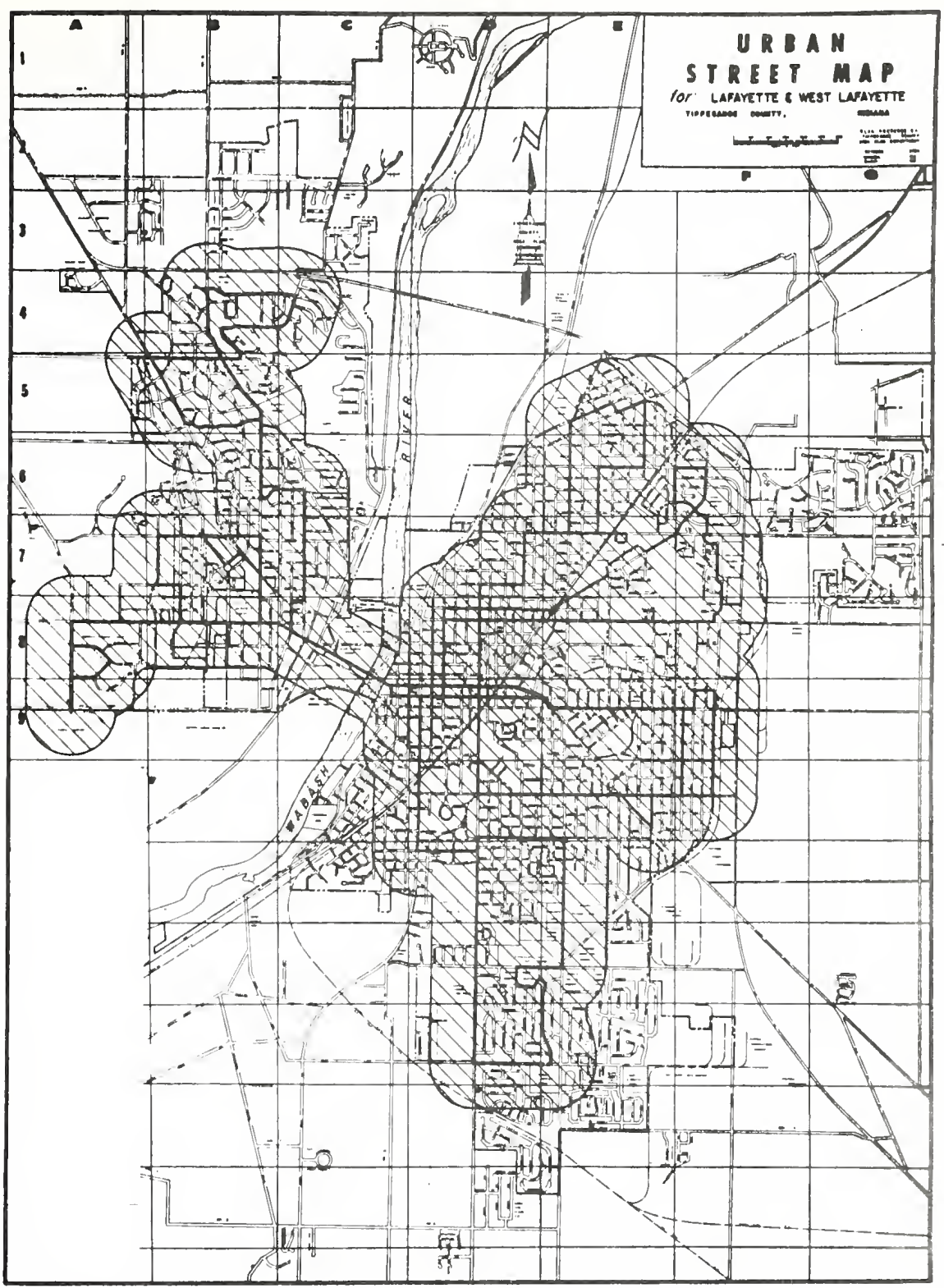

FIGURE 5-2 ROUTE COVERAGE OF THE OLD BUS SYSTEM ( $1 / 4$ MILE ON EACH SIDE OF ROUTE) 
South Street-Salisbury served Wabash Village and the residential areas of West Lafayette, the downtown area of Lafayette, South Street including Home Hospital, 29 th Street, and kossuth street. One bus was used, giving a one-hour headway.

Kossuth-Purdue Airport corresponded closely to the South Street-Salisbury route in Lafayette; it also served the Purdue Campus and the Purdue Atrport. One bus iras used on this route also, giving a one-hour headway.

Figure 5-2 indicates that most of the developed area in Lafayette was covered by some transit service. However, it also shows that there are some new developments which are out of reach of the old bus service. These developments or sections include the area north of Sagamore Parkway in West Lafayette, the area east of Sagamore Parkway in Lafayette along Greenbush and Union Streets, the Lafayette Square Shopping Center at Teal Road, and the shopping plaza composed of K-Mart, T-Way and the new mall at the intersection of Teal Road and Sagamore Pakway. The area southeast of Beck Lane and the area northwest of Teal Road along State Road 43 were also deprived of bus service.

Equipment: The bus sytem was composed of some 23 buses. Their seating capacity was in the order of 33 passengers and larger. The seating capacity of the buses was considered to be more than adequate for the passenger load 
and was rarely exceeded. The average age of the buses approached 20 years. The condition of the equipment was such that none of it can be retained for future use. Also, there is no salvage value for the bus equipment as the buses are out-dated and in a very poor condition.

\section{Characteristics of Transit Riders}

A number of characteristics of the bus users were obtained from the on board survey conducted on Thursday, November 19, 1970. The form used in the survey was designed to gather trip related data including origin, destination, and purpose as well as characteristics of the bus rider such as age, sex, education, drivers license and car ownership status.

Figure 5-3 shows the relationships between the various categories of sex, age, trip purpose, driver's license availability and car ownership of the users of transit.

Work trips accounted for almost half of the total trips followed by school trips making up approximately one fifth. Over $40 \%$ of the passengers were 45 years of age or older, while almost $30 \%$ were under the age of 20 . The females constituted the great majority of bus passengers $(73.5 \%)$.

A review of the characteristics reveal that there is a substantial group that is dependent on the bus system to 

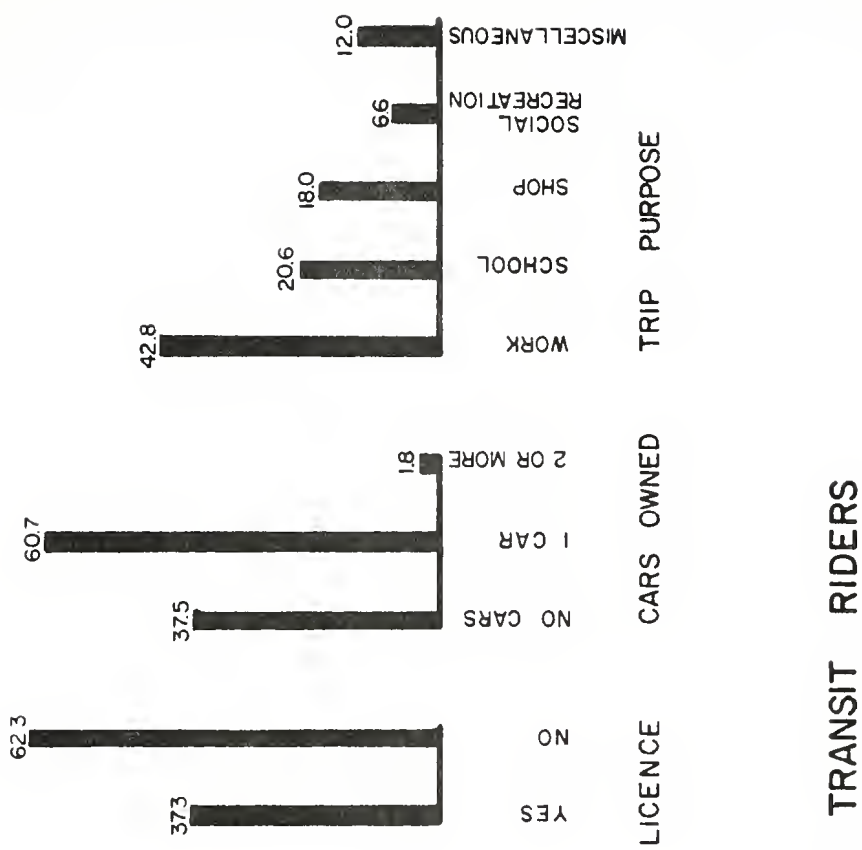

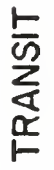

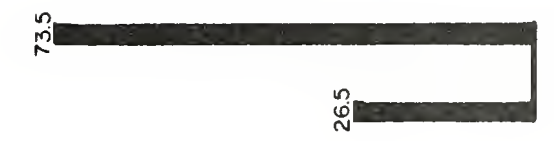

$\exists า \forall พ \exists y$

$37 \forall w$

$\underset{\infty}{\infty}$

岁

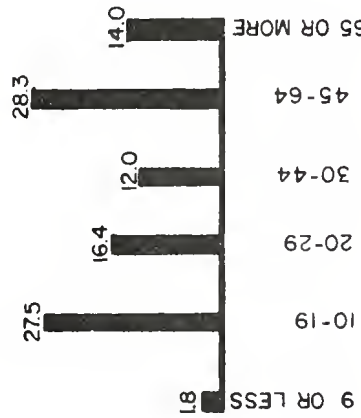

옹
웅
응

品

岕

$\frac{x}{\alpha}$

$m$
1

$\frac{\omega}{\frac{U}{0}}$ 
achieve their travel needs. One third of the transit riders reported no car ownership. The over 65 and under 20 age groups composed more than $40 \%$ of the total transit riders. The two areas of age and auto ownership give some indication as to the amount of captive ridership on the system. This group of captive riders is a majority of the total bus riders.

Another major group of riders is the wife who is using the bus as a "second car" for shopping or for a vital work trip function which is indicated by the large number of women riders combined with the predominance of one-car household.

These two groups, the captive riders and the housewives, possibly constitute the major demand on the bus sys tem.

\section{Travel Data}

The hourly volume variation by time of day is shown in Figure 5-4. As most of the public transportation systems, the distribution shows two peaks, one in the morning and one in the afternoon. The highest peak occurred in the afternoon around 5:00 p.m. This is clearly the effect of the work to home trips which start at that time. 


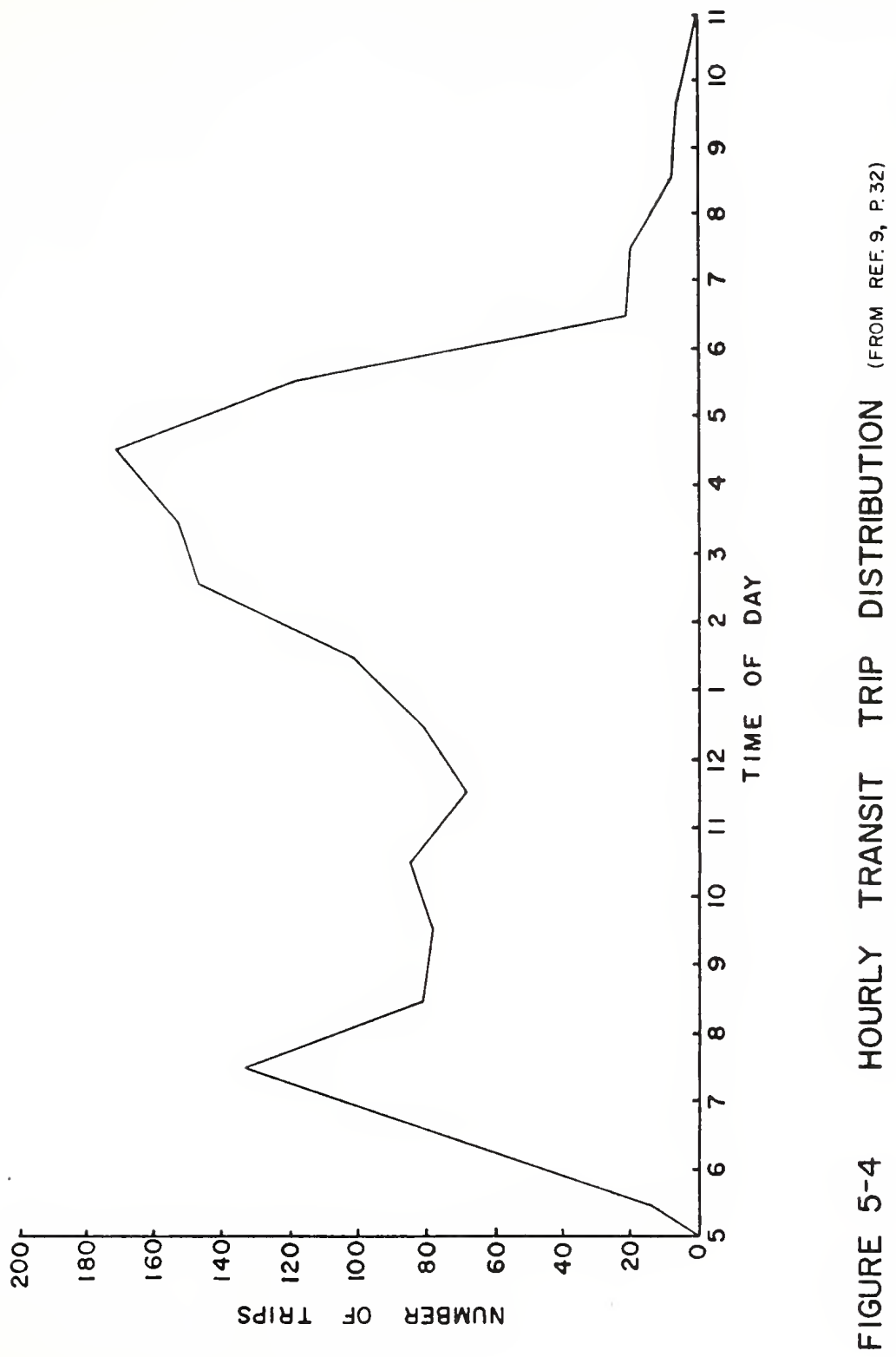


A tabulation of the peak time percentage distribution of total bus transit trips is shown below:

Fairpark-Union

$$
\begin{gathered}
(6: 30-8: 00 \text { a.m. }) \\
15 \%
\end{gathered}
$$

$$
\begin{gathered}
(2: 30-5: 30 \text { p.m. }) \\
46 \%
\end{gathered}
$$

Total $\quad 61 \%$

$$
\text { Kossuth-Purdue Airport }
$$

$$
(6: 00-8: 00 \text { a.m. })
$$
$15 \%$

$$
\begin{gathered}
(3: 00-5: 00 \text { p.m. }) \\
35 \%
\end{gathered}
$$

$$
\text { Total }(4-1 / 2 \text { of } 14 \text { hrs. }) .
$$

South Street-Salisbury

$$
\begin{gathered}
(6: 30-7: 30 \text { a.m. }) \\
11 \% \\
(3: 30-5: 00 \text { p.m. }) \\
21 \% \\
(2-1 / 2 \text { of } 12 \text { hrs. }) \\
32 \%
\end{gathered}
$$

Monon Shops-University

$$
\begin{gathered}
(6: 30-8: 00 \text { a.m. }) \\
11 \% \\
(3: 30-5: 30 \text { p.m. }) \\
24 \% \\
(3-1 / 2 \underset{35 \%}{35} 18 \text { hrs. })
\end{gathered}
$$

The figures indicate that the majority of the trips were made during the morning and afternoon peak periods. The Fairpark Union 1 ine had $61 \%$ of the trips occurring in 4-1/2 hours of a 12 hour operation. Likewise, the KossuthPurdue Airport line handled $50 \%$ of total trips during the peak periods.

An examination of the distribution of bus passenger trips, based on trips ending in a given traffic zone, indicated that the following eight areas are major trip generators: 
Traffic

Zone No.

001

002

503

203

100

314

304

403
Location

Downtown (West of City Hall)

Downtown (East of City $\mathrm{Hall}$ )

Purdue (Near Union Building)

Market Square

Immediately NE of Central Business

District ( 9 th and Cincinnati)

Jefferson Square

Earl and Kossuth

4 th and Owen
No. of

Trip Ends

185

120

92

67

48

44

33

32

Economic Condition

The economic condition of the bus system fluctuated between good and bad years. However, the last four years have produced a continued decline in revenue and services. With the decline in revenue and services, the cost of providing these services has continued to increase, thus reducing any profit the company might make.

Figure 5-5 shows the net taxable income of the bus company. It is calculated by subtracting the total operating costs from the total revenues. The total cost of operation does not include the cost of general office expenses, tax deductions, bus depreciation, or compensation paid to the officers of the corporation in Indianapolis. Still, the graph does present a fair picture of the good and bad economic periods of operation. The graph shows three relatively good periods of operation in 1959, 1962 and 1967 and two relatively low periods in 1961 and 1963. 


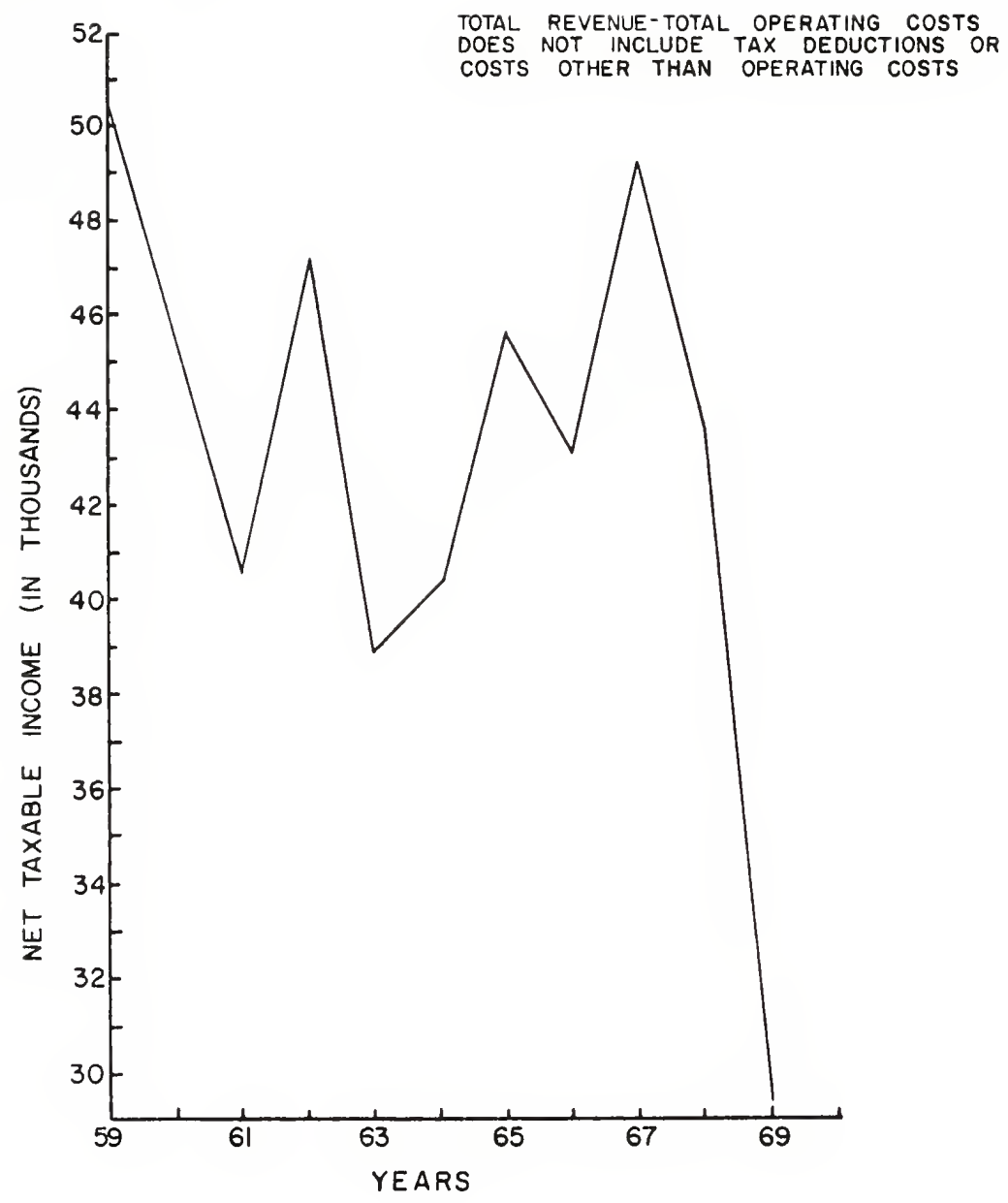

FIGURE 5-5 NET TAXABLE INCOME- GREATER LAFAYETTE BUS COMPANY (FROM REF. 9, P.37) 
The 1967 year was probably the best year of operation for the company. Besides the increase in the operating costs, the total revenue was the highest since 1960. This increase was attributed to the increase in passenger revenue as well as to the increase in the special and charter revenue.

Since 1967, the operating costs have continued to rise while the passenger revenue and total revenue have continued to decline which brought the bus company to the deficit situation.

Conclusions Regarding the 01d Bus Service

The analysis of the old bus service indicates shortcomings in four general areas, routing, headways, hours of operation and quality of service variables.

The routing patterns offered no service to new growth areas of the city, residential or commercial. Loop type route patterns were used to gain wider coverage, doubling ride times and lowering the level of service.

The frequency of service in certain areas amounted to one hour headway. It generally produced long waiting times and inconvenience to the bus riders.

The hours of operation did not provide evening service on most routes. Besides, there was no bus service on Sundays or holidays. The transit patrons found it very difficult to rely or depend on the transit services to meet all their travel needs. 
In general, the quality of service was poor. The old buses were unable to maintain schedules, even on short routes. The ride was uncomfortable due to exhaust fumes, rough ride and lack of air-conditioning and flow-through heat. Bus drivers received little training or incentive to build a better public image.

Development of the New Fixed Route Bus System

\section{Objectives}

The main objective of the new fixed route bus system is to provide a better bus service to the community of Greater Lafayette Area. A better bus service means the best selection of routes, shorter headways, larger coverage area and a more convenient ride. These improvement policies are limited by practical financial considerations. In other words, they are limited by the number of buses available for service.

Therefore, the best fixed route bus network is the one that achieves a proper balance between area coverage and rider convenience and economics of operation subject to the constraint of physical assets.

\section{Guidelines for Route Development}

Although bus routes should be conceived on a system wide basis, the following guidelines were developed to be used as an evaluating criteria for individual route development in small urban areas. 
1. Transit route- should be linear where possible, returning inbound over the same route used outbound. It provides directness of travel to the rider between his points of origin and destination and decreases his bus stravel time.

2. Through-routing is preferred to cycle-routing. Through-routing is simply routing the vehicles from one side of town to the other generally through the central business district. Cyclerouting is running the buses into the central business district and routing them back out over the same line, usually at fixed interval. Both of these plans allow arrivals at the central business district to be scheduled for convenient transfers to other lines. Through-routing will minimize the number of passengers who must transfer at the central business district to complete their trips. On the other hand, if a service interruption occurs, two lines are affected rather than one. Cycle-routing simplifies scheduling somewhat, but it forces more passengers to transfer from one line to another. If through traffic is heavy, through-routing is preferable because it minimizes time, energy and money costs $(22)$. 
3. Closer space routing or fine-grained routing through residential areas at the outlying end of a line is recommended. This technique can be rega nded almost as door-to-door service. It increases the access to the transit service by minimizing the walking time of the consumer.

4. Loop-routing should be avoided where possible. The use of large one-way loops of transit lines is generally not good practice. Large loops have the effect of causing people to wait through layovers, sometimes fairly time-consuming, before reaching their final destination. They also preclude the extension of lines at some future time into areas of new development.

5. Routes should not be duplicated, except where they converge to assure maximum service area penetration by each route. It is desirable that a bus operating on one route not duplicate the area served by a bus on another route.

6. Routes should attempt to touch as many traffic generators as possible without becoming too circuitous (22).

7. Routes should, if possible, attempt to have traffic generators at both ends of the line. This tends to generate passenger movements on both directions of the route at various times of the - service. 
8. Buses should, if possible, enter a shopping center, apartment complex, recreation area, or factory complex (22).

9. At a major downtown terminus, the buses should pull up next to one another to expedite transferring (22).

10. The number of transfers between various lines which a transit rider must take between his point of origin and destination must be minimized. It eliminates unnecessary waiting times, especially if service interruption occurs one one of the routes. It also decreases the possibilities of misusing the transfer tickets by the patrons.

11. Bus routes should be limited to arterial streets, except in residential areas where the use of feeder routes connected with arterial routes can be justified.

12. Each route should have as few turns as possible, and have adequate provision for turn around at both ends, and for layover where necessary.

13. Very long complex routes should be avoided where possible. Very long bus routes, particularly if they have several branches are hard to operate at a satisfactory level of schedule adherence. From the operating point of view, it is deemed desirable to keep routes as short as possible and to limit 
the branches on longer routes. This criteria is, of course, in conflict with the aim of providing the maximum number of through rides for passengers, and in many instances, compromise is necessary.

14. Individual bus routes should be kept as simple as possible and easy to understand by a person traveling for the first time. In addition, the entire route structure should be simple so as to minimize confusion and make it possible for a person to easily choose the best route for his destination.

15. The system of routes should be reasongly flexible over the long-term so that they may meet changing conditions in the future.

\section{Fixed-Route Selection Procedures}

The procedures used in developing the different route configurations for Greater Lafayette Area are outlined below. They are generalized for use as route development procedures for small urban areas.

1. The initial point for all routing configurations starts with a street map of the total area to be served. On this map all streets suitable for transit routes (i.e., adequate widths, running speed, turning radii, and abutting land use), should be identified. In most small urban areas 
these streets fall into the categories of major and minor arterials, and such streets should make prime candidates for bus routes.

The traffic signals on these streets are most often coordinated in such a way that traffic maintaining the proper speed can make the entire trip without having to stop for traffic signals. Parking is usually forbidden on these streets, which decreases the time required to load and unload at bus stops. Besides, the private automobile drivers generally select routes that minimize travel time and these routes should be considered as bus routes.

2. After all the possible candidate routes have been chosen, the second point is to locate the major traffic generators on the map. The major traffic generators common to all small urban areas are:
a) Shopping centers
b) Industrial areas
c) Commercial areas
d) High density housing
e) Low income housing
f) Health care facilities
g) Schools and Universities
h) Airports and bus terminals
i) Recreation areas 
These are the points where people may come and go. obviously, the route layout should serve these points or terminals.

3. To expedite transferring between bus lines a common point of transfer should be chosen, where bus routes could converge. Since most of the arterial streets in small urban areas tend to converge in the downtown area, and because the majority of the desired lines of travel are oriented towards downtown, the choice of the downtown area as a common transfer point should be recommended. In addition, the common point could be used as a check point to control the operation of the buses.

4. Iso-lines of running times from the common transfer point towards the outlying points of the study area are drawn next on the map. Ten minutes interval of iso-lines may be used. The travel times could be established either by referring to the timetables of the existing bus system or by actual testing in the field. These lines would indicate the time needed by the bus to reach the end of the different legs of the candidate routes from the common points. 
5. A decision should be made on whether any link of the study area connected to the central business district should be given a preferential treatment in service to other parts of the study area. A special service is recommended in high-density corridors of travel linking two major activity centers. But, in most small urban areas the density of travel is uniform among all parts of the city and no preferential treatment is usually warranted.

6. At this stage, with the number of buses available for service in mind, and the range of headway chosen on the basis of the service area, the number of route legs from the transfer point could be determined. However, the number of routes and the frequency of service are interrelated. Within a fixed service area and a fixed number of buses, headways can be reduced by placing lines farther apart and minimizing the number of routes. On the other hand, walking distances can be reduced by placing lines closer together and increasing the headways. If the size of the service area is increased, the headways increase for the same number of routes and a fixed number of buses. An increase in the number of operating buses would reduce the headways if the route lines are 
spaced the same. A decrease in the number of routes would also reduce the headways for a greater size area. So, routings must be necessarily a compromise when viewed from "walking distances" and "headway" aspects.

In the transit industry a quarter mile distance on both sides of the bus line is considered to be the maximum catchment area for that route. Thus, in residential areas, the spacing of routes one-half mile apart is considered to be the traditional rule of thumb. This rule of thumb, however, should be discarded in favor of routes that are closer together, especially if the transit firm is to attract automobile owners, for studies have shown that ridership falls off sharply beyond the first block.

Normally, the headways are better provided in even portions of an hour, i.e., at 15 minutes, 20 minutes or 30 minutes interval because the schedules are easier to remember.

\section{Alternate System Concepts}

In the Greater Lafayette Area, the major street system tends to converge in the downtown area at the courthouse providing a good point for common transfers. There are only two practical river corssings that the buses can use in moving from the city of West Lafayette to the city of Lafayette and visa versa. These are the Main Street bridge 
and the Harrison bridge. This physical constraint limits the choice of alternatives in route development. Another physical constraint is the railroad crossings in the city of Lafayette. These railroad crossings, at grade with the street network, create traffic delays when the trains cross the city. It may prevent the buses from meeting their assigned schedules. Since the city of West Lafayette has no railroad crossings and to facilitate the problem of scheduling and operation, it is felt that cycle-routing should be used instead of through-routing at this stage of development, until the railroad relocation plan has been executed.

Taking these problems into consideration, and following the guidelines for route development and the route selection procedures, the following system concepts have been developed.

Concept A - A fifteen bus, eleven leg system: The system shown in figure 5-6 was developed using the concept of linear routing where possible. It is composed of eleven legs. The short route on Wabash Avenue is not considered as a separate leg, since it is a part of another longer route, the Harket Square - Greenbush route. Two buses operate on each of the four long legs to provide the 30 minute headways on the entire system. The disadvantages of this concept are that the people living south of Teal Road have to make a large loop to go downtown, which might 


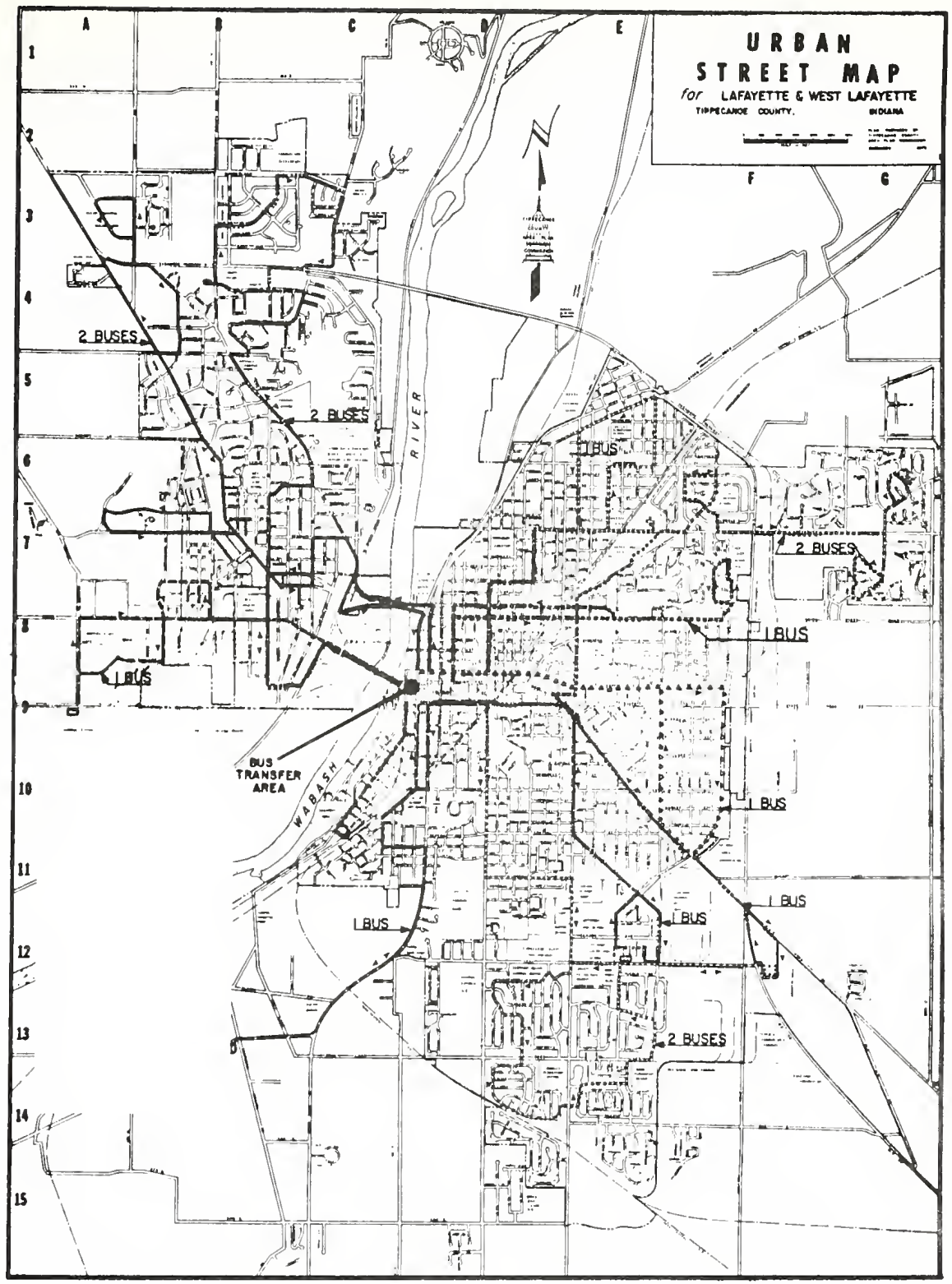

FIGURE 5-6 ROUTE CONCEPT A 
take them twice the time of direct travel. The area covered by the Union and Hedgewood Line has no direct access to the Market Square Shopping Center, except through transfer at courthouse, which is a long way of travel. The advantage of the system is that it provides a good coverage of the service area. It also cuts down on left-turning movements which tend to increase the operating speeds.

Concept B - A fifteen bus, 9 leg, one two way loop system: The concept $B$ as shown in Figure 5-7 does not differ much from Concept $A$. The headways and the service area are much the same, except for the additional area south of Brady Lane which is served by this concept. The West Lafayette area has the same route patterns as in Concept $A$.

The disadvantage exhibited in the previous system on Union Street and Hedgewood Drive is being eliminated in this system. A two-way loop service is made out by connecting the Market Square - Elmwood route and the Hartford - Schuyler route. It eliminates the need for an out-of-the-way trip downtown if travel is desired between the adjacent areas. Furthermore when cut in frequency of service is desired, such as during evening periods, the route may be turned to a one-way loop service which reduces the number of buses in operation.

The obvious disadvantage in this system is that people living southwest of Teal Road and 18 th Street have no 


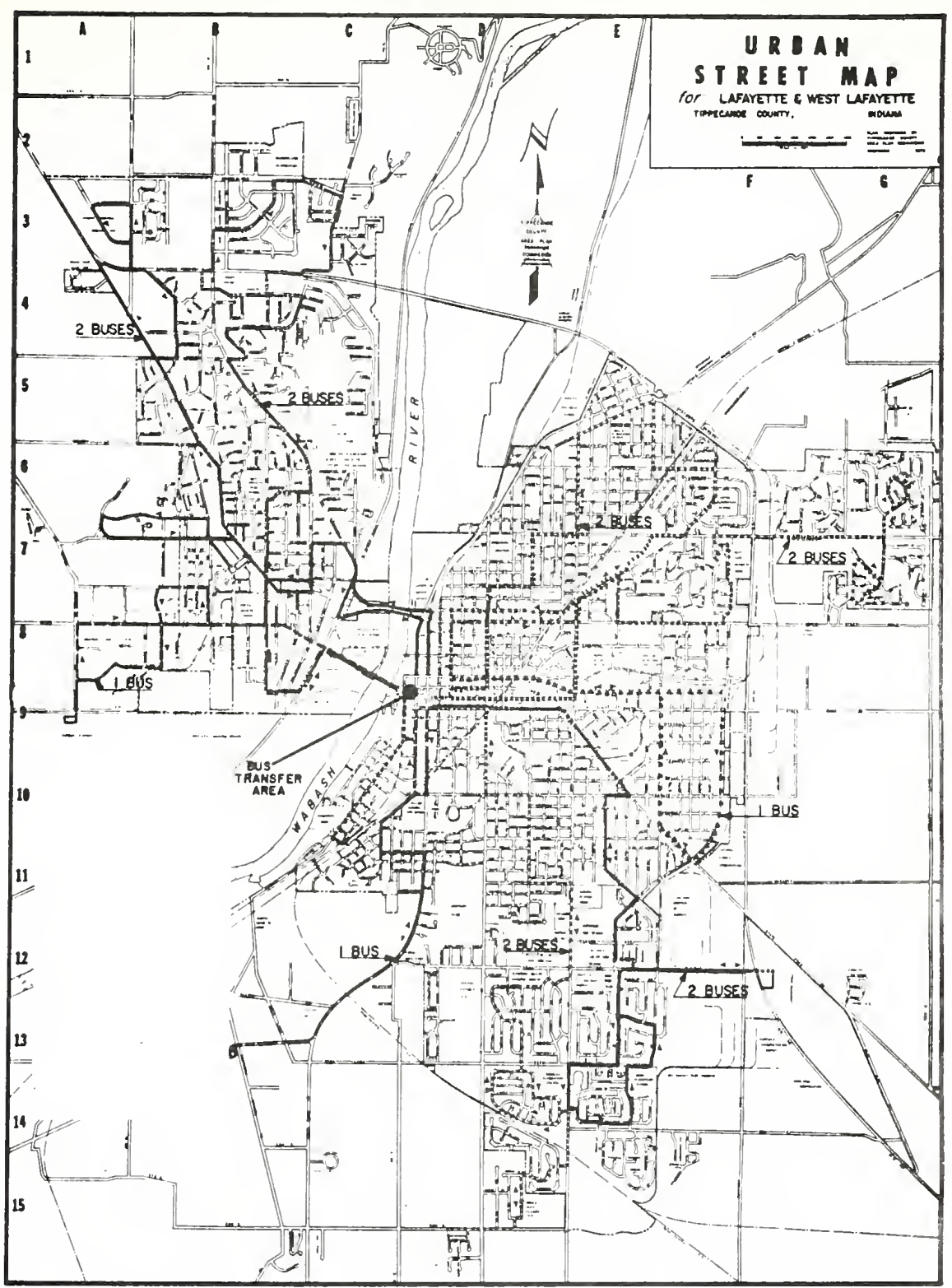

FIGURE 5-7 ROUTE CONCEPT B 
direct access to the Lafayette Square Shopping Center and to the shopping mall at the intersection of Sagamore Parkway and Teal Road. They have to transfer either at downtown or at the end of the line near Eastway Street. Both transfers subject the passengers to either long bus travel times or long waiting times, which may discourage the use of transit for that direction of travel. Concept C - A fifteen bus, 7 leg, three two-way loop system:

Concept $C$ may be considered the best system developed for it is designed to contain the best of the two previous concepts.

Concept $C$, as shown in Figure $5-8$, is an improvement to Concept B. The Columbia Park - Mall leg is joined to the 18th Street leg to achieve greater flexibility to the system by providing two-way loop service. The disadvantage identified in Concept $B$ is being eliminated by this connection.

Similarly the connection of Salisbury and Northwestern legs in the city of West Lafayette allows an easy movement between the two legs without going through the downtown area. In addition, it makes the busy commercial strip on Sagamore Parkway a common part of both legs.

A special route operating on Canal Road was added to the system. The route would operate as a test route for peak periods only. It requires only one bus to provide a half-hour headway. It is felt that since a good number of 


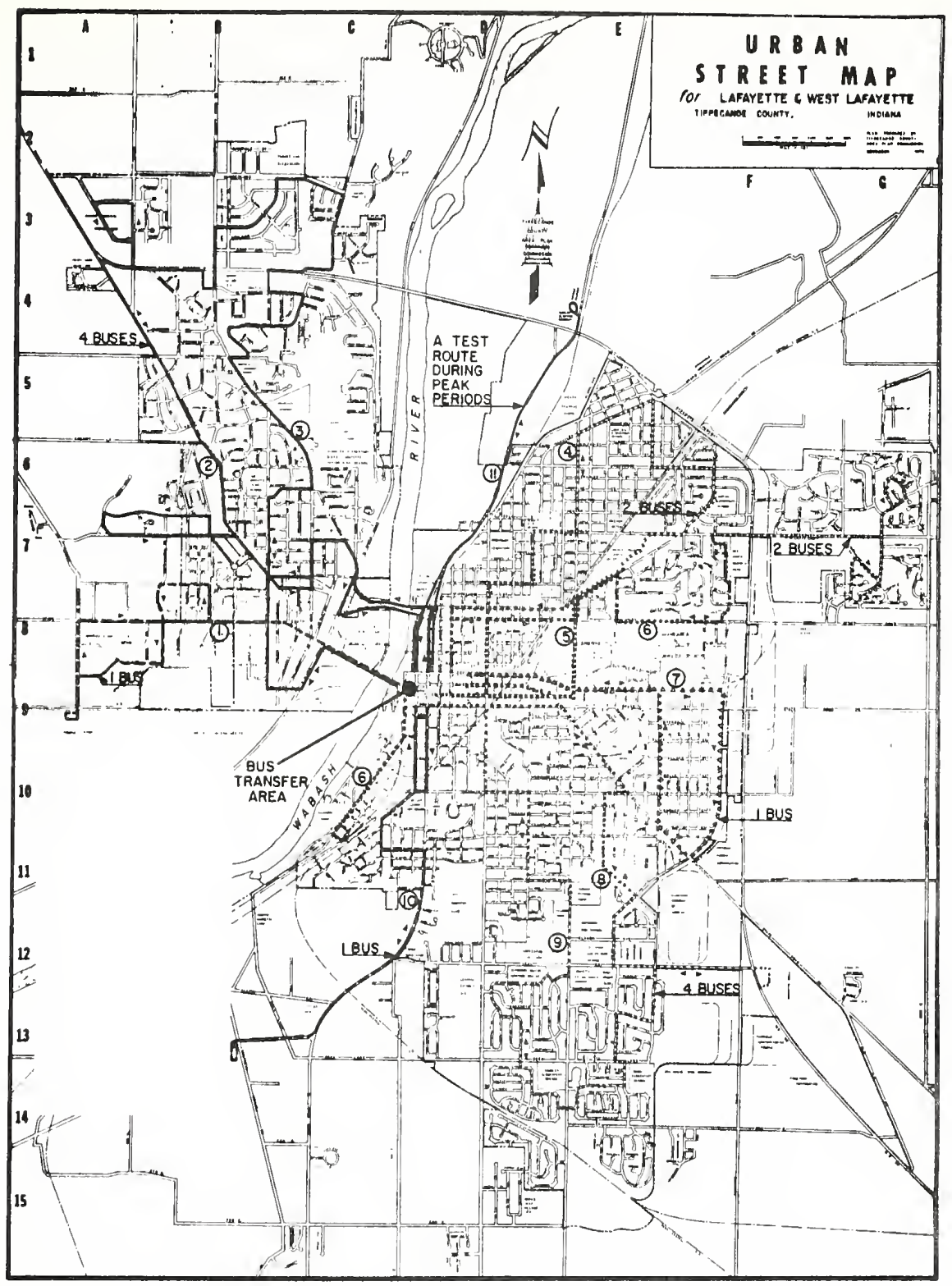

FIGURE 5-8 ROUTE CONCEPT C (THE SELECTED SYSTEM) 
small industries and commercial strips are located on that route which employ a good portion of the labor force, a bus service during peak periods could be feasible'. However, if the route is found to be inefficient and is raising little patronage, the service could be easily discontinued.

The system $C$ is well adaptable to reduction in service in off-peak periods. No need is required to alter the route configurations or to interrupt the service on certain routes. The two-way loop service could be changed to one-way loop service and by cross-connecting the halfhour legs, the entire system could be served by five buses providing an hour headway on all routes.

The disadvantage of the two-way loop service is that it inhibits the extension of the routes to new service areas. However, the transit network chosen should never be considered fixed for all time. Each route should be reviewed and reevaluated for its effectiveness as the conditions require. Therefore, the above disadvantage should be overlooked for the greater flexibility achieved in the system, especially when the design is for shortrange planning.

Analysis of the Selected System

The route configuration of Concept $C$ was subjected, before its final selection, to a detalled analysis to 
improve its operating efficiency and to analyze its benefits and disadvantages.

Discussion with the bus drivers and the bus management provided valuable information on problem areas that should be serviced, areas of poor road geometry including turns and grades and unique local requirements.

It was obvious from the length of the various routes that 30 minute headways could be provided on the entire system. The routes had been chosen on the assumption that an operating speed of 12.0 miles/hour on the average would be feasible. A field testing of the routes confirmed the above assumption. No problem was encountered on all the driven routes. During the test runs the short routes were driven in 30 minutes and the long routes were driven in one hour. No modifications was felt necessary on any of the routes, and based on the field test data, 30 minute headways could be implemented on the entire system. Route Name Designation: Having established the final route configuration, it was necessary to designate each route. Each leg of the system is given a different name. But a problem would arise with the two-way loop routes. The solution would be to identify each of them as composed of two one-way loop routes, one turning clockwise and the other turning counter clockwise.

The names chosen for the routes as numbered in Figure 5-8 are: 


$$
\begin{aligned}
1 \text { - University } \\
2 \text { - Northwestern-Salisbury } \\
3 \text { - Salisbury-Northwestern } \\
4 \text { - Hartford-Market Square } \\
5 \text { - Market Square-Hartford } \\
6 \text { - Wabash-Union-Greenbush } \\
7 \text { - Ferry-Earl } \\
8 \text { - Mall-18th Street } \\
9 \text { - 18th Street-Mal1 } \\
10 \text { - 4th Street-Road } 25 \\
\text { 11 - Canal Road }
\end{aligned}
$$

*This route would be implemented on a trial basis for peak periods only.

Schedules: The basic schedule would provide 30 minute service on all routes. On the one-hour routes two buses are used to provide a 30 minute headway.

Tabulated in Table 5-2 are the half and one hour schedules of all the routes. In this schedule, only prominent stops on each route are considered for timing. One bus for each route leaves the Courthouse area at the same time, which is considered as zero-hour time for ease of comparison.

As mentioned before, the one-hour service on all routes would be achieved by converting the two-way loop routes to one-way loop routes and cross-connecting the 30 minute routes. This would only require five buses for the total service. If the two-way loop service on the longer routes is still desired, seven buses would meet the one-hour service for the entire system.

It is recommended that bus service would be provided on Sundays and Holidays, on the same basis as weekdays. It 
TABLE 5-2 THE SELECTED ROUTES TIMETABLES

Route 1- University

\begin{tabular}{|c|c|c|c|c|c|}
\hline $\begin{array}{c}\text { Court- } \\
\text { House }\end{array}$ & $\begin{array}{c}\text { State- } \\
\text { Gront }\end{array}$ & $\begin{array}{c}\text { Purdue } \\
\text { Airport }\end{array}$ & $\begin{array}{c}\text { Stote- } \\
\text { Intramural }\end{array}$ & $\begin{array}{c}\text { State- } \\
\text { Gront }\end{array}$ & $\begin{array}{c}\text { Court- } \\
\text { House }\end{array}$ \\
\hline $0: 00$ & $6: 00$ & $14: 50$ & $18: 20$ & $21: 00$ & $27: 00$ \\
\hline
\end{tabular}

Route 28,3 - Northwestern - Solisbury

\begin{tabular}{|c|c|c|c|c|c|}
\hline $\begin{array}{l}\text { Court- } \\
\text { House }\end{array}$ & $\begin{array}{c}\text { Northwestern- } \\
\text { Gront }\end{array}$ & $\begin{array}{c}\text { Northwestern } \\
\text { Sagomore Pkw. }\end{array}$ & $\begin{array}{c}\text { Grants } \\
\text { Store }\end{array}$ & $\begin{array}{c}\text { Grant- } \\
\text { Northwestern }\end{array}$ & $\begin{array}{c}\text { Court- } \\
\text { House }\end{array}$ \\
\hline $0: 00$ & $7: 50$ & $22: 15$ & $38: 50$ & $49: 50$ & $58: 10$ \\
\hline
\end{tabular}

Route 4 \& 5- Hartford-Market Square

\begin{tabular}{|c|c|c|c|c|c|}
\hline $\begin{array}{l}\text { Court } \\
\text { House }\end{array}$ & $\begin{array}{c}\text { St. Eliz. } \\
\text { Hospital }\end{array}$ & $\begin{array}{c}\text { Schyler } \\
-24 \text { th }\end{array}$ & $\begin{array}{l}\text { Market } \\
\text { Square }\end{array}$ & $\begin{array}{c}\text { South } \\
-18 \text { th }\end{array}$ & $\begin{array}{l}\text { Court } \\
\text { House }\end{array}$ \\
\hline $0: 00$ & $7: 15$ & $12: 30$ & $20: 00$ & $24: 30$ & $29: 00$ \\
\hline
\end{tabular}

Route 6 - Union-Greenbush-Wobash

\begin{tabular}{|c|c|c|c|c|c|}
\hline $\begin{array}{c}\text { Court- } \\
\text { House }\end{array}$ & $\begin{array}{c}\text { Market } \\
\text { Square }\end{array}$ & $\begin{array}{c}\text { Greenbush- } \\
\text { Shenandoah }\end{array}$ & $\begin{array}{c}\text { Market } \\
\text { Square }\end{array}$ & $\begin{array}{c}\text { Wabosh- } \\
\text { Manford }\end{array}$ & $\begin{array}{l}\text { Court- } \\
\text { House }\end{array}$ \\
\hline $0: 00$ & $11: 30$ & $22: 00$ & $39: 00$ & $55: 45$ & $58: 30$ \\
\hline
\end{tabular}

Route 7 - Ferry-Earl

\begin{tabular}{|c|c|c|c|c|c|}
\hline $\begin{array}{c}\text { Court- } \\
\text { House }\end{array}$ & $\begin{array}{c}\text { Ferry- } \\
\text { Earl }\end{array}$ & $\begin{array}{c}\text { Eart- } \\
\text { Main }\end{array}$ & $\begin{array}{c}26 \text { th- }^{-} \\
\text {Ferry }\end{array}$ & $\begin{array}{c}\text { Ferry- } \\
9 \text { th }^{-}\end{array}$ & $\begin{array}{c}\text { Court } \\
\text { House }\end{array}$ \\
\hline $0: 00$ & $7: 30$ & $12: 10$ & $20: 45$ & $24: 15$ & $27: 45$ \\
\hline
\end{tabular}

Route 8 \& 9 - Mall- 18 th st.

\begin{tabular}{|c|c|c|c|c|c|}
\hline $\begin{array}{c}\text { Court- } \\
\text { House }\end{array}$ & $\begin{array}{c}\text { Lafayefte } \\
\text { Square }\end{array}$ & $\begin{array}{c}\text { Lafayefle } \\
\text { Mall }\end{array}$ & $\begin{array}{c}\text { Teal } \\
-18 \mathrm{th}\end{array}$ & $\begin{array}{c}\text { Kossuth } \\
-9 \text { th }^{-}\end{array}$ & $\begin{array}{c}\text { Court- } \\
\text { House }\end{array}$ \\
\hline $0: 00$ & $12: 30$ & $20: 00$ & $41: 25$ & $47: 45$ & $57: 00$ \\
\hline
\end{tabular}

Route 10- 4 th-Rd. 25

\begin{tabular}{|c|c|c|c|c|c|}
\hline $\begin{array}{c}\text { Court } \\
\text { House }\end{array}$ & $\begin{array}{c}4 \text { th- }^{-} \\
\text {Kossuth }\end{array}$ & $\begin{array}{c}\text { Three } \\
\text { Sons }\end{array}$ & $\begin{array}{c}\text { Westchester } \\
\text { Apts. }\end{array}$ & $\begin{array}{c}4 \text { th- }^{-} \\
\text {Owen }\end{array}$ & $\begin{array}{c}\text { Court- } \\
\text { House }\end{array}$ \\
\hline $0: 00$ & $4: 00$ & $7: 15$ & $11: 10$ & $20: 30$ & $27: 15$ \\
\hline
\end{tabular}


would encourage the patrons to depend on the bus service to meet all their travel needs. This service should be tried for the first six months of the implementation of the new bus system. Then, an evaluation of the ridership would decide whether to continue or discontinue the service.

Coverage: The area covered by the selected system is shown in figure 5-9. In this figure, the quarter mile distance on both sides of the route is being used as the catchment area. Using this criteria, the service area is well covered by the recommended system. However, to compare the areas that are better served and to indicate the areas that would require bus routes if better level of service is desired, another map is prepared using the $1 / 8$ mile as the maximum walking distance to the bus route. The map is shown in Figure 5-10. It also shows that most of the service area is covered by the selected system. The uncovered areas are thin and small in size and are not concentrated in one part of the study area. No additional routes are needed to cover these areas. If more buses were to be used to improve the service, the reduction in bus headways using the same routes would be recommended. Level of Service: The level of service is a measure of the service offered to the customers by the operations of the bus system. It depends on many factors which are part qualitative and part quantitative. The qualitative 


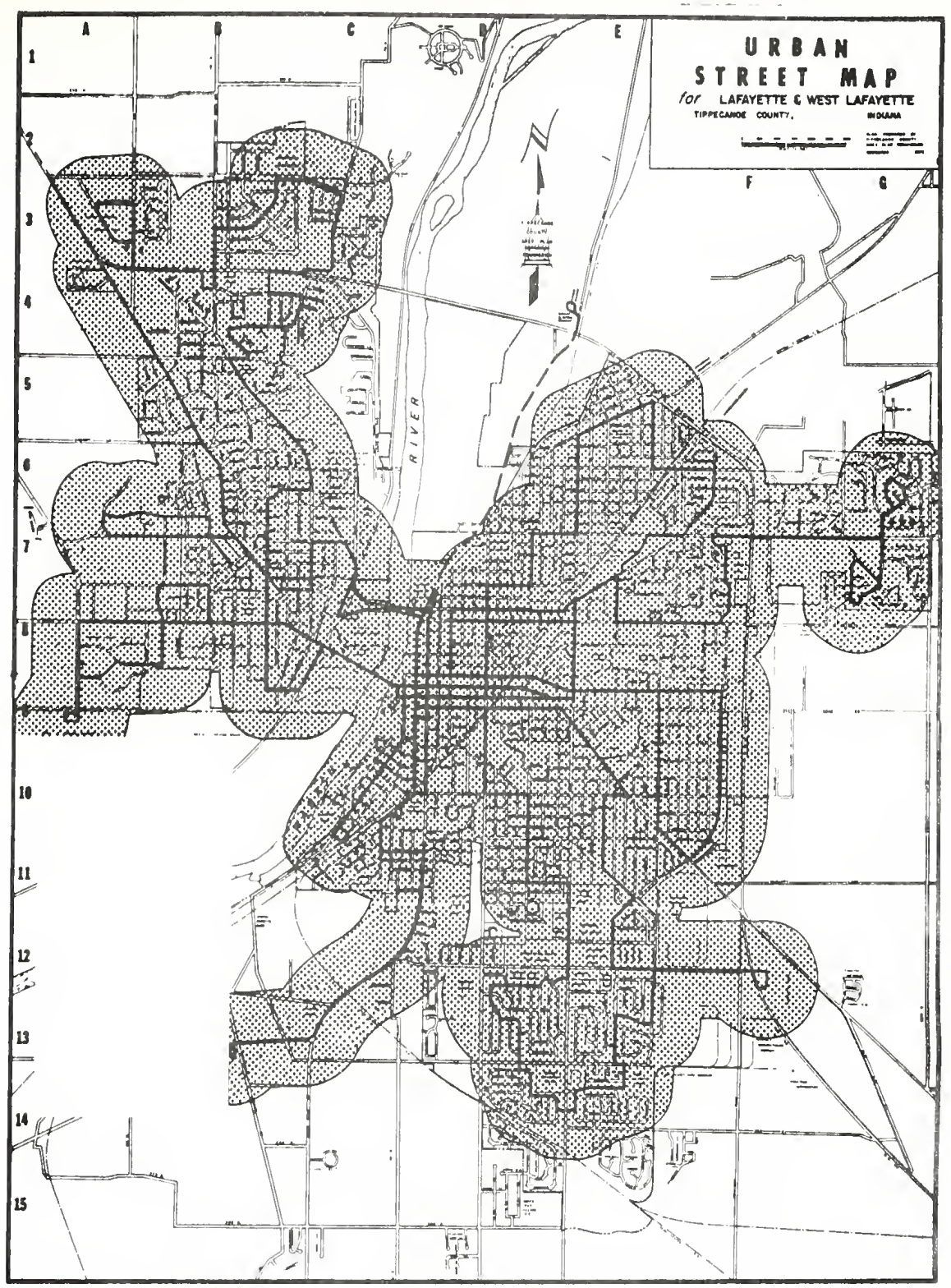

FIGURE 5-9 BUS ROUTE COVERAGE (I/4 MILE ON EACH SIDE OF ROUTE) 


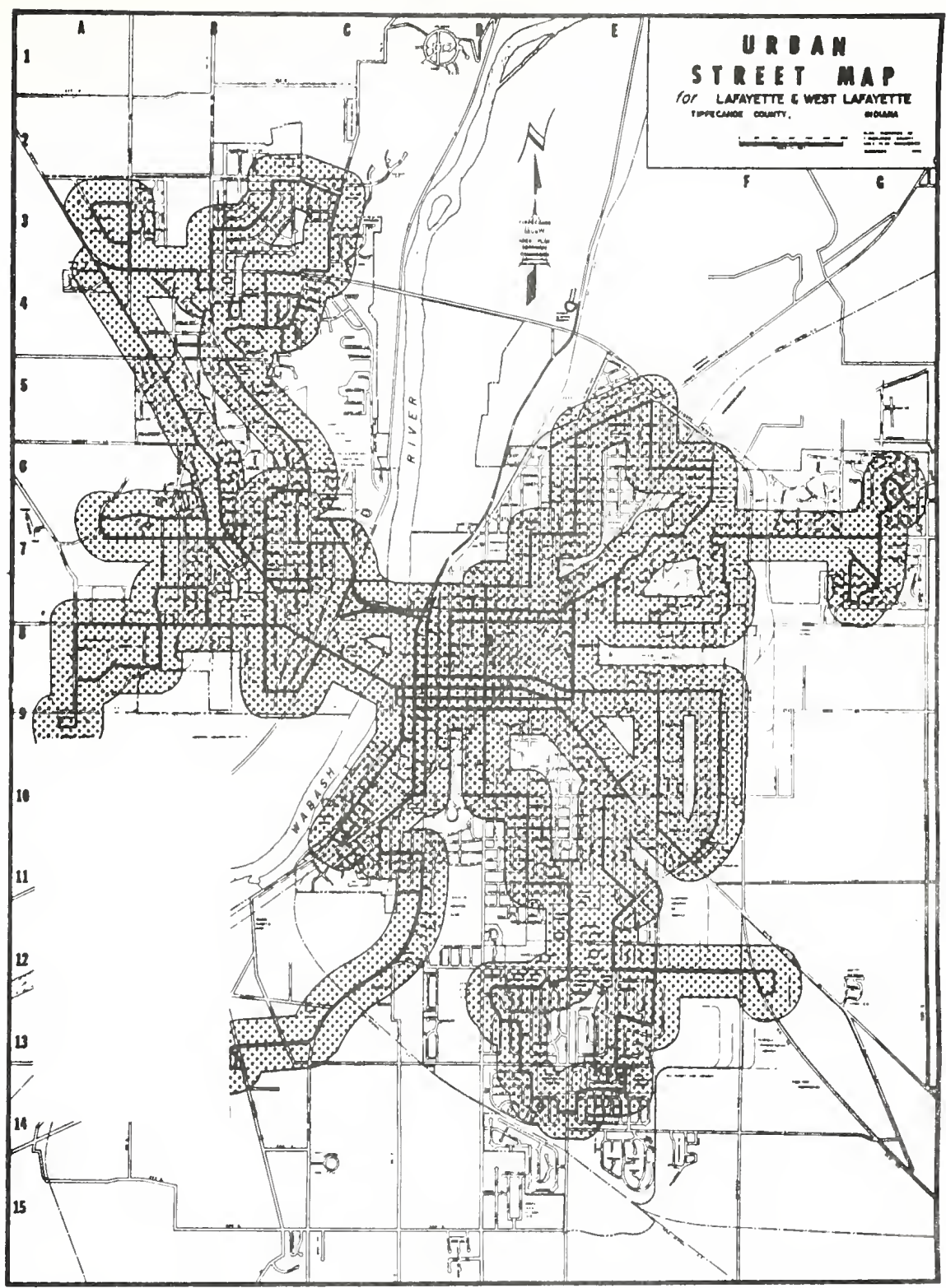

FIGURE 5-IO BUS ROUTE COVERAGE (I/8 MILE ON EACH SIDE OF ROUTE) 
variables in this research such as safety, comfort and convenience are assumed to be provided by the bus systems in consideration. It is a justifiable assumption under the present technology of the bus transportation systems. The quantitative variables such as travel time, accessibility (waiting time and walking time) and seat availability are the main factors that are considered in determining the level of sercice. Seat availability in the fixedroute bus system is not a problem. The selected system provides 750 passenger seats per hour, a capacity which is difficult to exceed with the present and forseeable future demand, even during the peak periods. The passenger seat figure is calculated from fifteen, 25 to 30 passenger buses running at half-hour headways. Therefore the total time spent by the user on the system is the main factor to consider in determining the level of service. The total time is composed of bus travel time, waiting time and walking time in case of the fixed-route system. But the time spent by the user on the system is relative, rather than absolute in value. This figure is compared to the time taken by the user if he made his trip by car instead of by bus. Hence the level of service figure is calculated as follows:

$$
\text { Level of Service }=\frac{\text { System Total Service Time }}{\text { Direct Travel Time by Auto }}
$$


The ratio will also be used to measure the level of service offered by the demand-responsive bus system which will be analyzed in the next chapter. It will allow a. comparison between the level of service offered by the two bus systems.

The value of the level of service offered by the selected fixed-route bus system is equal to 2.35. The computations are described in detail in Appendix A. A hand simualtion (using Monte-Carlo Technique) of 50 demands during the peak periods is used in the computation. The traffic zones are assigned different probabilities for being a source of origin and a source of destination for a particular demand. The destination assignment is based on the number of employees in that zone. The origin assignment is based on the number of working force in that zone which is calculated by subtracting the young and old people from total population.

The bus travel time is calculated from the time schedules of the system. Eight minutes are considered to be the average walking time to and from the bus routes by the user at both ends of the trip. It is clearly shown from the coverage maps displayed earlier that it is a conservative estimate. Seven minutes is considered to be the average waiting time of the user at the bus stop.

The auto travel time is computed similariy as in the computer simulation of the Demand-Responsive bus system. 
This will be discussed in detall in the next chapter. other values of level of service are computed for different waiting times. The value of level of service is found to be equal to 2.78 and to 3.67 for an average wating time of 12 minutes and 22 minutes respectively. The average level of service of the 15 bus-selected system for the two waiting times of 7 and 12 minutes is equal to 2.5 which is still an acceptable level of service. The 22 minute waiting time corresponds to a service of 7 buses operating on a one-hour headway. The capacity of the system at this cut-in-service diminishes to 175 passenger-seats per hour, although the coverage area remains the same. These figures show that as the average wating time increases due to cut in service, the measure of level of service deteriorates rapidly to untolerable limits. Therefore to keep the level of service within the acceptable limits which is between 2.2 and 2.5 times the direct auto travel time, according to an M.I.T. study (19), 15 buses should be used in the fixed-route system to operate on a half-hour headway. 
CHAPTER 6: DEMAND RESPONSIVE BUS SYSTEM

\section{Introduction}

The fixed-route, fixed-schedule bus system primarily serves a few radial corridors in urban areas. For many urban trips, transit riders must walk or drive some distance to the nearest transit stop, wait for the next vehicle, and usually transfer before reaching their final destination. With the tendency toward low-density living and more diverse travel patterns, the situation becomes more critical.

To provide a better level of service for the community of Greater Lafayette Area, an alternative concept of providing bus public transportation is being considered. The concept of a demand-responsive bus service, usually known as a Dial-A-Ride, was studied and analyzed.

Dial-A-Ride can provide direct door-to-door service between any two points in an urban area, thus serving the wide variety of travel desires that are predominant today in low and medium density urban areas. Dial-A-Ride, due to its high quality service, could also be a desirable alternative for those who can drive but prefer public transportation. 
Operational Characteristics of Dial-A-Ride

How it Works

Dial-A-Ride is a personalized door-to-door public transportation service. A fleet of small vehicles serves customer requests as they are recefved. The buses operate without fixed schedules on flexible routes. Vehicle assignments are determined by a digital computer program, operating on the current customer requests to produce maximum vehicle productivity and insure that all customers are picked up and delivered within reasonable time periods. Dial-A-Ride is thus a flexible, dynamic transportation system that adapts to travel desires as they become apparent.

The operation of Dial-A-Ride is shown in Figure 6-1 (6). A customer telephones his request for transportation to a current dispatching office, where the operator notes such trip details as origin, destination and the number of passengers requesting service. The operator enters this information on a typewriter console connected to the Dial-ARide scheduling computer, which in a few seconds assigns the best vehicle to pickup the new demand, using a series of scheduling rules. It then produces the estimated pick up and delivery times and the cost of the trip for the new demand. This information is relayed to the customer who then waits for the vehicle to arrive. After the customer boards the vehicle he will be taken to his desired 


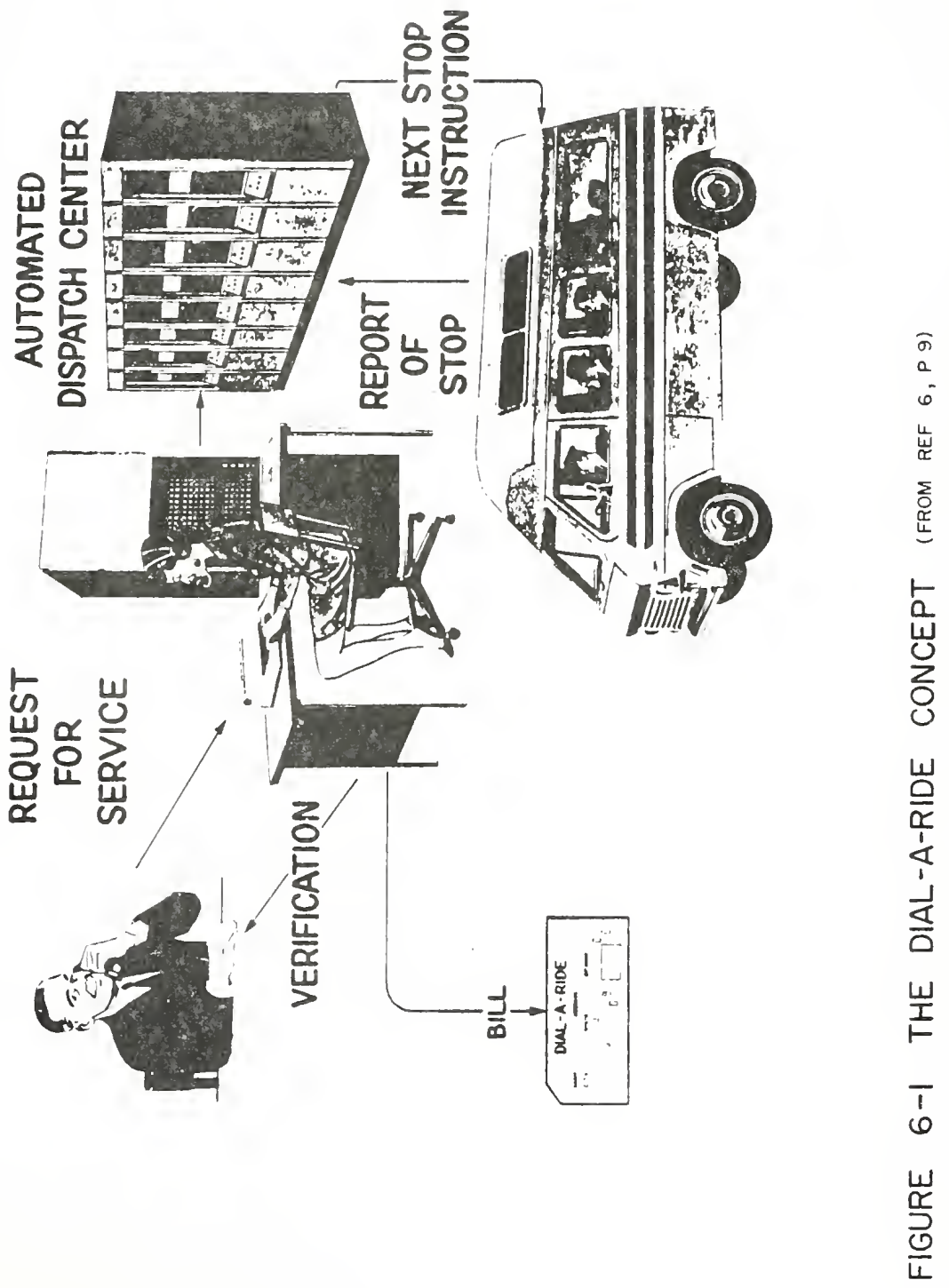


destination. While moving on its provisional route, the vehicle will make minor detours to pick up and drop off other passengers.

Whenever the vehicle driver makes a pickup or delivery, he keys the computer (using voice communication) to ask for his next destination. The computer supplies the address for the next stop, the customer identification number, and whether the stop is a pickup or a delivery. If the system requires the driver to collect a fare, the cost of the trip will also be provided. The driver will choose the best streets to reach that stop or seek help from the central dispatcher or passengers if he is unsure. Therefore, the driver proceeds on a stop-by-stop basis knowing only his next stop at any time. On the other hand, the computer stores the complete, tentatively planned tour of each vehicle at all times. Complete tour information is not given to the driver because of frequent tour changes and the impossibility of remembering all the planned stops for the entire tour (19).

The possible services of Dial-A-Ride range from "manyto-one" (many origins to one destination) to "many-to-many" (many origins to many destinations). Many-to-many is applicable where the origins and destinations are diversified, a phenomenon occurring with increasing frequency in today's metropolitan areas. The Greater Lafayette Metropolitan Area is no exception. The activity 
centers are scattered and dispersed and the urban travel patterns are varied and decentralized, especially in offpeak hours. A many-to-many Dial-A-Ride service with computerized dispatching operation is being considered for the study area.

\section{Problems Encountered in the Operation of Dial-A-Ride}

1 - Telephone lines: An intending passenger has to have access to a telephone line in order to call for service. This medium of communication might limit the potential users at one end of the trip (house-to-others) to telephone owners. Today the majority of urban residents have telephone lines. Yet, the small minority of poor residents who do not have telephone lines may have a problem in reaching the service. At the other end of the trip predominantly others-to-home, special direct telephone lines must be installed at the activity centers to allow the users to dial for service.

2 - Operators: Adequate number of operators must be hired to answer the service calls depending on the volume of demand. The requests must be processed with a minimum delay. The customer will be discouraged to use the service if he waits a long time to receive an answer. His first point of contact with the system through telephone communication is very important. The operators should be well-trained to receive his request correctly, quickly, and 
in a manner that does not irritate or annoy the customer. They should be able to transmit correctly the format messages to the central control computer and to provide efficient answering services.

3 - False Calls: The operators could receive a number of false calls from youngsters or trouble makers. They should be able to screen these calls as they gain experience. A heavy penalty should be indicted on the false callers to 1 imit such acts.

4 - No-Show: An expected passenger's non-appearance (noshow) could occur when the bus reaches the doorstep of the caller. A policy should be reached by the management on the time the driver should spend waiting for the customer. After that time the driver should proceed to his next destination.

5 - Manual-Voice Communication: Another problem area could be the communication sub-system between the driver and the dispatching center, which indicates the driver's next destination. If voice communication is chosen, the frequency used should not be interferred with other frequencies used in the area such as those used by the police department, by taxi cabs, and others using radio communication. It should have a high intensity to reach the furthest point in the area from the dispatching center. 
6 - Computer Break-down: The computer controlling the operation of Dial-A-Ride system may fail. It is mandatory to have a method of continuing system operation. It could be either by including an automatic computer backup system, which is very expensive, or by adopting a manual backup scheme. The manual backup system should efficiently replace the computer operation. The operators and the drivers should be well-trained in advance to meet such an emergency.

Area Size

The size of the study area is a controlling factor in the operation of Dial-A-Ride system. It affects the level of service provided to the customer with a given number of buses. More buses are required to provide the same level of service in a larger size area, if passengers are promised to be delivered within a restricted time of their pick-up. The productivity of the bus would decrease as the size of the area increases. The bus then, would have to haul a particular demand a long distance to satisfy his guaranteed times, which would limit its ability to pick other customers on the way. At this stage, the buses would closely operate as taxis and would defeat the purpose of the system.

Dial-A-Ride system is probably not best suited for long trips and so should only play a complementary role in 
transportation in large cities. Studies conducted in the field of demand-responsive bus systems have not reached a decision on the upper limft of the size of the service area. However, the work done at M.I.T. (25) through computer simulation have shown that an area size of 6 miles $x 6$ miles is feasible for this kind of service. The size of Greater Lafayette Area has the dimensions of 4.6 miles $x 5.5$ miles, which are within the feasible limits of such an operation.

The effects of different area shapes on the level of service have been studied through computer simulation at Northwestern University (1). The results show that DialA-Ride operation in districts of different shapes, but similar land area, will be almost identical.

\section{Demand Level}

Dial-A-Ride is a form of public transportation that is controlled by its users. In broader sense, it is called by planners a "demand-responsive" system. In contrast, to fixed route bus system the Dial-A-Ride operation is determined by its demands. The demands by their volume control the number of buses in operation and by their spatial distribution and service requirements affect the level of service provided. After the routes and schedules are designed in a fixed route system, the buses operate without any consideration to the short term variation in demand. 
The level of demand determines the feasibility of operation of the Dial-A-Ride systems. At very low demand levels, taxis would be competitive with Dial-A-Ride. Their less sophisticated control system might result in lower costs at similar vehicle productivities. At high demand levels, fixed-route buses are well suited to take advantage of large-vehicle capacity and simplicity of operation. Their productivity would continue rising with increasing demand level when the Dial-A-Ride productivity had been shown to level out. Thus at fairly high demand levels fixed-route buses would be more efficient than Dial-A-Ride. This implies that a medium demand level would be best for Dial-A-Ride.

A look at the hourly trip distribution of the old bus service system as shown in Figure 5-4 indicates that the demand level during the peak-hours ranged between 750 to 180 passengers per hour. The above demand may stay at this level or may increase with an increase in level of service. In both cases, the Dial-A-Ride system required to satisfy the peak-hour demand at a good level service exceeds the feasible operational limit that the future bus system of Greater Lafayette Area can provide. This assumption will be clearly identified in the analysis of the simulation runs at the end of this chapter. So, this study limited its analysis of the Dial-A-Ride system to off-peak periods. 
No attempt was made in this study to calculate the expected level of demand for Dial-A-RIde in off-peak hours. Instead, a range of demand was considered to cover all the possible levels of demand that the system may encounter in its off-peak operation. A demand as low as $30 \mathrm{calls} / \mathrm{hour}$ and as high as 150 calls/hour was considered in the computer simulation of the system.

\section{Scheduling Algorithm of the Dial-A-Ride System}

Introduction

The technical operation of the system, as mentioned earlier, requires the development of the set of rules (algorithm) that the computer will use to make vehicle assignments to passengers requesting service. This assignment algorithm plays a vital role in the system. It governs the quality of service and also the number of vehicles required, which is the principal determinant of the cost to the user. Thus the success of Dial-A-Ride depends on how well the assignment algorithm performs.

This study did not attempt to develop a new scheduling algorithm for the system. Instead, it was decided to choose one of the already developed algorithms for such an operation. After literature review on the subject, the algorithm developed at M.I.T. was chosen for use. In addition, the computer simulation model which uses the algorithm was available to the author for use. 
In the remainder of this section the rationale for the development of the proposed algorithm, and the algorithm itself will be summarized.

\section{Algorithmic Considerations}

In the design of assignment algorithm for the Dial-ARide system, the following three specific issues are to be addressed (25):

1. Information requil rements

2. Algorithm objectives

3. Implications of real-time environments

The information requirements describe the variables which define the state of the system at any time. Having defined the data available, the algorithm is the mechanism for achieving certain service objectives which should be defined. The implications of the real time define the computational environment within which the algorithm will have to operate.

Information Requirements: In order to develop any algorithm, certain information about the current state of the system must be available to the computer. This information is of three types, user dependent, vehicle dependent, and system dependent (25).

User-dependent Information

1) Location of the origin of the desired trip. ii) Location of the desired destination point. 
iii) Time of which request was made.

iv) Number of people making the trip.

Vehicle-dependent Information

i) Next destination of each vehicle (output from algorithm).

ii) Information relating to each passenger on board such as his destination and service time.

System-dependent Information

1) Street Network and the associated travel times between points in the network.

Algorithm objectives: The aim of the ideal algorithm would be to maximize the satisfaction of all system users at minimum cost. In more quantitative terms, the general aims of minimization of the user costs and service times may be stated as follows (25):

1. To minimize the total time spent on the system (both present and future) within constraints on the worst individual service times allowable and on the number of vehicles available.

2. To minimize the number of vehicles required to provide a service offering guaranteed bounds on the mean and worst service times.

system service time is the sum of 1) the time the customer waits to be picked up after he calls for service and 2) the driving time to his destination. 
In order to evaluate and compare service in different demand environments, in a general manner, a level of service figure is defined as:

Level of Service $($ LOS $)=\frac{\text { System service time }}{\text { Meandirect driving time }}$

Real-time Environment: In developing an assignment algorithm it is also important to recognize the real time environment within which it must operate. This imposes computational limits on the algorithm and modifies the time cost framework within which alternative algorithms should be compared. Since the cost of computation must be included in the overall system costs, the aim in designing an algorithm must be to formulate a method for obtaining good assignments quickly.

\section{Statement of the Problem}

Formulation of the problem involves defining sets of constraints which guarantee feasibility, and an objective function to select the best of the feasible solutions. The constraints may be stated as follows (25):

1. The origin point of all uncollected demands and the destination point of all demands must be visited by one vehicle once and only once. This ensures that all demand points are visited. 
2. The orfgin and destination points of each uncollected demand must be visited by the same vehicle. This assumes that no passenger changes vehicle to reach his destination.

3. For each uncollected demand the origin must precede the destination on the vehicle's proposed route.

4. All passengers currently on board a vehicle must be delivered by that vehicle.

5. The proposed route of each vehicle must be continuous.

6. The arrival times at each passenger's origin and destination points must be within the service guarantees.

7. The maximum allowable number of passengers on board a vehicle at any time must not be exceeded.

8. There are a known number of vehicles operating in the system.

This set of constraints determines the feasibility or infeasibility of a particular solution.

The desirable objectives of the algorithm were stated before but because of the uncertainty associated with the occurrence of future service requests it is not possible to formulate in closed form the minimization of service times to all current and future users. This would require a complex probabilistic expression which would render 
infeasible the application of the algorithm in the realtime environment. It is then impractical to look for an optimal solution to the problem as it exists, and some approximation of the problem is required. The most promising approximation to the desirable objective is discussed below:

1. Minimize some combination of total current users service times and total vehicle travelling times. The minimization of the total vehicle travelling times is best from the future users viewpoint, because vehicles are freed as soon as possible to serve these, as yet unknown, requests. However, service to current system users will not generally be optimal. This fairly general objective attempts to reconcile service to current and future users.

The above objective function works as a selection criteria for the best feasible solution.

\section{Algorithm Design}

The research done at M.I.T. (25) has found that the classical optimization solutions to the customer-tovehicle assignment problem such as integer programming, dynamic programming, branch and bound are not feasible. While theoretically they could be formulated and solved for small problems, no reliable method for solving problems 
of realistic size has been found. This statement is true even if the real time constraints under which the algorithm must operate are relaxed.

Since optimal-solution algorithms are infeasible the non-optimal algorithms (heuristics) were surveyed. A type of heuristic featuring the provisional assignment of new demands was selected as being the most promising for further developments.

The assignment heuristic is primarily concerned with deciding which vehicle should serve which user. The assignment of a new demand to a vehicle has two components:

1. Search for feasible assignments.

2. Choice of the best of these feasible assignments.

The search for feasible assignments of a new demand starts by considering the provisional routes of all vehicles which provide the service for all passengers. The provisional route of a vehicle is a sequence of stops which passes through all the origin and destination points of its assigned passengers.

These provisional routes are designed first and foremost to satisfy the wating, travel and total service time guarantees of all users. If these services guarantees are satisfied for all users active on the system, the current instantaneous state may be termed feasible. 
When a demand arises the aim of the heuristic is to provisionally assign it to one vehicle while maintaining a feasible state i.e. Without violating the service constraints of the existing passengers or the new passenger.

slacks representing permissible deviations from the direct route are computed from the binding constraints. Two types of slacks are considered, the node slack and the link slack. The node slack is the allowable increase in length of the provisional route which can be made without breaking the service guarantee for that node. The link slack is the allowable increases in link lengths which result in no constraint violations on the complete provisional route of the vehicle. These slacks are used to determine whether particular placings of the new origin and destination of a new request will violate any of the user's guarantees for passenger assigned to that vehicle and the new users.

Figure 6-2 shows an insertion of a new origin in the provisional route of vehicle 6 . Travel times between points $S 3$ and $S$ and $S$ and $S 4$ must be estimated as input to the node insertion process. To select vehicle 6 for passenger 11 , the algorithm delivery of passengers 8,9 , and 10 . The calculations for this node insertion process are shown in Tables 6-1 and $6-2$. Since the link slack $(P 4=4)$ is greater than 


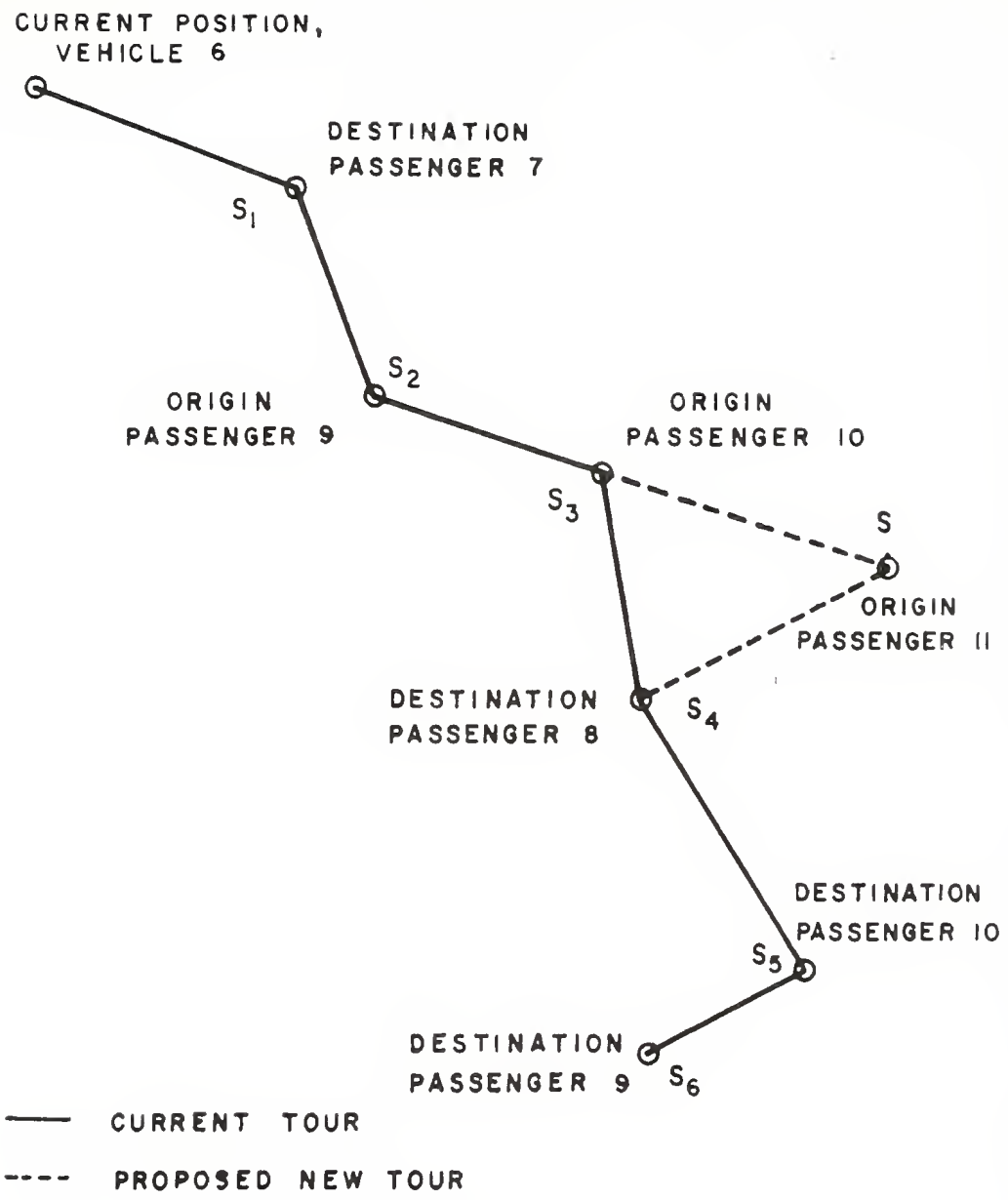

FIGURE 6-2 NODE INSERTION PROCESS (FROM REF. 25, P. 4-10) 


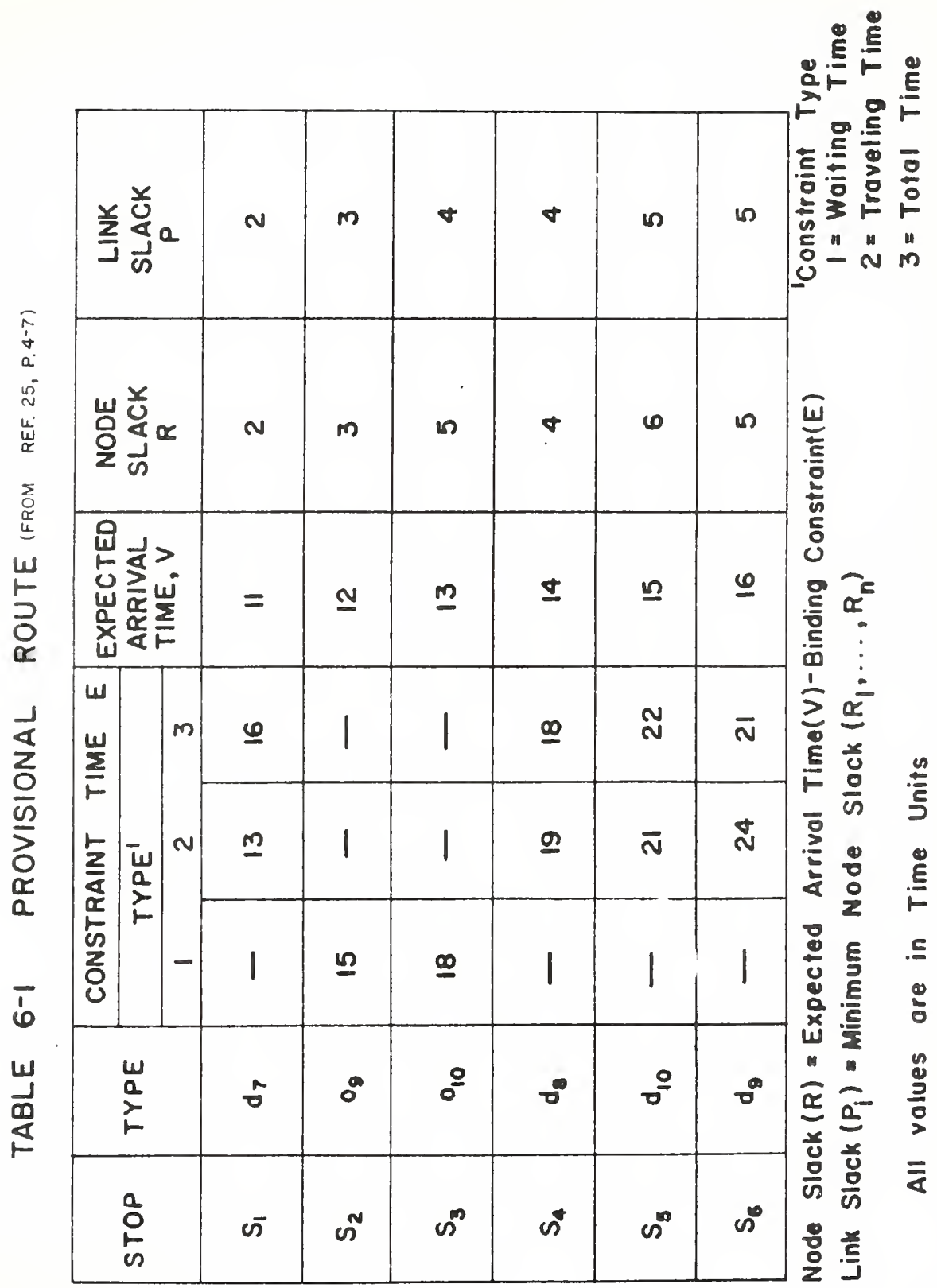




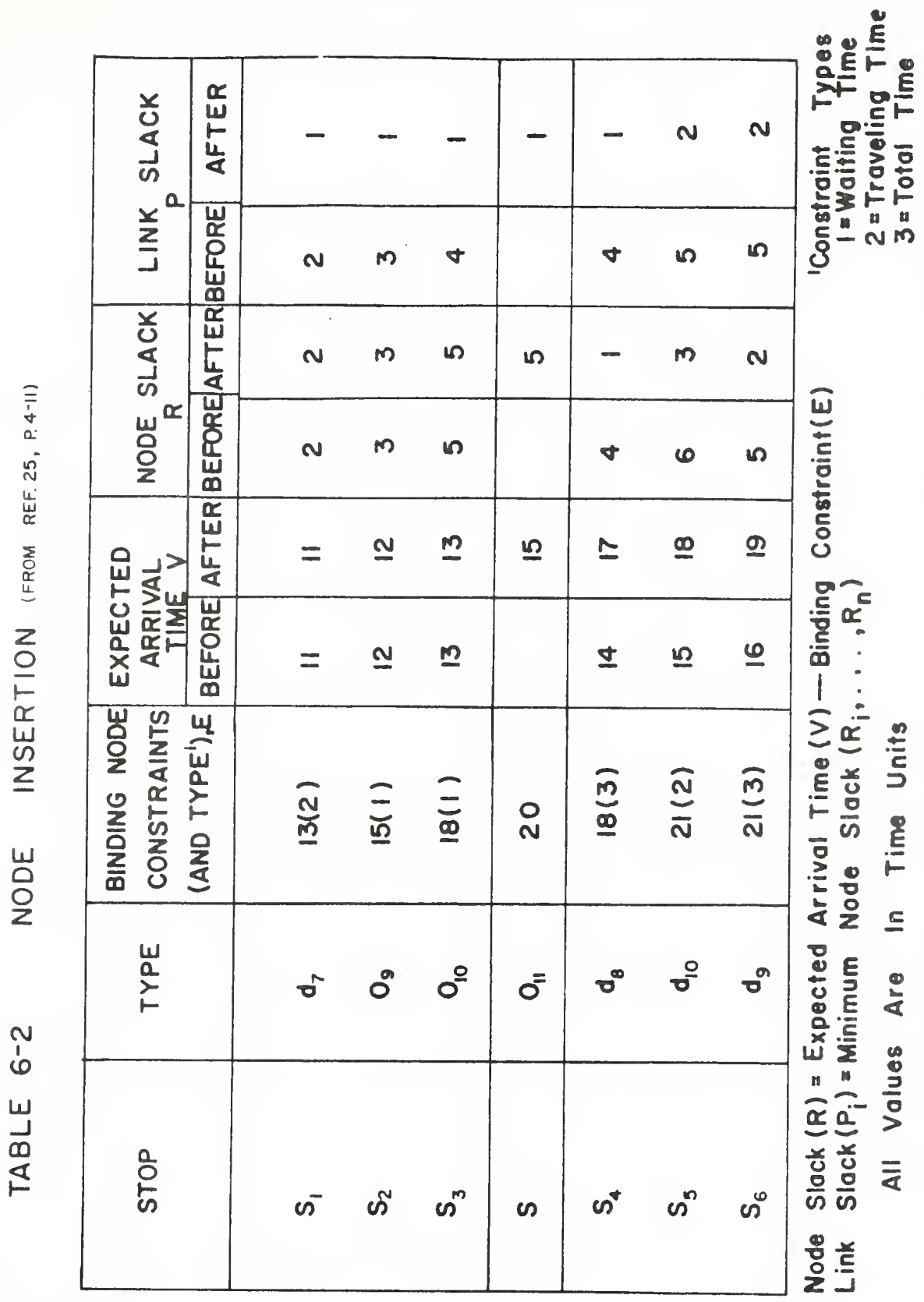


the detour required to visit $S$, the node insertion is feasible, i.e., no existing constraints are violated. In summary, when a new demand arises, the aim is to fit both origin and destination into the route of one vehicle without making any of the existing node slacks negative while still satisfying the binding constraints for the new demand. Each such fit is a feasible assignment of the new demand.

The actual assignment is chosen by evaluating a selection criterion for all feasible assignments. The selection criterion as described in the problem statement tends to minimize the expected service times of present and future users.

To simplify the search process and reduce the computational load a simplified selection criterion was developed. The final form of this objective function $Z$ is (26):

Minimize $Z=\left(N_{1}+1\right) E_{1}+\left(N_{2}+1\right) E_{2}+S T$

Where $N_{1}$ is the number of customer deliveries after the insertion of the origin stop for the new demand.

$\mathrm{N}_{2}$ is the number of customer deliveries after the insertion of the destination stop of the new demand.

$E_{1}$ is the vehicle detour time due to the insertion of the origin of the demand.

$E_{2}$ is the vehicle detour time due to the insertion of the destination of the new demand. 
ST is the service time of the new customer for

this insertion.

Where the new demand has been assigned to one of the many possible vehicles, the projected future route for that vehicle is updated to include the new passenger's collection and delivery points.

\section{Computer simulation of the Dial-A-Ride System}

\section{Introduction}

A computer simulation model is used to test and evaluate the heuristic assignment algorithm. Computer simulation is used for modelling because the relationships between variables in a Dial-A-Ride system operating with a specific heuristic are probabilistic and too complex in nature for any other fruitful means of analysis.

Simulation is a technique for conducting experiments on a computer using mathematical models to describe the behavior of systems over periods of time. With simulation, the analyst duplicates real world conditions, as nearly as possible, by means of computer programming. It is an effective tool in circumstances where it is desirable to study changes in a system without having to affect physically the system's current operation, or where it is economically infeasible to implement various experimental schemes for evaluation of the results. 
Simulation is useful as a technique to evaluate alternative designs. Specifying a set of input parameters in a simulation model will produce a certain final condition of the system. However, this observation will not directly help in predicting system performance under a different set of parameters since the complete system effects are still not understood. Simulation is therefore a very useful tool with which to analyze the overall implications of altering one of the inter-event relationships in a stochastically complex system. Although it is the least desirable solution technique for solving problems, it has the greatest applicability.

\section{Objective of the Simulation Model}

In this study, the main objective of the simulation model is to estimate the number of vehicles required for specific operating conditions and quality of service. These results would be used in an economic analysis of the system which would in turn lead to a decision on the utility of a Dial-A-Ride type of system.

\section{The Model}

Program Structure: A brief description of the simulation model is presented in this discussion. A more detailed discussion of this subject is contained in reference (27). 
The model is written in Fortran and is an event structured formulation. It consists of roughly fifty subprograms, each performing a specialized function. The minimum amount of core storage necessary is 150,000 bytes for IBM 360 Computers. For other computers an equivalent amount would be necessary.

The program works by generating demands for service from probabilistic distributions selected by the user. Demands are then assigned to a particular vehicle, by the user specified routing algorithm. As the vehicles collect and deliver their assigned passengers, statistics are gathered on system performance and service quality.

The algorithm, being the main function of the program structure, may be segmented into two major halves, each of which is a composite of several programs.

1. Assign a new demand to a vehicle's tour

2. Determine where a vehicle should go next having completed its current tour.

Briefly, the demand-to-tour assignment involves looping over all vehicle tours. For each vehicle tour, every link is checked as possible fit for the pickup, and for each legal pickup the following links in tour are checked for the delivery stop. This function contains two subfunctions. Determining whether or not insertion of a stop will violate the link constraints and whether or not a certain stop insertion will satisfy the demand's constraints. The three 
previous logical functions, vehicle looping, link constraint verification, and demand constraint satisfaction are concerned with generating possible alternatives. However, an evaluation of these alternatives must be made. The relative weights of the choices is the last logical function of demand-to-tour assignment. They are looping on vehicles, verification of link constraints, verification of demand constraints, and evaluating the possible choices.

The second major component of the algorithm is determining where to send a vehicle when it has completed its current stop. There are only two possible cases: There are remaining stops on the tour or the tour has been completed. In the first case, it is only necessary to send the vehicle to the next stop on the tour. However, if there are no more stops on the tour some decision must be made as to what should be done with the vehicle. One is to leave the vehicle where it is, i.e., where it made its last stop, the other alternative is to send the vehicle to one of a set of dispatching points.

Program Variables: The program enables an analyst to simulate a wide range of different conditions in a Dial-ARide environment. These different conditions can be simulated by changing one or more of the following major variables: 
1. Objective function

2. Number of vehtcles

3. Vehicle capacity

4. Length of simulation

5. Priority classes \& their characteristics

6. Dispatching points

7. Type of service - Many-to-Many

$$
\begin{aligned}
& \text { Many-to-Few } \\
& \text { Many-to-One }
\end{aligned}
$$

8. Temporal demand distribution

9. Size, shape, and demand characteristics of simula tion area.

This breadth of system variables enables the system environment to be easily changed. It also indicates the - flexibility of the model structure.

Input Parameters: Within a fixed environment the variations between runs of the model may be affected by input changes. The input parameters are summarized below:

$$
\begin{aligned}
& \text { Vehicle Data } \\
& \text { - Number of vehicles } \\
& \text { - Maximum occupancy } \\
& \text { - Mean speed between stops } \\
& \text { - Stopping time }
\end{aligned}
$$


Demand data

- Inter-demand time

- Origin and destination co-ordinates

- Number of people per demand

Service Characteristics

- Waiting time constraint

- Travel time constraint (a function of distance)

- Total time constraint (a function of distance)

Run Characteristics

- Initial values for random number generators

- Positively or negatively correlated strings

- Length of simulated period

- Output specification and intervals

The format in which the input data should be prepared is explained by the Implementation and User's Guide manual of the computer program. A sample of the data input is shown in Table B-l of Appendix B.

Output 0ptions: The standard printed output from the model includes the following information and may be repeated as frequently as the analyst desires during a run:

For each vehicle

- Current provisional route

- Current position and occupancy

- Percentage of time 1) empty, 2) unassigned 
For each outstanding demand

- Origin and destination

- Time of request and collection

- Number of people

Demand statistics

- Mean, variance, minimum and maximum waiting travel and total service times

- Mean, variance, minimum and maximum waiting travel and total service times, normalized by length of trip

- Number of times each type of constraint has been violated, mean amount of violation.

In addition, the vehicle productivity for the entire run and during the stated periodic times is printed. Statistics on the level and measure of service, and on the service-time characteristics by trip length are also included.

A sample of output data and the interpretation of the abbreviations used are shown in Appendix $B$. The information on the output data was taken from the CARS Basic Program Implementation and User's Guide (28).

\section{Simulation Experiments}

Two measures are of importance to help achieve this objective of the simulation: the cost of the service and the service times experienced by the users. The major 
cost components are related to the vehicle. Therefore an indication of cost to the user is vehicle productivity, or the number of passenger trips served by a vehicle in an hour. This is computed from the number of vehicles required to serve the area and the demand level. Thus, the critical parameters that determine the cost operating configuration for Dial-A-Ride system are the area size, demand level, number of vehicles, and level of service. The first three are simulation input parameters while the level of service is an output parameter. The relationship among the different parameters of the simulation is shown in Figure $6-3$

The size and the shape of the study areawere not varied through the simulation experiments. Hence their effect on the other critical parameters were not studied. Similarly, the demand characteristics, area characteristics, and vehicle characteristics were kept the same through all the simulation runs. The only input parameters that were varied are the number of vehicles and the demand level. The level of service is an output of the variation of these two parameters.

Specifically, to isotate the effect of each of these three parameters on the performance of the system, a sertes of experiments were conducted to study:

1. The effect of number of vehicles on the level of service with the demand level held constant. 


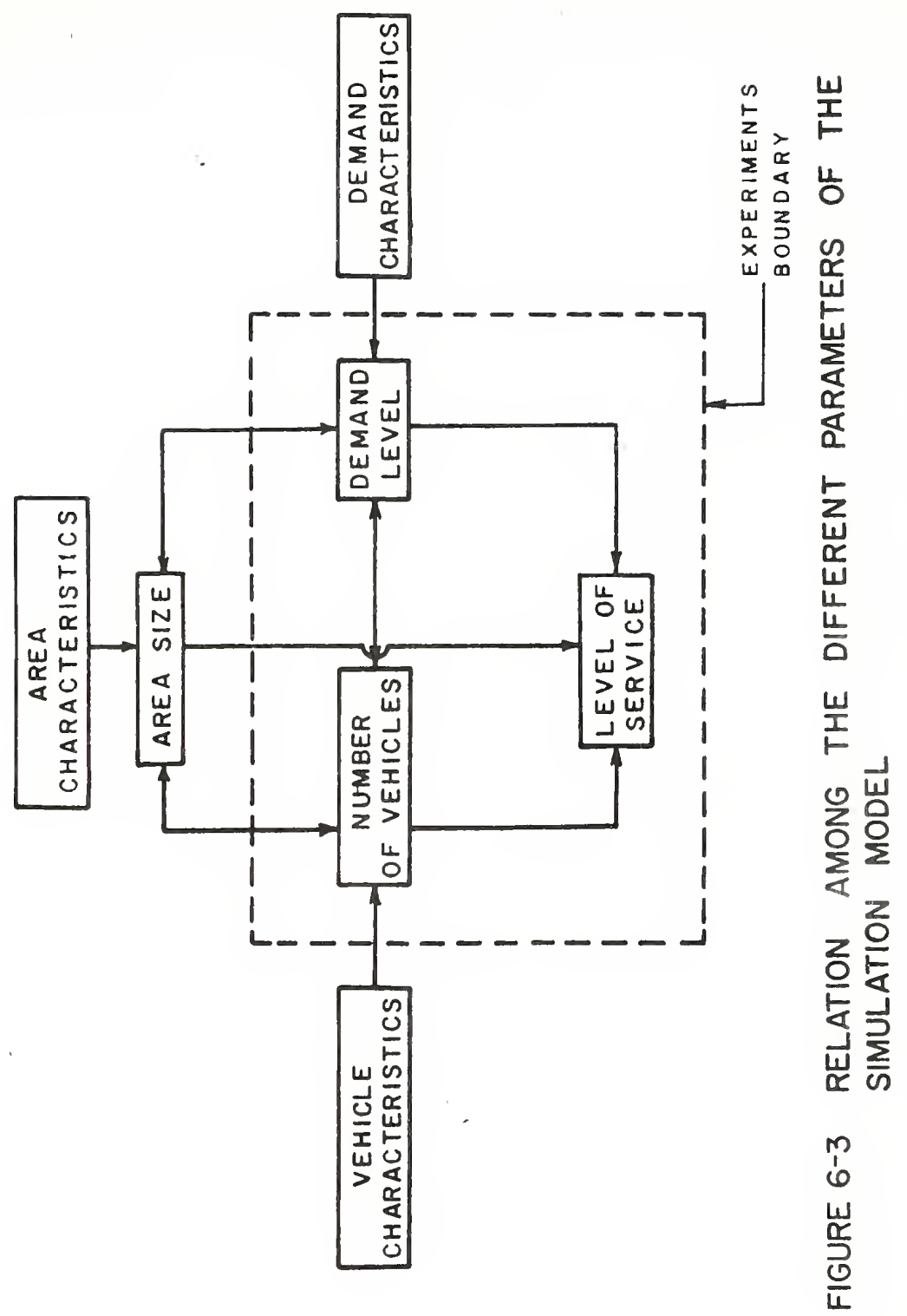


2. The effect of demand level on the level of service with the number of vehicles held constant.

3. The effect of demand level on number of vehicles with the level of service held constant. This was achieved after conducting a number of experiments with different combination of demand level and number vehicles.

The values given to the two variable parameters in the simulation experiments are listed in Table 6-3. The number of vehicles range between 5 and 14 small buses and the value of demand level range between 30 and 150 calls per hour. These values were selected to represent the possible conditions in the Greater Lafayette Area, as far as the number of vehicles available for service, and the number of customers expected during the off-peak hours. In addition, the number of simulation experiments was limited by the funds available for the research.

The demand level of 60 calls per hour was held constant while experimenting with the effect of the number of buses on the level of service, Table 6-3 (part b). Similarly, 10 buses were held constant while studying the effect of demand on the level of service, Table 6-3 (part a).

A constant value of level of service of 2.2 to 2.3 is obtained through the experiments shown in part $\mathrm{C}-1$ of Table 6-3. 
TABLE 6-3 VALUES OF DEMAND LEVEL AND NUMBER OF BUSES USED IN THE SIMULATION EXPERIMENTS

\begin{tabular}{|c|c|}
\hline $\begin{array}{c}\text { DEMAND } \\
\text { LEVEL } \\
\text { (Calls/Hour) }\end{array}$ & $\begin{array}{c}\text { NUMBER } \\
\text { OF BUSES }\end{array}$ \\
\hline 30 & 10 \\
\hline 60 & 10 \\
\hline 90 & 10 \\
\hline 120 & 10 \\
\hline 150 & 10 \\
\hline
\end{tabular}

\begin{tabular}{|c|c|}
\hline $\begin{array}{c}\text { DEMAND } \\
\text { LEVEL } \\
\text { (Colls/Hour) }\end{array}$ & $\begin{array}{c}\text { NUMBER } \\
\text { OF BUSES }\end{array}$ \\
\hline 60 & 5 \\
\hline 60 & 8 \\
\hline 60 & 10 \\
\hline 60 & 12 \\
\hline
\end{tabular}

\begin{tabular}{|c|c|c|c|c|c|}
\hline $\begin{array}{c}\text { NUMBER } \\
\text { OF BUSES }\end{array}$ & 5 & 8 & 10 & 12 & 14 \\
\hline $\begin{array}{c}\text { DEMAND } \\
\text { LEVEL } \\
\text { (Calls/Hour) }\end{array}$ & 30 & 60 & 90 & 120 & 150 \\
(c)
\end{tabular}


For each of the above experiments, four simulation runs were conducted using different random number generator seeds for the different probability functions. This will allow the initial system status on the spatial demand distribution to be varied from one run to another. The variance of the results within the same experiment will be minimized by summing the results of the four runs and dividing them by four. However, to allow for comparison between two alternative experiments, the external features of the model should be the same, i.e. the initial location of the vehicles and the spatial demand distribution should be the same. This is obtained by using the same probability seeds for the different runs of the two experiments.

The area, demand, and vehicle characteristics that were held constant in the simulation experiments are discussed below.

\section{Area Characteristics}

The Dial-A-Ride computer program specifies that the sahpe of the service area should either be a rectangle or a square. It should not be divided into more than 50 rectangular zones. Part of these zones could be void zones such that the vacant, the undeveloped, and the water sections of the service area are included. It is also possible to define rectangles which are simply points. This is provided for a high activity centre which has a many-to-many demand pattern. 
Following these conditions, the study area has been defined by a rectangle of dimensions 4.6 miles in the east-west direction and 5.5 miles in the north-south directions. The rectangle has been subdivided into 48 rectangular zones, as shown in Figure $\mathrm{C}-1$ of Appendix $C$.

In establishing these rectangular zones, consideration was given to the different land use categories, such as residential, commercial, and industrial. Sixteen of these zones are void zones. They were established to cover the river crossingsbetween the two cities, and to fill the undeveloped and the unserviced areas of the defined rectangle. Four of these rectangles were defined as high-activity points. They represent the shopping centres of Three Sons, K-Mart, Lafayette Square, and Market Square.

The relative probabilities of the different zones of containing an origin or a destination of a demand were developed by an intuitive judgment approach based on demographic characteristics of the zones. The demographic data for each zone includes such characteristics as number of dwelling units, total population, number of people older than 62 , number of households owning one car or less, number of households owning two cars or more, and number of employees. These data were compiled from the data presented earlier in Chapter 4. To facilitate the assignment of the relative weights, aggregation of the data on a higher level was felt necessary. Thus, the study area is 
divided into Lafayette and West Lafayette parts. The West Lafayette part is further subdivided into the northern section and the southern section, where the southern section contains the student community. The demographic factors were accordingly aggregated to this level.

The Lafayette part of the study area is considered to originate $74 \%$ of the demand and to receive $69 \%$ of the destinations of that demand. The southern section of the West Lafayette part is considered to include $13.5 \%$ of the origins and $22.5 \%$ of the destinations of the demand. The northern section of West Lafayette is considered to include the remaining percentages. These percentages or weights are further distributed among the zones of the three divisions. The above weighting is established for demands in the off-peak hours.

The values of the demographic data, the zone numbers, the zoning coordinates, and the relative weights of the different zones are shown in Tables $C-1$ and $C-2$ of Appendix c. The relative weights are multiplied by 1,000 to eliminate fractions.

The distribution of the trip origins and destinations of the four different runs of the simulation experiments are shown in Figures $C-2$ to $C-5$ of Appendix $C$ for a demand of $60 \mathrm{calls}$ per hour. 
Distance Adjustment Factor: Another parameter that is related to the area characteristics and which was held constant in the simulation runs is the distance adjustment factor. The computer program computes the aerial distance between any two points in the study area from the cartesian coordinates. An adjustment factor should be developed to relate the air-line distance to the actual distance on the street network of the area.

A number of points were randomly chosen from the maps of the Greater Lafayette Area. Their aerial and actual distances were computed and plotted one against the other as shown in Figure 6-4. The slope of the fitted line came out to be close to 1.2. Instead a value of 1.3 was adopted as the ratio of real distance to aerial distance, to be safe and to include some of the worst possible conditions.

Trip Length Distribution: The relative weighting of the various trip lengths in the simulation experiments was assumed to be uniform. The distribution consists of one step of 6.5 miles width, which is the maximum trip length that can be requested in the study area. No preference is given to any trip length and the trip length is left to be determined by the relative probabilities of the zones. The minimum requested trip length allowed by the system is chosen to be 0.75 miles. It is assumed that the customers will not request the Dial-A-Ride service for a trip less than 0.75 miles. 


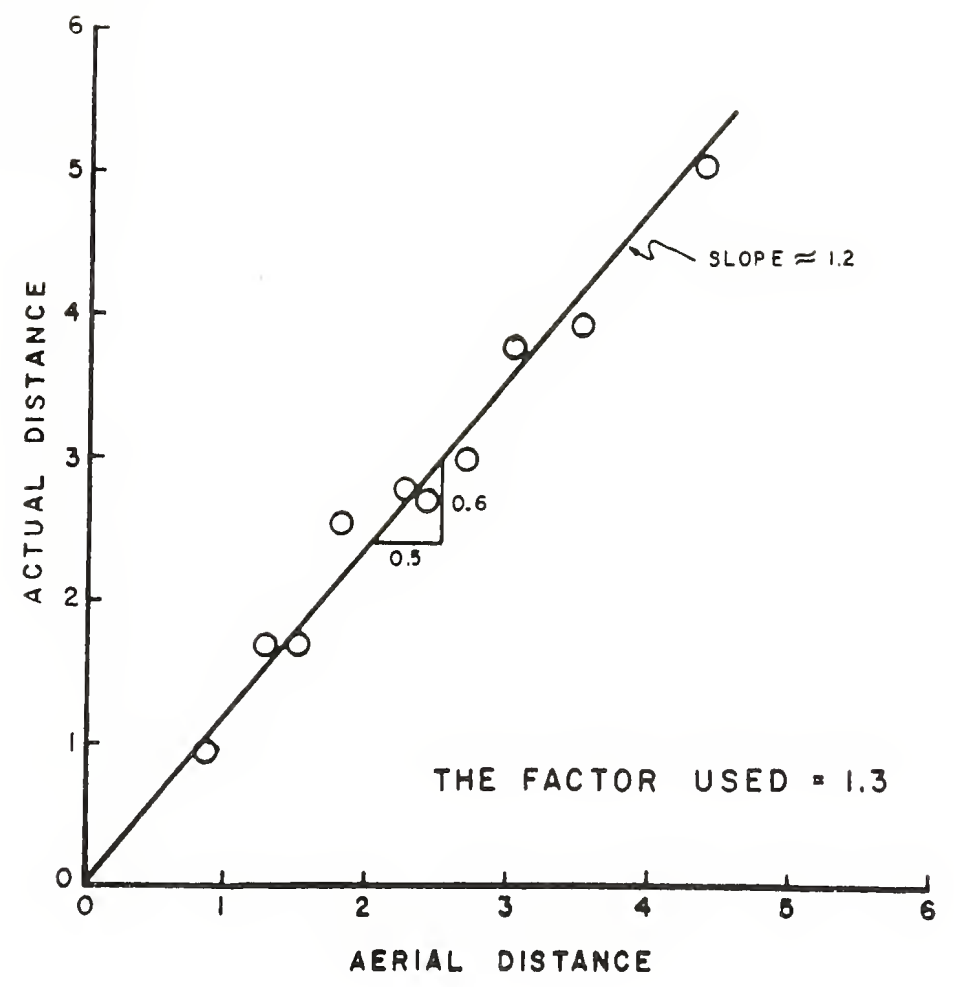

FIGURE 6-4 RELATIONSHIP BETWEEN THE AERIAL DISTANCE AND ACTUAL DISTANCE 


\section{Demand Characteristics}

Service constraints: The service constraints are to be spectfied by the user of the computer program. They are composed of waiting time constraints, travel time constraints, and total time constraints. As mentioned before, the scheduling algorithm of the program will try to satisfy these constraints in searching for a feasible assignment of a new oemand to a vehicle. They constitute a major element in the demand-to-vehicle assignment process and they effect the quality of service offered to the customers.

A series of experiments were performed at M.I.T. (25) to determine the effect of variations of the service time constraints on the performance of the heuristic. In these tests, values of the constraints were varied but the ratios between their values were kept the same as the corresponding ratios of the means with infinite constraints. In Figures 6-5 through 6-7 the mean and maximum waiting, traver, and total times normalized with respect to the service norms are shown as functions of the actual constraint values as a multiple of the mean service times with infinite constraints. The calculation of normalized quantities is explained in Appendix B. It is seen from Figure 6-7 that minimum normalized mean total service times are achieved by setting all constraints to values of infinity, i.e., making them 


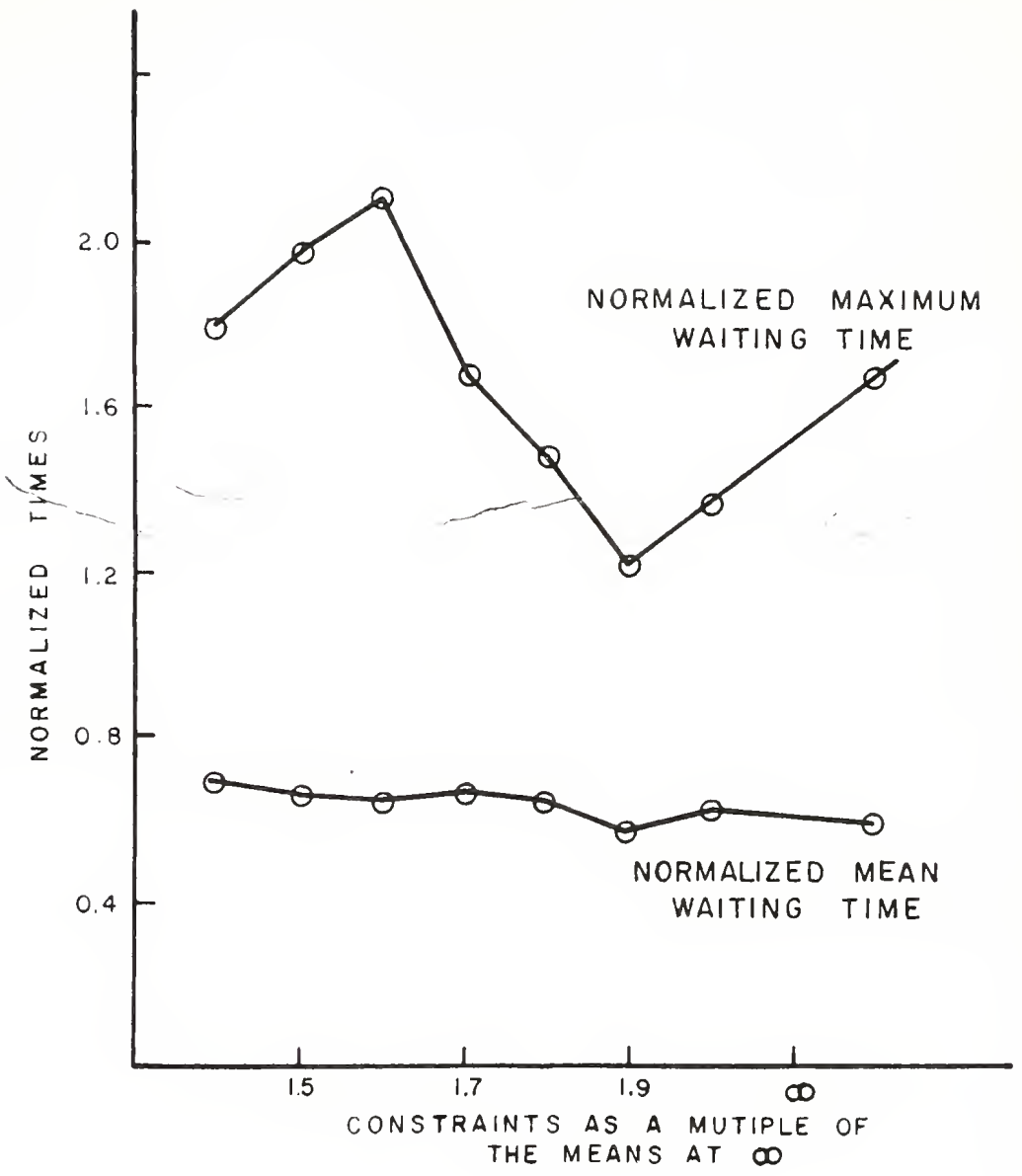

FIGURE 6-5 EFFECT OF SERVICE CONSTRAINTS ON THE NORMALIZED MEAN AND MAXIMUM WAITING TIME (FROM REF. 25, P. 5-19) 


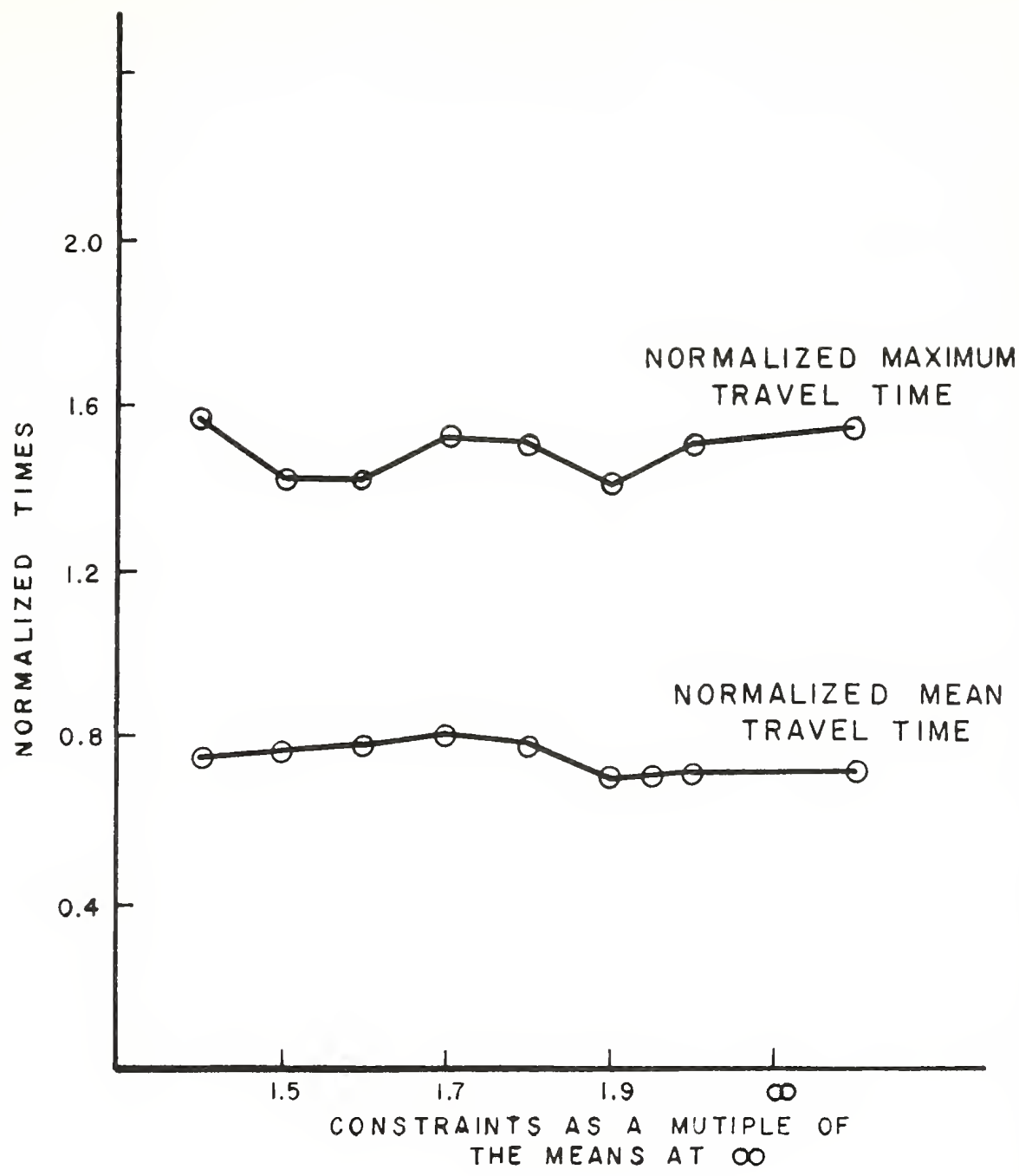

FIGURE 6-6 EFFECT OF SERVICE CONSTRAINTS ON THE NORMALIZED MEAN AND MAXIMUM TRAVEL TIME (FROM REF. 25, P.5-10) 


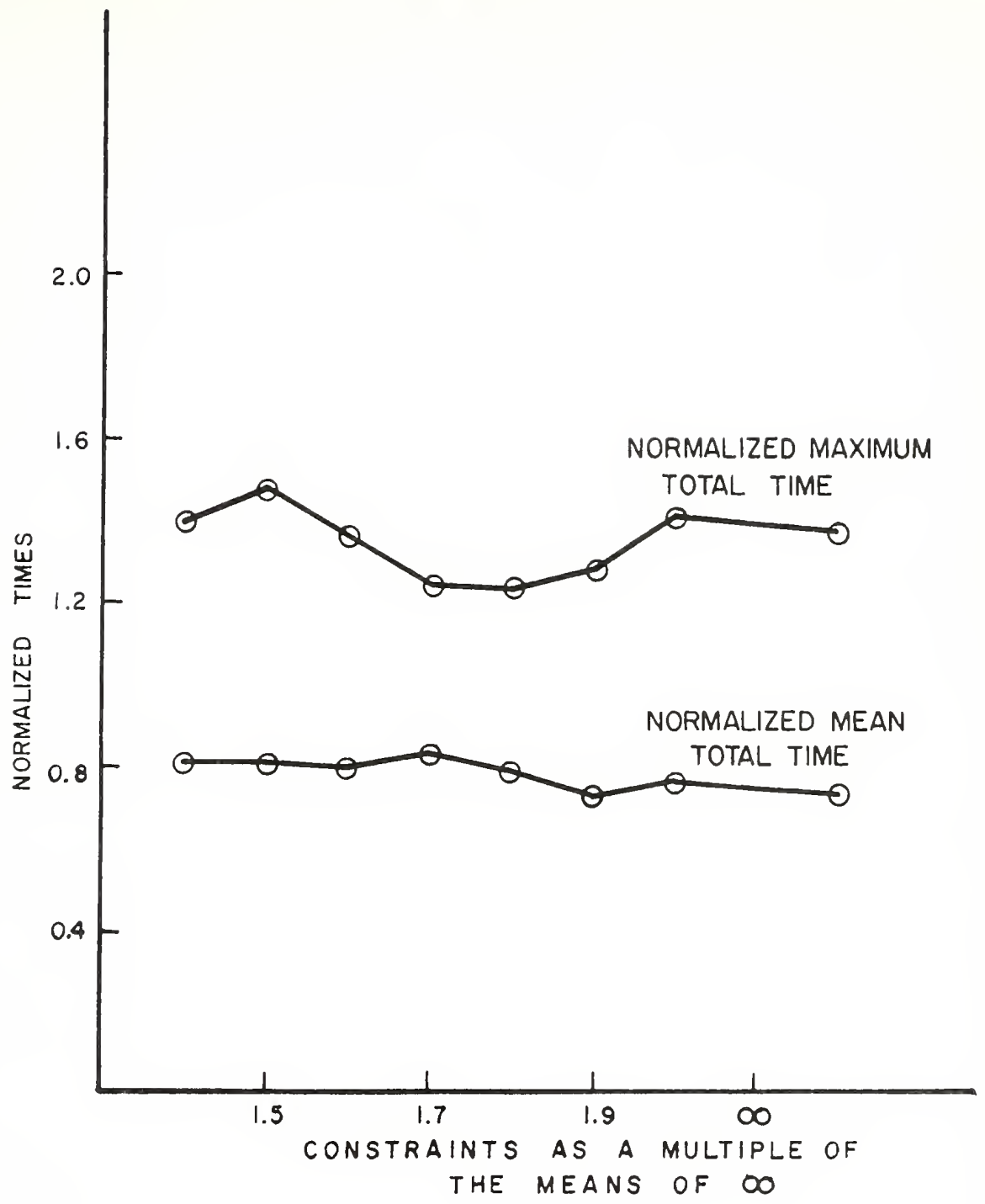

FIGURE 6-7 EFFECT OF SERVICE CONSTRAINTS ON THE NORMALIZED MEAN AND MAXIMUM TOTAL

TIME (FROM REF. 25, P.5-12) 
inoperative. This would be expected since in this case the heuristic can make an unconstrained choice of the best assignment which tends to minimize the mean service times. It is also noted in Figures $6-5$ and 6-6 that with infinite constraints, both the mean wafting time and the mean travel time have minimum values.

More surprising, however, is the fact that, as seen in FIgure 6-6, the normalized maximum total service time with infinite constraints, is not very different from the constrained values. This indicates that the assignment selection criterion considers quality of service to all users to be a desirable attribute. The normalized maximum reflects service to only one passenger and,hence, is not very reliable since this one passenger may have been unusually unlucky.

From these tests it is clear that the selection of the constraint values should depend on the user's preference for low mean or low maximum service times. If the lowest possible means are desired, constraints should be set so high that they are seldom, if ever, invoked.

In this study, to provide low mean service times, the service constraints were set at very high values. The values of the three service constraints are shown below:

1. Waiting time constraint $=999.0$ (mins.)

2. Travel time constraint $=9.9$ STRGHT +99.0 (Mins.)

3. Total time constraint $=9.9$ STRGHT +999.0 (mins.) 
STRGHT is the time necessary for the vehicle to go from the origin to the destination of the demand.

Priority Classes: The demand for the Dial-A-Ride service is not separased into different priority classes. All customers are given the same priority for service and were generated from one priority class all the time.

Number of Passengers Per Demand: A unfform distribution Was assigned to generate the number of passengers per demand. It s lower limit is 1.0 and its upper limit is 2.10. Two passengers per demand, having the same trip origin and destination, is considered to be the maximum expected request for Dial-A-Ride service. For three passengers or more per demand, the passengers will try to use the taxi which would provide a better level of service with approximately the same price under such conditions.

The above distribution produced on the average in the simulation experiments $10 \%$ of the calls requesting service for two passengers, which is considered to be reasonable.

Inter-Demand Times: An exponential distribution was used to generate inter-demand time, i.e., time in minutes between requests for service. The mean value of the distribution specifies the demand level of the simulation run. It must be defined as mean minutes/demand implying a change in units from demand/hour. 
Access: Access is the extra-vehicular time of a private automobile trip not spent in that vehicle (parking, walking to and from automobile parking lot). It is added to the mean direct travel time. to compute the mean measure of service. It was given the value of 4.0 minutes in the simulation experiments.

Initial Demands: The initial demands were assigned arbitrarily to the simulation experiments with different demand levels. They range from 5 to 12 initial demands increasing with the increase of demand levels.

Vehicle Characteristics

The following vehicle characteristics were assumed for all the simulation experiments:

1. Vehicle capacity of 12 .

2. Mean vehicle operating speed between stops of 15 m.p.h. or 4.0 minutes per mile.

3. Discrete vehicle location. With discrete vehicie location the algorithm only knows the location of the last stop made by a vehicle. This implies that the algorithm cannot insert a stop before the first stop in a vehicle's projected tour.

4. Stopping time values to both pick up and deliver each passenger are generated from a uniform distribution defined by a lower limit of 0.25 and by an upper limit of 0.5 minutes (28). 
5. When the vehicle has no assignment at the end of its tour, it is left where it made its last stop. It waits there for a new assignment.

\section{Pun Characteristics}

Complete outputs were requested every 15 minutes in each of the simulation runs. Statistics were taken for demands arising between 15 and 120 minutes in each simulation. The simulation period ends when all the demands arising between 15 and 120 minutes have been served.

\section{The Simulation Results}

The simulation experiments were conducted to provide the decision maker with the number of Dial-A-Ride vehicles required in off-peak periods in many-to-many operations in different environments of demand and level of service. The results of these experiments, as they were designed to isolate the effect of each of these three parameters, can be divided into three major groups.

1. Results pertaining to the number of vehicles required under different levels of demand with level of service held constant.

2. Results showing the effects of demand levels on level of service with the number of buses held constant.

3. Results showing the effects of number of buses on level of service with the demand level held constant. 
The results are all tabulated in Appendix D.

Number of Vehicles

The results of the effect of variation of demand level on the number of vehicles with level of service held constant are shown in Figure 6-8. Figure 6-8 shows that the number of vehicles increases linearly with increasing demand level but with a slope less than unity. These results are better illustrated in Figure $6-9$ showing vehicle productivity, which is number of passenger trips per vehicle hour, increases parabolically with increasing demand level. Above 120 demands per hour, the rate of increase in productivity is quite slow and below 30 demands per hour, the system is quite inefficient. In the investigated range, the productivity. increased by about $65 \%$.

These results are quite significant when considering the role of Dial-A-Ride system in urban transportation with respect to other competing modes with different vehicle productivity demand relationships such as taxis and fixedroute buses. Taxis show a relatively constant vehicle productivity since they cannot carry more than one demand group at any time. They would be competitive with the DialA-Ride system only at very low demand levels. With their less sophisticated control system lower costs may result at similar vehicle productivities. Fixed-route buses, conversely, are well suited to take advantage of the 
CONDITION:

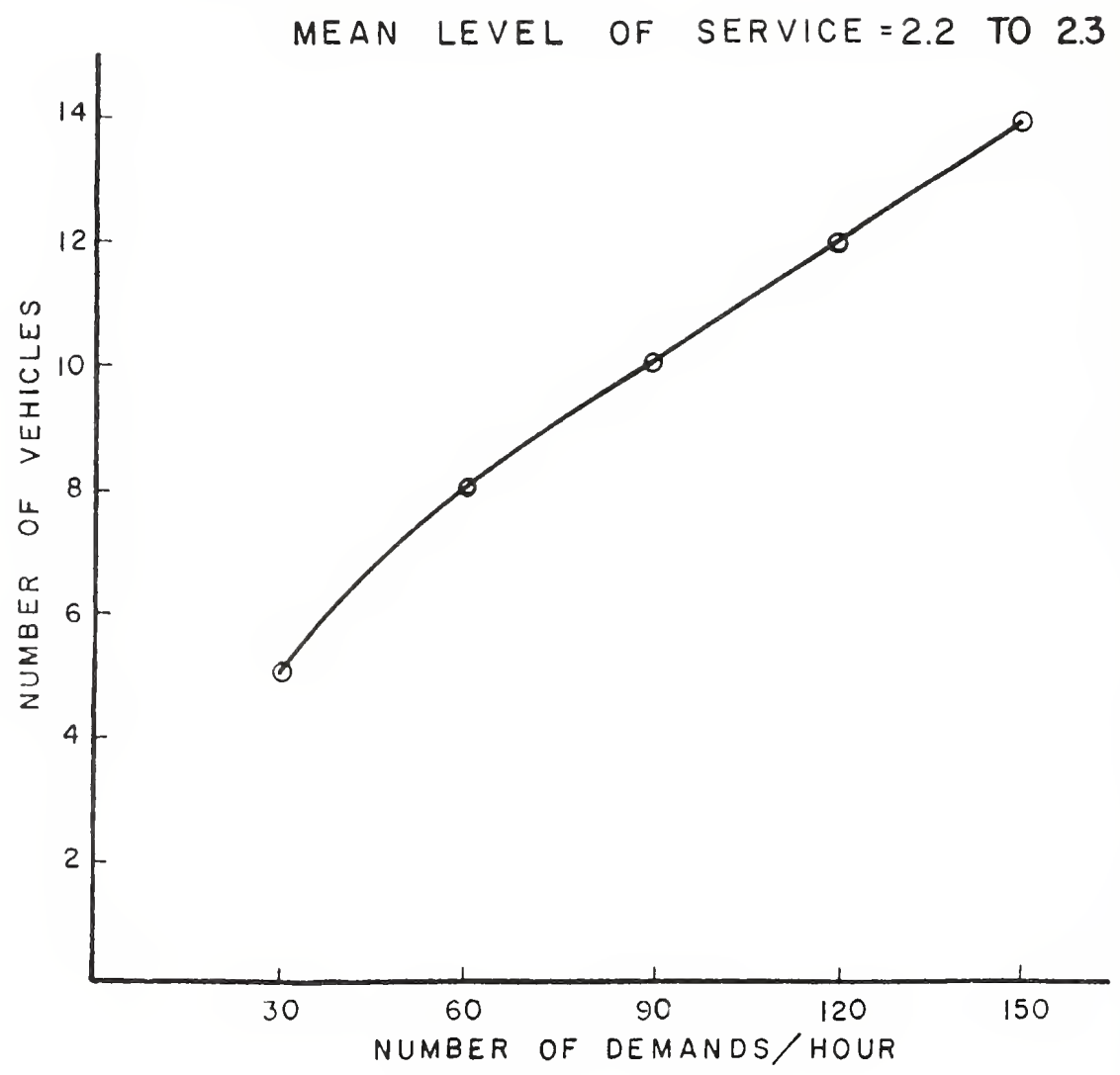

FIGURE 6-8 EFFECT OF DEMAND LEVEL ON NUMBER OF VEHICLES 
CONDITION:

MEAN LEVEL OF SERVICE $=2.2$ TO 2.3

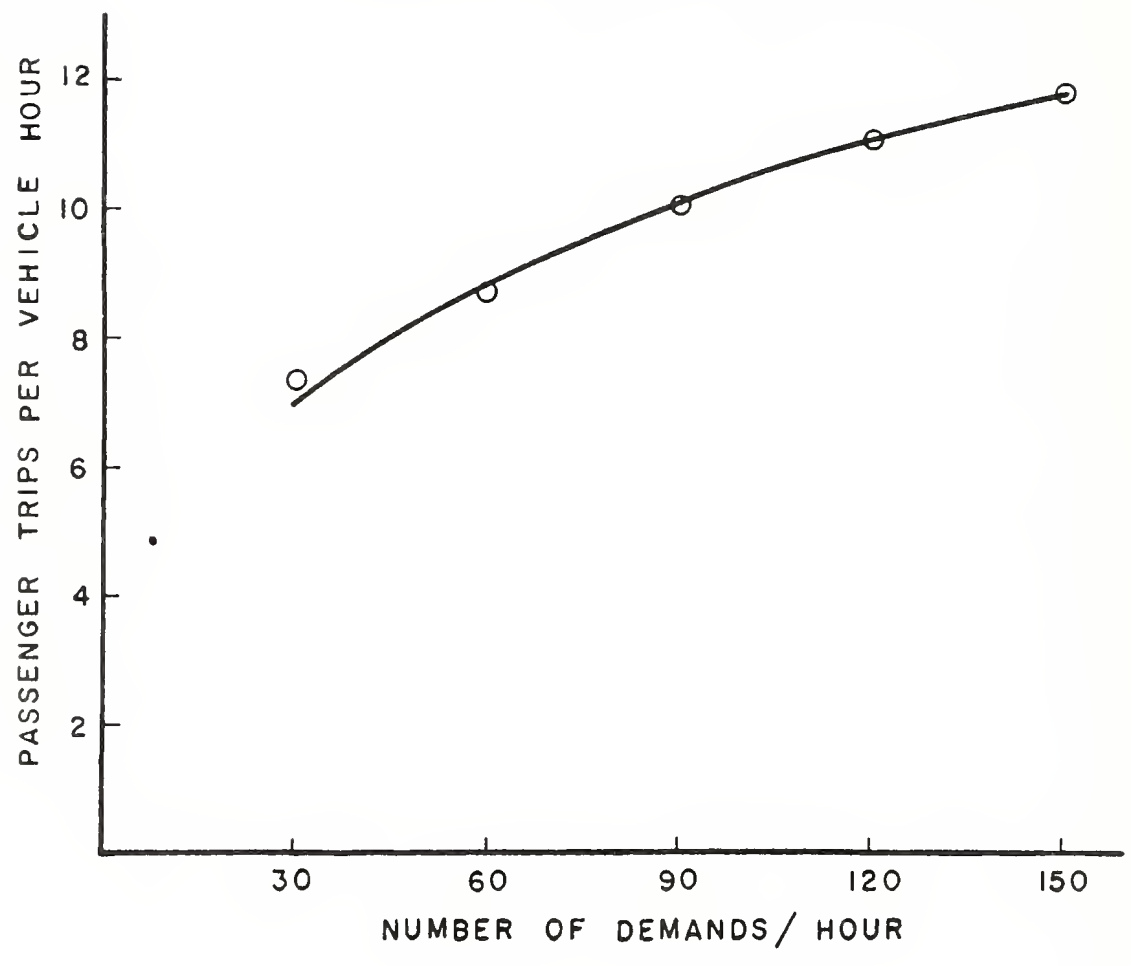

FIGURE 6-9 EFFECT OF DEMAND LEVEL ON VEHICLE PRODUCTIVITY 
economics of scale and their vehicle productivity would continue rising with increasing demand level after the Dial-A-Ride system curve has levelled out. Thus at fairly high demand level, fixed-route buses would be more efficient than DARS. This implies a medium demand level operation would be best for DARS.

The results show an average mean measure of service of about 2.3. To supplement this figure, more additional information is given below.

$$
\begin{array}{ccc}
\text { Waiting Time } & \text { Travel Time } & \text { Total Time } \\
\text { (min.) } & \text { (min.) } & \text { (min.) }
\end{array}
$$

Nean

14.5

17.5

32.0

Maximum

46.5

60.0

78.3

The percentage of time the vehicle is unassigned indicates the availability of that vehicle to serve a new demand. This value reflects on the level of service offered to the customers. The results show an average of 1.25 percent of the time the vehicles are unassigned.

\section{Level of Service}

The second series of tests investigated the effect on the level of service of varying the demand level while holding the number of buses constant. The results are shown in Figures 6-10 to 6-12.

Figure 6-10 shows that the level of service varies linearly with the demand level but with a slope less than 


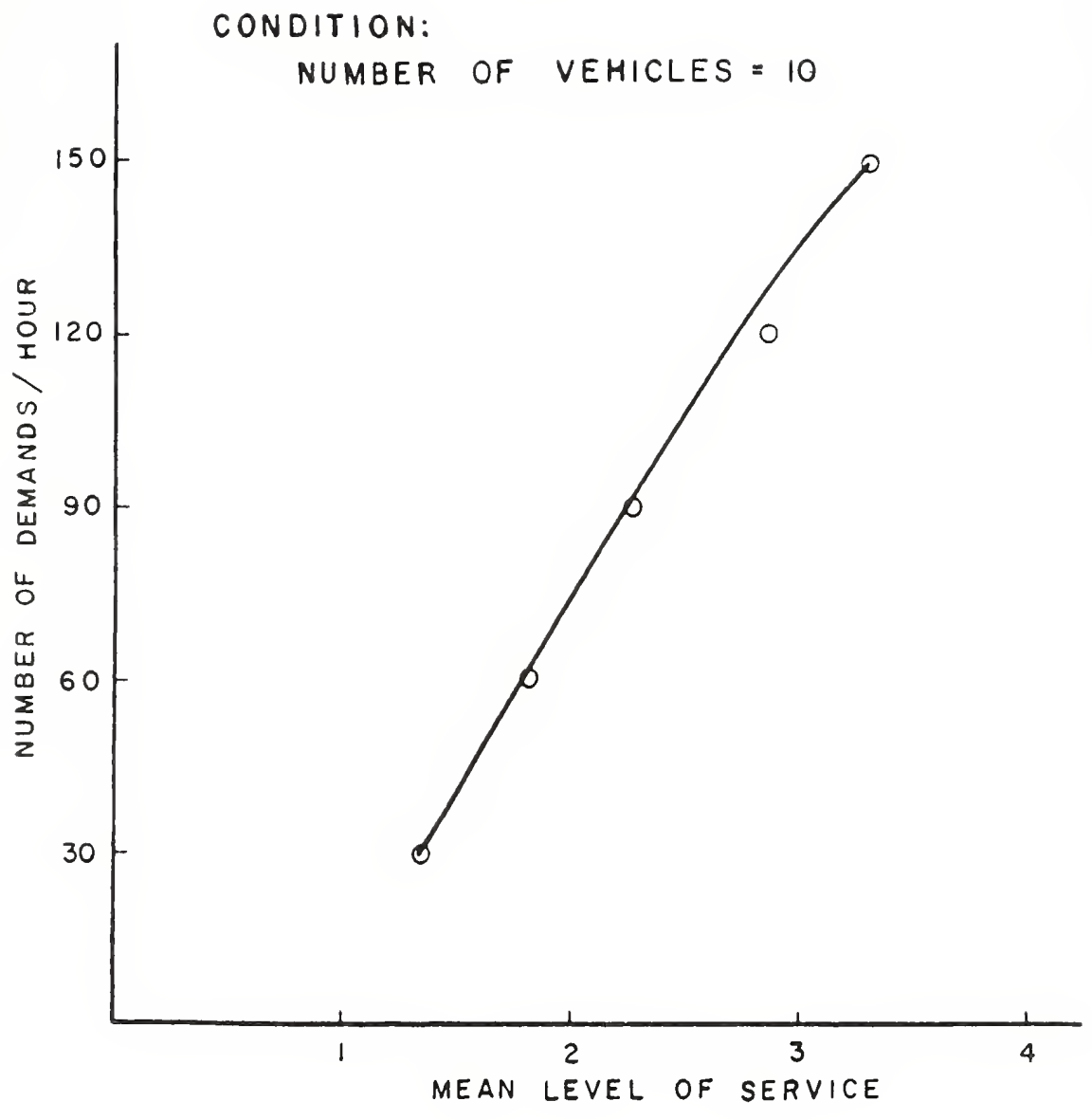

FIGURE 6-10 EFFECT OF DEMAND ON MEAN LEVEL OF SERVICE 


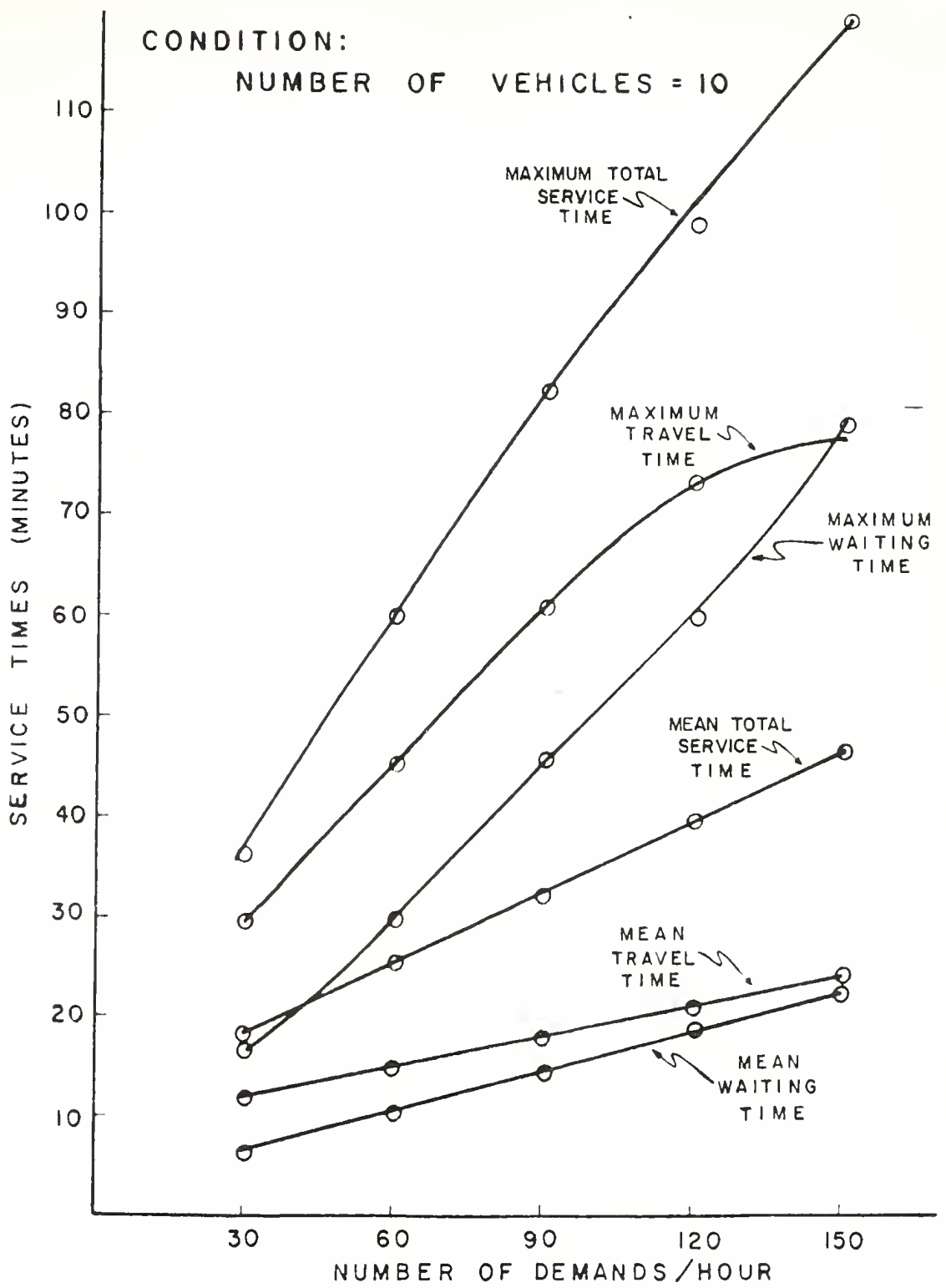

FIGURE 6-II EFFECT OF DEMAND LEVEL ON MEAN AND MAXIMUM SERVICE TIMES 


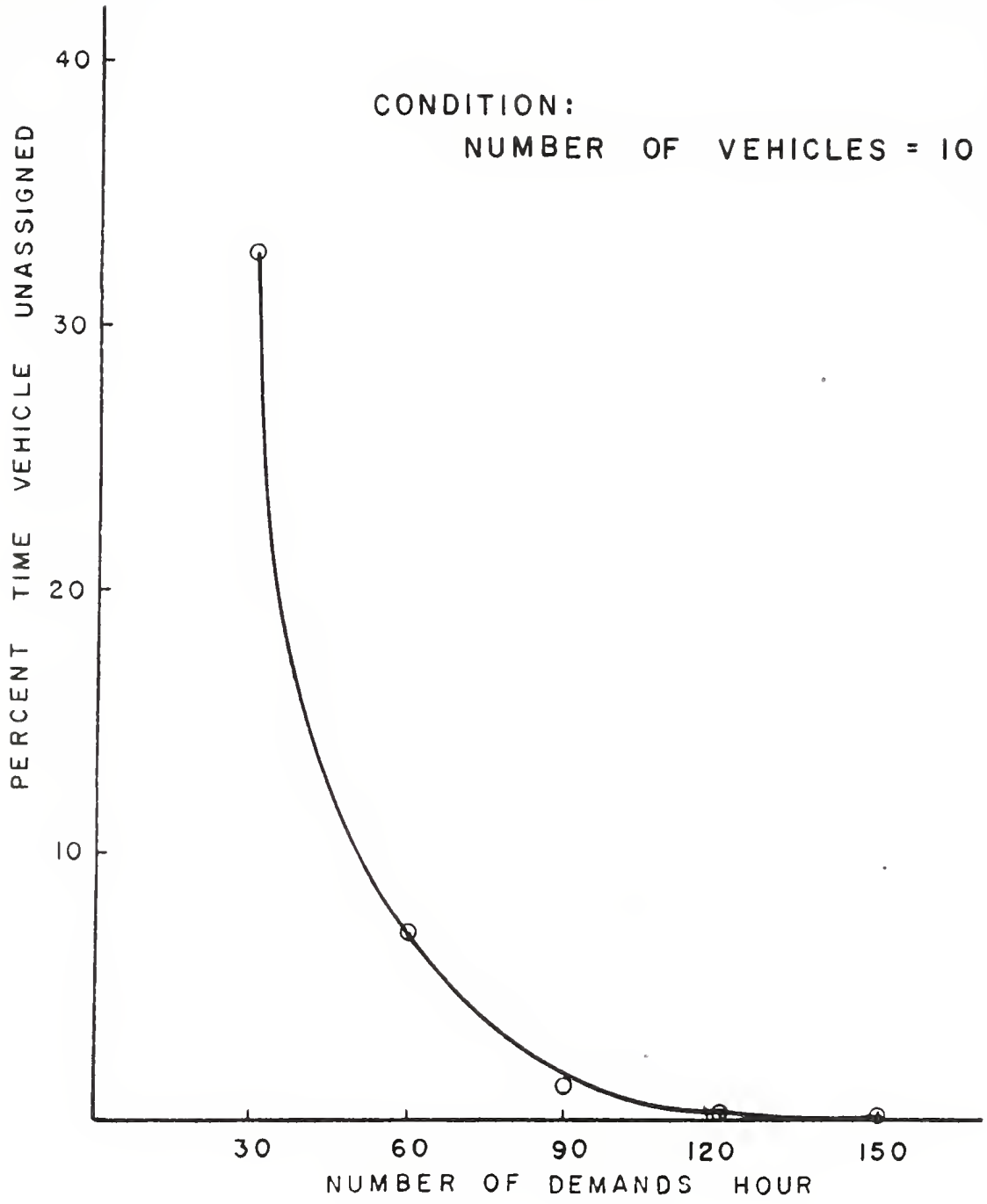

FIGURE 6-12 EFFECT OF DEMAND LEVEL ON PERCENT TIME VEHICLE UNASSIGNED 
unity. The greater the demand level, the slower is the service provfded, i.e., the higher is the mean level of service. It also clearly indicates that to provide a better mean level of service to more customers, more buses should be used.

Figure 6-11 shows the deterioration of the service times, which determines the level of service, with the increase of demand level. Mean and maximum of waiting time, travel time, and total time are plotted against different demand values. The mean service times increase linearly with increase demand levels with slopes less than unity. The rate of increase of mean travel time is less than the rate of increase of mean waiting time, which indicates that at higher demand levels the increase in total service time is duc mainly to increase in waiting time of the customer. This is more explicitly shown in the plots of the maximum service times. However, the maximum total time increases to non-acceptable limits with high demand values, even to one passenger.

The variation of the vehicle percent time unassigned with demand levels is shown in Figure 6-12. The curve has a rectangular hyperbolic form with the same number of vehicles. The value of vehicle percent time unassigned drops sharply as the demand increases from 30 to 60 calls per hour and then it levels out at values close to zero at the higher demand levels. It illustrates that a small increase in demand will 
keep the vehicles busy and assigned.

The third series of tests investigated the effect on the level of service of varying the number of buses, while holding the demand constant. The results are shown in Figures 6-13 to 6-15.

It is seen from Figure 6-13 that the mean level of service curve has a rectangular hyperbolic curve. As would be expected, the more vehicles used, the faster is the service provided. It is clearly impossibie to provide a better mean level of service than 1.0 since this is the direct driving time. It should be added that lower levels of service could be obtained but at a prohibitive cost in terms of the number of vehicles operating.

Conversely, decreasing the number of vehicles below a certain point leads to deterioration in the mean level of service. From these experiments and from other experiments conducted at M.I.T. the best mean measure of service for system operation seems to be between 2.0 and 3.0 . However, the actual operating point would be governed by the reaction of the users to different cost/service combinations.

The decomposition of the level of service into its elements of waiting time, travel time, and total time with respect to the variation of number of buses is shown in Figure 6-14. The same trend in service times is seen in this figure as compared to the variation obtained due to changes in demand levels. The decrease in number of buses 


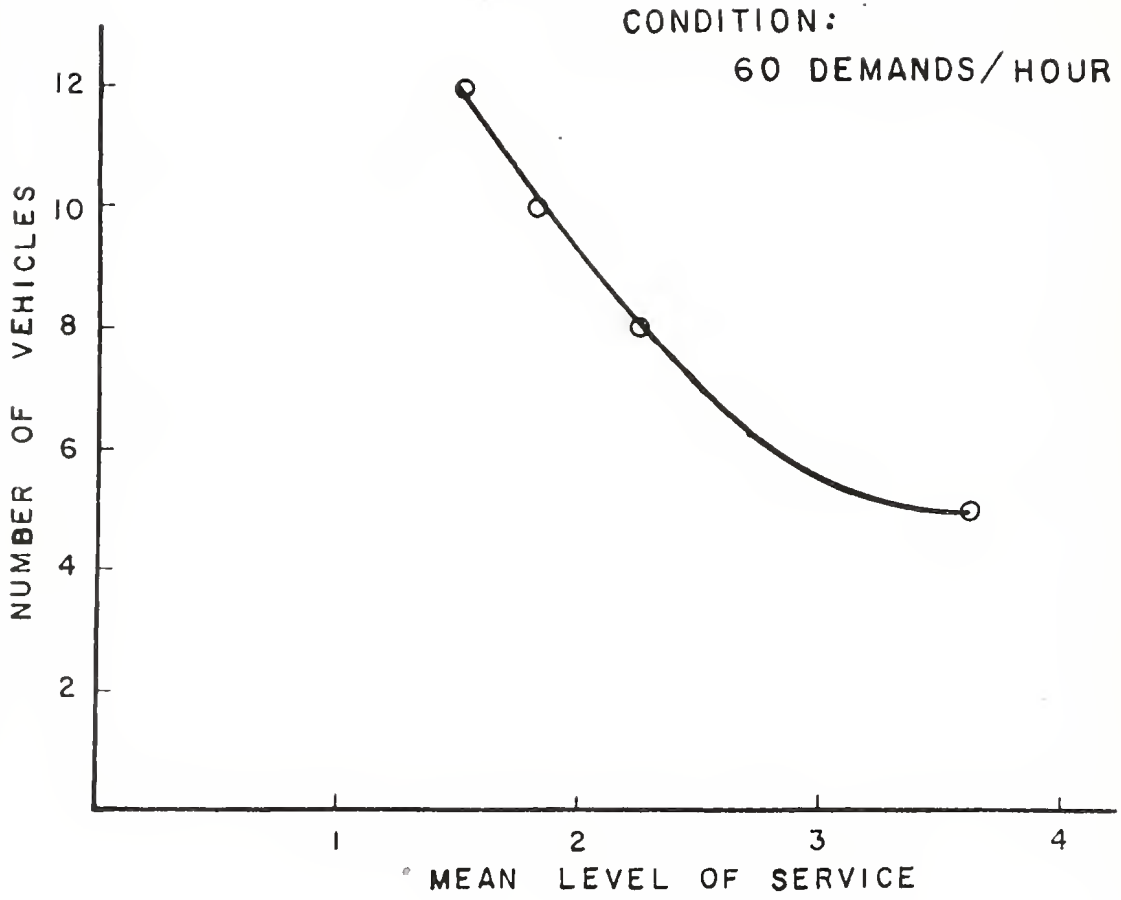

FIGURE 6-I3 EFFECT OF NUMBER OF VEHICLES ON MEAN LEVEL OF SERVICE 


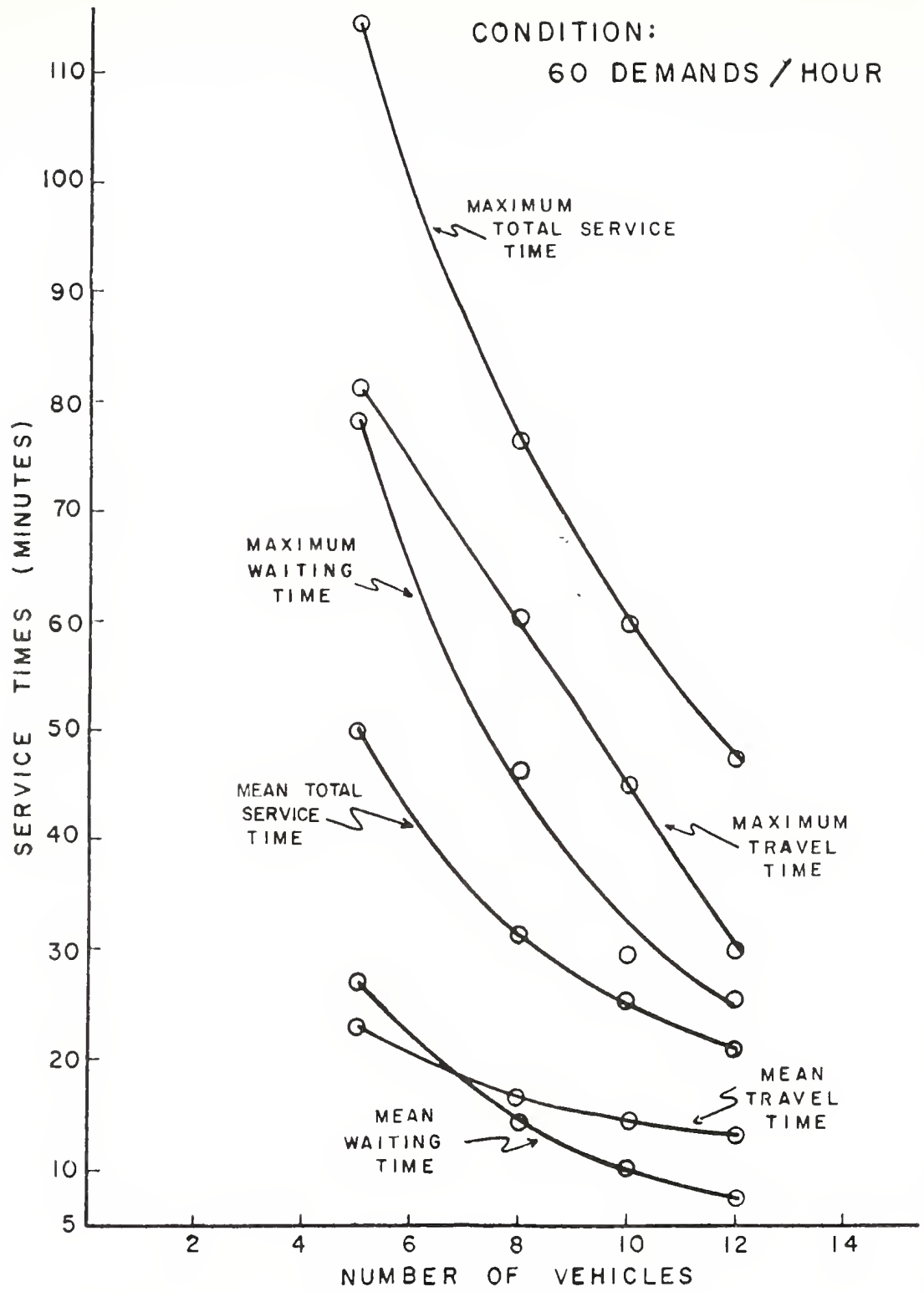

FIGURE 6-14 EFFECT OF NUMBER OF VEHICLES ON MEAN AND MAXIMUM SERVICE TIMES 


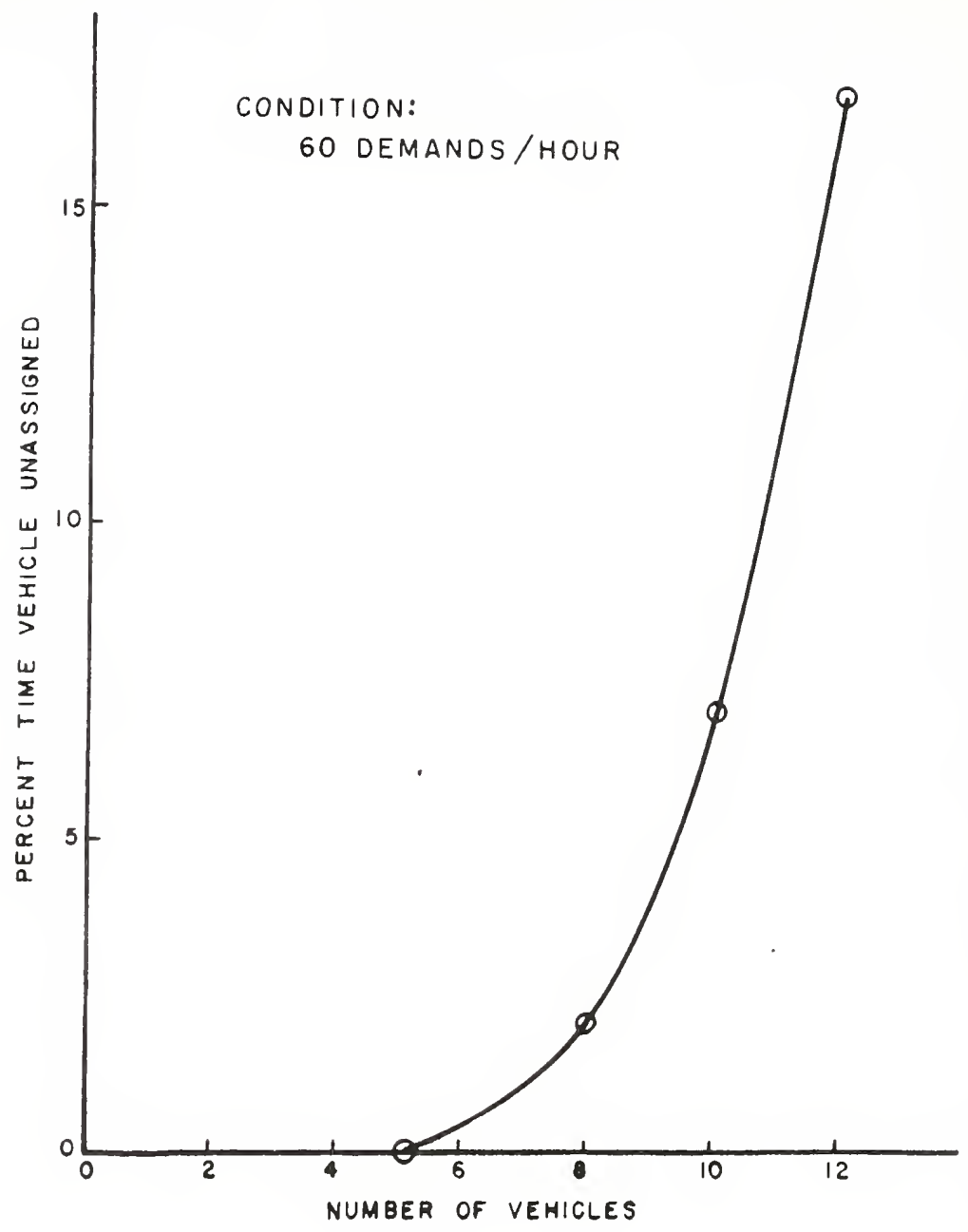

FIGURE 6-15 EFFECT OF NUMBER OF VEHICLES ON THE PERCENT TIME VEHICLE UNASSIGNED 
seems to have a similar general effect on service times as the increase in demand. Hence, the same interpretation could apply to the above results. The effect of number of buses on the percent time vehicle unassigned is also shown in Figure 6-15. The curve varies less rapidly with the decrease of number of buses than with the increase of demand.

\section{Trip Length}

The computer program calculates the mean level of service for the different trips by trip lengths. There are five divisions of trip lengths. The effect of number of buses and number of demands per hour on mean level of service by trip lengths is shown in Figures 6-16 and 6-17.

It is interesting to note from these figures that the mean level of service is better for longer trips within the study area under the same conditions. This could be interpreted by studying the definition of level of service. The level of service for a certain trip is the summation of waiting time plus the bus travel time divided by the mean direct travel time.

$$
\text { LOS }=\frac{\text { Waiting time }+ \text { travel time }}{\text { Mean direct travel time }}=\frac{\text { Total Service time }}{\text { Mean direct traveltime }}
$$

For short trips the waiting time constitutes a major element of the total time. Travel time by bus being close to the direct travel time produces a large numerator compared to the denominator and hence, a high value of 


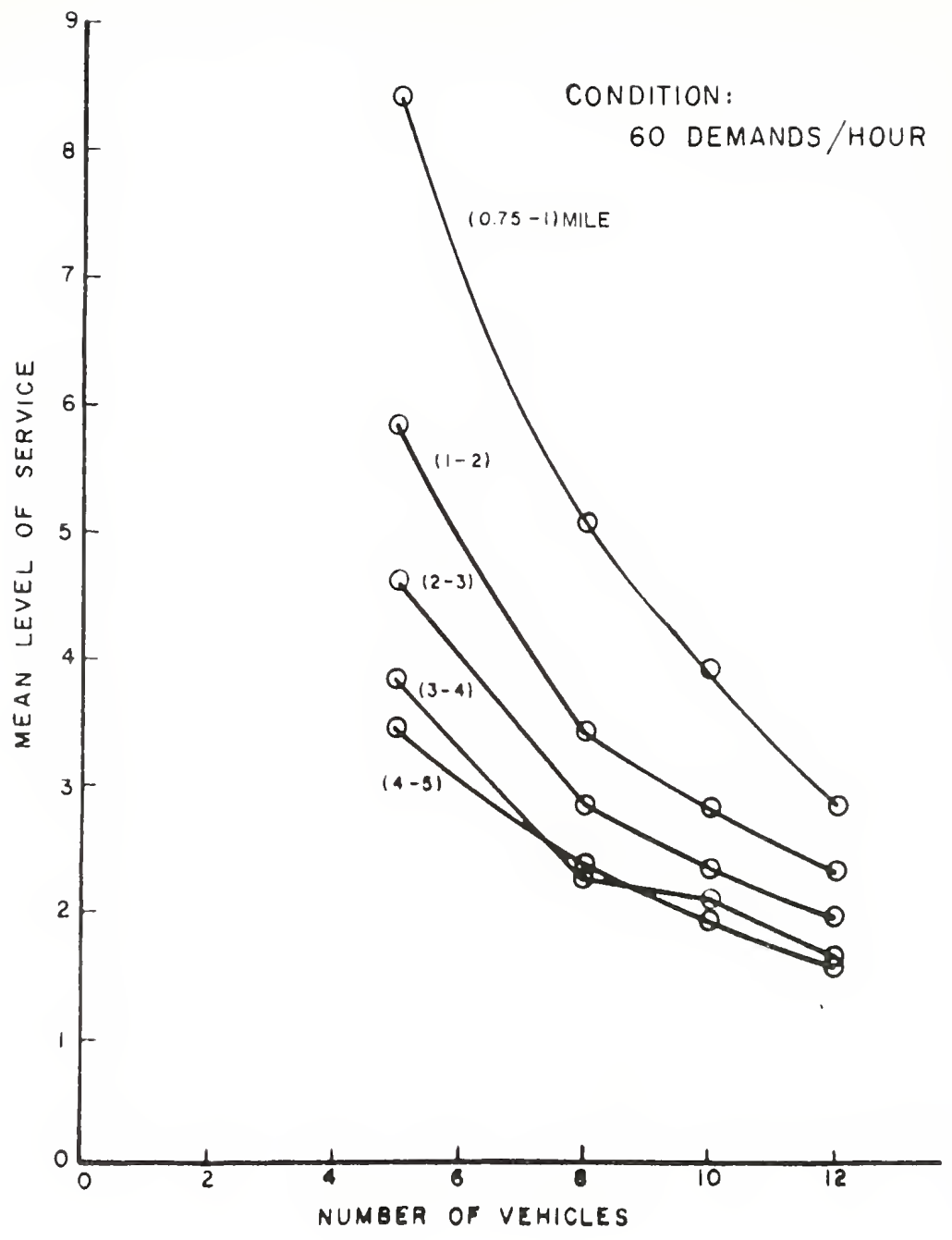

FIGURE 6-16 EFFECT OF NUMBER OF VEHICLES ON MEAN LEVEL OF SERVICE BY TRIP LENGTH 


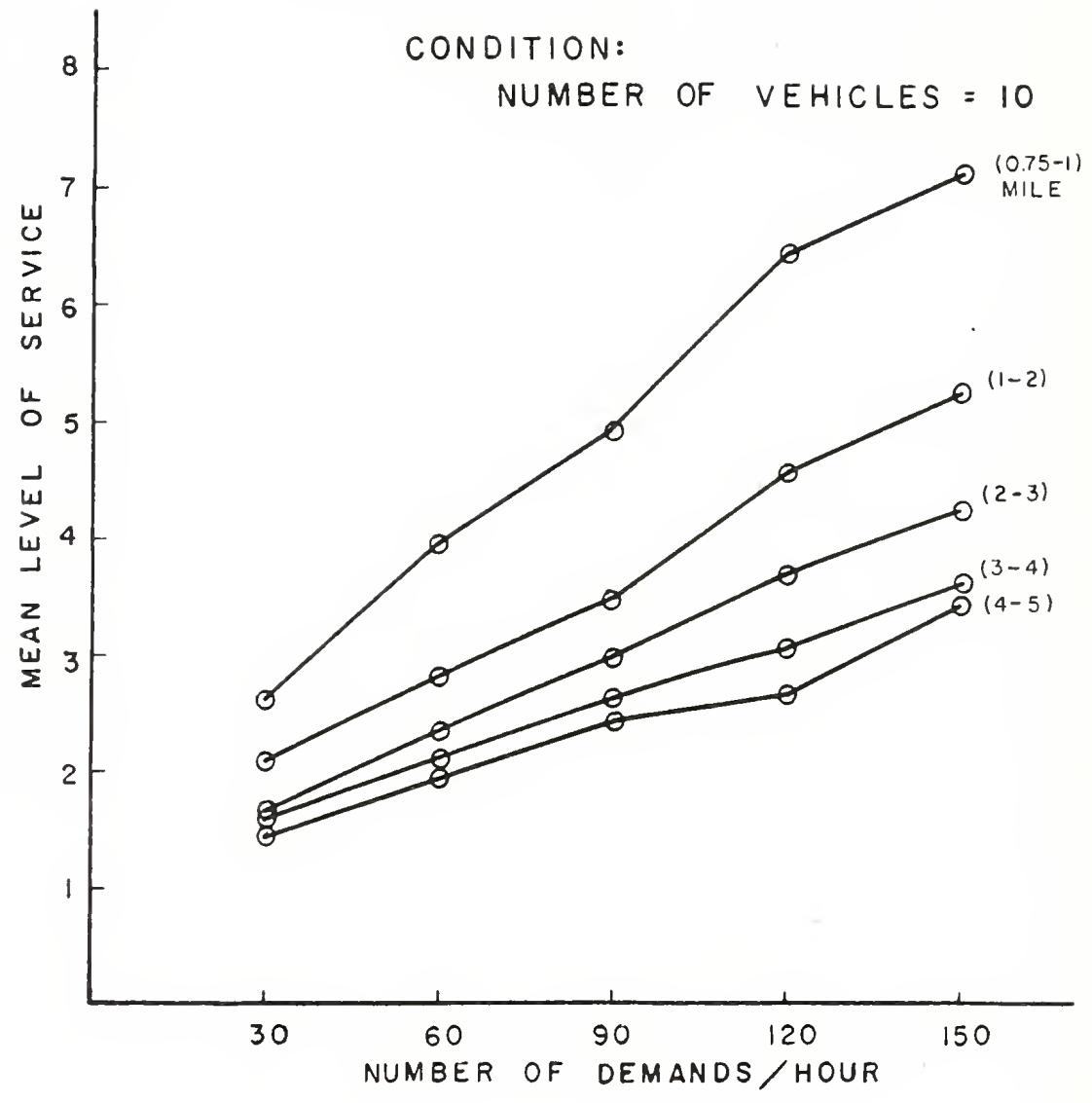

FIGURE 6-17 EFFECT OF DEMAND LEVEL ON MEAN LEVEL OF SERVICE BY TRIP LENGTH 
level of service. This effect decreases as the trip length increases. The waiting time is independent of the effect of trip length and approximately uniform in value. The travel time increases with the increase of trip length and consequently forms the major part of the total time. Being close in value to the direct travel time, it produces, on the whole, a lower value of level of service.

It can, therefore, be concluded that under the same conditions, the Dial-A-Ride system best serves trip lengths of 2 to 5 miles within the study area. 


\section{CHAPTER 7: COST ANALYSIS}

\section{Introduction}

The cost analysis will determine the feasibility of operation of the two bus modes under different demand levels at a required level of service. The mean level of service that is considered to be acceptable to the public, as discussed previously is equal to 2.2 to 2.5 times the mean direct auto travel time. The cost analysis of the different operations was investigated at this measure of level of service. But the measure of service for the two bus systems is not quite the same except from the time consumption point of view. The demand-responsive bus system in contrast to the fixed-route bus system offers a door-to-door service with confortable waiting times and no walking is involved. It offers a better service to the customers even where the timespent by the users on both systems is the same. However the importance of walking to the bus stop and waiting on the streets is rather a qualitative measure and it is hard to incorporate in calculating the measure of service. This research considered the total time spent by the users on the system as the only measure for comparing the levels of service offered by the two bus alternatives. 
The cost of a bus system will depend mainly on the number of buses in operation. The drivers' wages and the operating cost of the vehicles constitute the major component of the total system cost. In case of demandresponsive bus systems, the cost of dispatching and the cost of computer assignment will add another component to the total cost. Before the cost of the two systems is studied, the number of buses required to serve the various demand levels will be discussed first.

\section{Analysis of the Results of the Two Bus Systems}

The design of the two bus systems, which are studied in chapters 5 and 6 reveals the number of buses needed to serve the various demand levels for a certain level of service. The results are tabulated below for a 2.2 to 2.5 mean level of service.

$\begin{array}{lcc}\text { Demand Per hour } & \text { Number of Buses } & \text { Type of System } \\ \text { up to } 750^{*} & 15 & \text { Fixed-Route } \\ 150 & 14 & \text { Dial-A-Ride } \\ 120 & 12 & \text { Dial-A-Ride } \\ 90 & 10 & \text { Dial-A-Ride } \\ 60 & 8 & \text { Dial-A-Ride } \\ 30 & 5 & \text { Dial-A-Ride } \\ \star 750 & \text { Available passenger seats per hour }\end{array}$


It is seen from the above results that for a demand greater than 150 persons per hour, the fixed-route bus system requires less number of buses than the Dial-A-Ride to provide the same level of service. Consequently its cost will be cheaper than Dial-A-Ride because of its less sophisticated control systems. The high demands, those greater than 150 persons per hour, occur during the peak hours of the day in Greater Lafayette Area. Therefore the fixed-route system provides a better alternative during these hours.

For demand less than 150 persons per hour, the Dial-ARide system requires less than 15 buses to provide the same level of service. However the total system cost could be less, equal, or greater than that of the fixed-route system, depending on the number of Dial-A-Ride buses in operation. This is mainly due to the additional administrative and operative cost required by the Dial-A-Ride system The cost analysis investigated the break-even point between the cost of the two systems. The break-even point represents the number of Dial-A-Ride buses in operation that would produce the same total cost as the 15 buses in the fixed route system. Below that number of buses the Dial-A-Ride system would provide a better alternative than the fixedroute system.

Hence, the cost analysis investigated the operating cost per hour of the following systems: 
1. A 15 bus system operating on the developed fixed routes of Greater Lafayette Area.

2. A number of Dial-A-Ride buses that would be equivalent in cost to the fixed-route systern.

The costs for such common items between the two systems, as land cost, terminal facilities costs, and common administrative costs are not considered in the analysis. It is difficult to calculate their costs per hour and they might obscure the total operating costs. Besides they don't offer any valuable information for the comparison of the two systems which is the main purpose of the analysis.

\section{Cost Analysis of the Fixed-Route system}

The following vehicle characteristics and operating conditions are assumed in calculating the cost of the fixed-route system.

Vehicle

Operating Conditions

$$
\begin{aligned}
& 25-30 \text { passenger seats } \\
& \text { Twin Coach Type - Gasoline } \\
& 12 \mathrm{mph} \text { Average speed (inc. stops) } \\
& 12 \mathrm{Hrs} / \mathrm{Day} \quad 144 \mathrm{miles} / \mathrm{Day} \\
& 365 \text { Days/Year } 52500 \mathrm{miles} / \text { Year } \\
& 4380 \text { hours/year }
\end{aligned}
$$

The 12 hours per day cover the non-peak operating hours of the system. It is already established that the fixedroute system is a better alternative during the peak hours. During the non-peak hours the choice between the two bus systems will depend on their cost comparison. 
The total operating cost of the fixed-route system is summarized in the following table.

Purchase Cost of 15 buses:

$\$ 506,000$; Capital Recovery

cost assuming a 10-year

life expectancy, at an $8 \%$

interest rate

$\$ 75450 /$ year

$\$ 1.72 /$ hour

Purchase Price of 15 Two-

Way Radio units with a base

station: $\$ 25,000$; Capital

Recovery cost at $8 \%$ interest

rate assuming replacement

every 10 years

$\$ 3725 /$ year

$\$ 0.85 /$ hour

Fixed Radio Maintenance

charges 15 mobile units at

$\$ 6$ each per month 1 Base

unit at $\$ 12$ per month

$\$ 1224 /$ year $\$ 0.28 /$ hour

Insurance, 15 buses insured at $\$ 700$ each

$\$ 1050 /$ year

$\$ 0.24$ /hour

Wages

15 Drivers at $\$ 3.20$ per hour plus $10 \%$ unemployment taxes, social securities and workman compensation plus $5 \%$ Hedication, Life Insurance and Driver Uniforms

$\$ 3.20$ /hour/driver

$\$ 0.32 /$ hour/driver

$\$ 0.16 /$ hour/driver

$\$ 3.68 \times 15$

$\$ 55.20 /$ hour

Fuel at $16.9 \$ / g a l l o n$ at $4.425 \mathrm{miles} / \mathrm{gallion}$ and at $12 \mathrm{miles} / \mathrm{hour}$

$\$ 0.46 /$ hour/vehicle

0 il at 65c/gallon

6 Quarts of oil every month $\$ 15.00 /$ month $\$ 0.04 /$ hour

Haintenance Including Tires, Battery, Antifreeze, Transmission Fluid and Grease $\$ 0.75 /$ hour

Total Cost $\$ 65.98 /$ hour 
The cost figures were obtained from Greater Lafayette Public Transportation Corporation. The administration costs and the mechanics wages were not included in the analysis since they are common to the operations of both systems.

\section{Cost Analysis of the Dial-A-Ride System}

The following vehicle characteristics and operating conditions are assumed in the cost analysis:
Vehicle
12-15 passenger seats
Compact mini-bus (Gasoline)
Operating Conditions

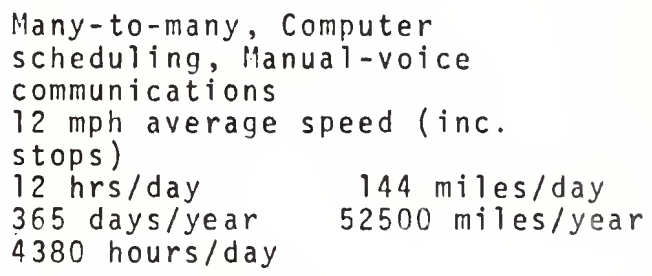

In the Dial-A-Ride operation, the vehicle could be empty and unassigned for a certain time, depending upon the demand level and the number of vehicles in operation. For a 2.2 to 2.3 level of service, it is found from the simulation experiments that the average percent time the vehicle is unassigned is $1.25 \%$. During this unassinged time the vehicle would be waiting at its last stop for a new assignment. This idle time, although it is small, will cut down on the total miles traveled and on the fuel consumption. The dial-A-Ride system would require a telephone operator, a dispatcher, a computer, and public telephone lines in addition to that needed for the operation of the 
fixed-route system. The computer cost is estimated to be equal to $10 \notin$ per trip by the M.I.T. researchers (23). But the number of trips that can be processed at the required level of service cannot be evaluated, without knowing the number of buses in operation. However, a mathematical relationship could be developed between the demand level and the number of vehicles, for a 2.2 to 2.3 level of service. From the results of the simulation experiments shown in Figure 6-8 the number of buses increases linearly with the increase of number of demands for demands greater than 60 calls per hour. This could be represented by the following function for number of buses greater or equal to 8 .

$$
D=60+15(N-8)=15 N-60
$$

where

$D$ is the number of demands per nour

$N$ is the number of vehicles in operation

The following table summarizes the total operating cost of the system according to the stated assumptions.

Purchase cost of $N$ buses at $\$ 10,000$ each; Capital Recovery cost assuming a 3-year 1 ife expectancy at an $8 \%$ interest rate

Purchase cost of $N$ two-way radio units: $\$ 1,400 \mathrm{~N}$; a base station $\$ 4,000$; Capital Recovery cost at $8 \%$ interest rate assuming replacement every 10 years

$$
\begin{array}{ll}
(\$ 209 N+596) / \text { year } \quad(0.0476 N+ \\
0.136) / \text { hour }
\end{array}
$$


Installation cost of 25

Direct-Public Telephone

Lines: $\$ 750$; Capital

Recovery cost at $8 \%$

interest rate assuming

replacement every 5 years

$\$ 187.5 /$ year

$\$ 0.0428$ /hour

Monthly cost of 25 directpublic telephone lines at $\$ 14.50$ each

Fixed Ratio Maintenance

Charges $N$ mobile units at $\$ 6$ each per month; 1 Base unit at $\$ 12$ per month
$6 \mathrm{~N}$

12

$(6 N+12) /$ month, $(0.0167 N+0.033) /$ hour

$\$ 362.5$ /month $\$ 1.01 /$ hour

Insurance

II buses insured at $\$ 700$ each

$\$ 700 \mathrm{~N} /$ year

$\$ 0.16 \mathrm{~N} /$ hour

Computer cost at $10 \notin$ per trip for $(1511-60)$ demands

per hour

Wages

II Drivers at $\$ 3.68 /$ hour each

1 Dispatcher at $\$ 3.80 /$ hour

1 Additional operator at

$\$ 3.68$ /hour

$\$(1.5 N-6.0) /$

hour

Fuel at $16.9 \mathrm{c} / \mathrm{galion}$

at 8.55 miles/gallon

at $12 \times 1.0125 \mathrm{miles} / \mathrm{hour}$

$\$ 0.241 /$ hour/vehicle

$\$ 3.68 \mathrm{~N} /$ hour

$\$ 3.80$ /hour

$\$ 3.68$ /hour

0 il at $65 \mathrm{c} / \mathrm{gal}$ ion

6 Quarts of oil every month

$\$ 1.00 \mathrm{~N} /$ month

$\$ 0028$ N/hour

Haintenance

Including Tires, Battery, antifreeze, transmission

fluid, and Grease

$\$ 220 \mathrm{~N} /$ year

$\$ 0.05 \mathrm{~N} /$ hour

Total Cost $\$ 6.5881 N+2.7018 /$ hour

The cost figures were also obtained from Greater Lafayette Public Transportation Corporation. 
The total cost per hour should be equal to the total cost per hour of the fixed route system.

$$
\begin{aligned}
6.58811 & +2.7018=65.98 \\
N & =\frac{63.28}{6.588}=9.65=10 \text { buses }
\end{aligned}
$$

Hence 10 buses of the Dial-A-Ride system would produce the equivalent cost of 35 buses operating on the fixedroute system. The demand served by 10 buses would be equal to $30 \mathrm{calls}$ per hour for the required level of service. Therefore the Dial-A-Ride system would provide a better alternative for demands less or equal to $90 \mathrm{calls}$ per hour. 


\section{CHAPTER 8: CONCLUSIONS AND RECOMMENDATIONS}

\section{Conclusions}

The research developed a methodology for the design of fixed routes of a bus system in a small urban area. Using this methodology it identified the best route configuration of the fixed-route bus system to be implemented in Greater Lafayette Area. A fifteen bus, seven leg, three two-way loop system is considered to be the best developed system. The medium size buses operate on half-hour headways to provide a mean level of service of 2.3 to 2.5 times the mean direct travel time. No cut in service of the selected system is recommended because the level of service would deteriorate rapidly to undesirable limits.

The research also investigated the number of Dial-ARide buses required tc satisfy demands of 30 to 150 calis per hour for different levels of service. For a 2.2 to 2.3 mean level of service it is found that the number of buses increases linearly with increasing demand level but with a slope less than unity. At the same level of service the rate of increase in vehicle productivity is quite slow for demands above 120 calls per hour. This implies that Dial-A-Ride would best operate in medium and low demand 
levels. In studying both the effect of demand level on level of service and the effect of number of buses on level of service it was clearly shown that to provide a better mean level of service to more customers, more buses should be used. The study has also concluded that the Dial-A-Ride system best serves trip lengths of 2 to 5 miles within the Greater Lafayette Area.

The results obtained from this study also identify the best operation in Greater Lafayette Area for the two bus modes, the fixed-route and the Dial-A-Ride for the different demand levels at a required level of service. These results are tabulated below:

$\begin{array}{lcl}\text { Condition: } & \begin{array}{c}\text { Level of Service } \\ \text { Travel Time }\end{array} \\ \text { Demands/Hour } & \text { No. of Buses } & \text { Type of Bus System } \\ 91-750 & 15 & \text { Fixed-Route } \\ 90 & 10 & \text { Dial-A-Ride } \\ 60 & 8 & \text { Dial-A-Ride } \\ 30 & 5 & \text { Dial-A-Ride }\end{array}$

From these results it can be concluded that the fixed-route system provides a better bus system for high demands, while Dial-A-Ride offers a better and less costly service for low demands. This conclusion is valid only when the concept of level of service as defined earlier, is used as a yardstick for comparison between the two 
systems. In other words, if the time spent by the users on the bus system compared to their auto travel time is used as a measuring criteria.

The results are applicable specifically to the Greater Lafayette Area. However, if other areas have the same size and structure as Greater Lafayette, the results might be used.

The study has confined its analysis to the many-tomany form of the Dial-A-Ride system. Other forms such as many-to-few and many-to-one have not been investigated. In addition manual dispatching instead of computer dispatching has not been considered. It could be a more viable form of dispatching at very low demands. Yet its effect on the level of service should be well investigated especially in a large size area as Lafayette with many-tomany form of operation.

\section{Recommendations for Further Research}

This research is a pioneer in the field of comparing the two bus modes, the fixed-route and the demand-responsive bus systems that are most likely to be considered in small urban areas. Additional research is needed in this field and some of the research ideas are listed below:

1. To compare the two bus modes for different area sizes and different area structures. 
2. To determine the importance of walking to and waiting at bus stops by the users with respect to their total travel time by bus.

3. To investigate the waiting time distributions of fixed-route bus users for different bus headways and area coverage.

4. To study the advantages and the disadvantages of implementing a many-to-few instead of many-tomany Dial-A-Ride system in low demand hours.

5. To study the effects of manual dispatching vs computer dispatching on the levels of service offered by the Dial-A-Ride system. This could not be studied, until a computer dispatching system is in operation, which is non-existent till this date.

\section{Recommendations for Implementation}

The proper hourly distribution of demand is hard to predict before implementing the bus systems. Hence it is difficult to find before hand the right combination of the two bus modes for the different operating hours of the day. Since the fixed-route system is a better system for high demands it is always safe to start by implementing it during the whole operating hours for at least 3 to 6 months. When enough and stabilized information on the demand distribution is obtained, then a decision on the 
application of the two bus systems for the different operating hours could be reached using the results of this research. 
LIST OF REFERENCES 


\section{LIST OF REFERENCES}

1. Bruggeman, J. M., and Heathington, K. W., "Sensitivity to Various Parameters of a Demand-Scheduled Bus System Computer Simulation Model," Highway Research Board, Highway Research Record 293, 1969.

2. Cantor, Kenneth P., The Environmental Handbook, Ballantine Books, inc., 1970, pp. 197-198.

3. Fertal, M., Weiner, E., Balek, A., and Sevin, A. F., Modal Split, U. S. Department of Transportation, Federal Highway Administration, December, 1966.

4. Fitch, Lyle, C., The Future of American Transportation, The American Assembly, Columbia University, 1971, pp. $169-170$.

5. Guenther, Karl, "Incremental Implementation of Dial-ARide Systems," Highway Research Board; Special Report 124, 1971 , p. 52 .

6. Guenther, K. W., and $0 \times 1$ ey, P. R., Dial-A-Ride for New Towns, Transportation Research and Planning Office, Ford Motor Company, October, 1970.

7. Hanson, Mark E., Ed., Project Metran - An Integrated Evolutionary Transportation System for Urban Areas, Massachusetts Institute of Technology, Report No. 8 , 1966.

8. Heathington, K. H., et. al, "Computer Simulation of a Demand-Responsive Bus System Offering Door-to-Door Service", 47 th Annual Meeting of the Highway Research Board, Highway Research Record, No. 251 .

9. Heathington, K. W., et. al., The Greater Lafayette Area Bus Transit Study, Purdue University, Joint Highway Research Project, April, 1971.

10. Howson, Larry L., and Heathington, Kenneth W., Algorithms for Routing and Scheduling in Demand Responsive Transportation Systems, General Motors Research Laboratories, January, 1970. 
11. Johnson, Lyndon B., Transportation For America, A Message from the Prssident of the United States to the Congress, Harch 2, 1966.

12. Kennedy, John F., The Transportation System of Our Nation, A Message from the President of the United States to the Congress, April 5, 1962.

13. Levinson, Herbert S., et. a1.. Traffic Management for Bus Priorities, Wilbur Smith and Associates, January 22,1973 .

14. Mowbray, A. Q., Road to Ruin, J. B. Lippincott Company, 1969, p. 240 .

15. Mowbray, A. Q., Road to Ruin, J. B. Lippincott Company, 1969, p. 232 .

16. Nixon, Richard 11., National Defense Transportation Day and National Transportation Week, Proclamation 4041, March 31, 1971.

17. Rapp, Mathias H., and Cohner, Claus D., Criteria for Bus Rapid Transit Sysems in Urban Corridors: Some Experiments with an Interactive Graphic Design System, Urban Systems Research Center, University of Washington, Seattle, April, 1973.

18. Roberts, Kenneth R., Vehicle Scheduling and Driver Run cutting, the MITRE Corporation, September, 1971.

19. Roos, Daniel, et. al., Summary Report: The Dial-ARide Transportation system, Massachusetts Institute of Technology, Urban Systems Laboratory, USL TR-7010, March, .1971, pp. 4-14.

20. Smerk, George M., Readings in Urban Transportation, Indiana University Press, 1968.

21. Smerk, George M., Readings in Urban Transportation, Indiana University Press, 1968, p. 315.

22. Smerk, George M., et. al., Mass Transit Management: A Handbook for Small Cities, Institute for Urban Transportation, Indiana University, February, 1971.

23. Stafford, J. et. al., Economic Considerations for Dial-A-Ride, Massachusetts Institute of Technology, Urban Sysems Laboratories, USL TR-70-11, March, 1971, p. 1-2. 
24. Voorhees, Alan M., and Associates, Inc., A System Analys is of Transit Routes and Schedules, Mass Transportation Demonstration Project INT-MTD-14, November, 1969.

25. Wilson, Nigel H. M., et. al., Scheduling Algorithms for a Dial-A-Ride System, Massachusetts Institute of Technology, Urban Systems Laboratory, USL TR-70-13, March, 1971.

26. Wilson, Nigel H. M., et. al., Simulation of a Computer Aided Routing System, Massachusetts Institute of Technology, Urban Systems Laboratory, R70-16, January 1970.

27. Dial-A-Ride Basic Program Documentation, Massachusetts Institue of Technology, Urban Systems Laboratory, December, 1970.

28. CARS Basic Program Implementation and User's Guide, Massachusetts Institute of Technology, Urban Systems Laboratory, December, 1970. 
General References

Acres, H. G. Limited, Guelph Transit Study, Guelph, Ontario, Canada, May 1971.

Bauer, H. J., A case Study of a Demand-Pesponsive

Transportation System, General Motors Research Publication, No. 1034 , sept. 9970.

Bendix Corporation, Columbia Transit Study, Mass

Transportation Demonstration Project, MD-HTD-2, April 1970.

Bonsal1, J. A., The Bay Ridges Dial-A-Bus Experiment,

Department of Highway, Ontario, Jan. 197T.

Bruch, H., et. al., Topics in the Design of Dial-A-Ride

Demonstration Experiments, Urban Systems Laboratory, M.I.T. Cambridge, Mass., Dept. RT-70-12, March 1971.

Gustafson, R. L., et. al., User Preferences for a DemandResponsive Transportation system: A Case Study Report, General Motors Research Publication, No.7047, Jan. 1971.

Jones, P. S., 1964, Dial-A-Bus, Proceedings, Stanford Research Institute U $\overline{r b a n}$ Alternatives Symposium - Stanford Research Institute.

Read, Voorhees, and Associates, Stratford Transit System, Stratford, Canada, Jan. 1972.

Voorhees, Alan li. and Associates, Inc., A Transit Development Program for Spokane, City of Spokane, Washington, May 1370.

Roos, D., et. al., Cars - A Prototype Dial-A-Bus System, Urban Systems Laboratory, H.I.T., Cambridge, Dept. R69-56, Sept. 1969.

Ward, J. E. and Rausch, R. G., Vehicle Communications for a Dial-A-Ride System, USL TR-70-15, H.I.T., Cambridge, March, 1971.

A Manual Backup System Handbook for Dial-A-Ride, USL, M.I.T., Cambridge, JuTy 1971. 
Computer Configurations for a Dial-A-Ride System, USL TR70-14, M.I.T., Cambridge, March 1971.

Dial-A-Bus, Ontario Department of Transportation and Communications, Ontario, Canada, Aug. 1971. 


\section{APPENDICES}




\section{APPENDIX A}

Appendix A reports the calculation of the level of service of the fixed-route bus system. Table A-l shows the cumulative frequency of a zone for being a source of origin and a source of destination for a particular demand. Table A-2 shows the level of service for 50 demands for a walking and waiting time of 15 and 20 minutes. The level of service for 30 minutes walking and waiting time could be calculated as follows:

$$
2.78+(2.78-2.35) \frac{(30-20)}{(20-15)}=3.64
$$

Figure A-l shows the desire lines of travel for the 50 demands. 


\section{TABLE A-I TRAFFIC ZONE CUMULATIVE FREQUENCIES OF CONTAINING ORIGINS AND DESTINATIONS}

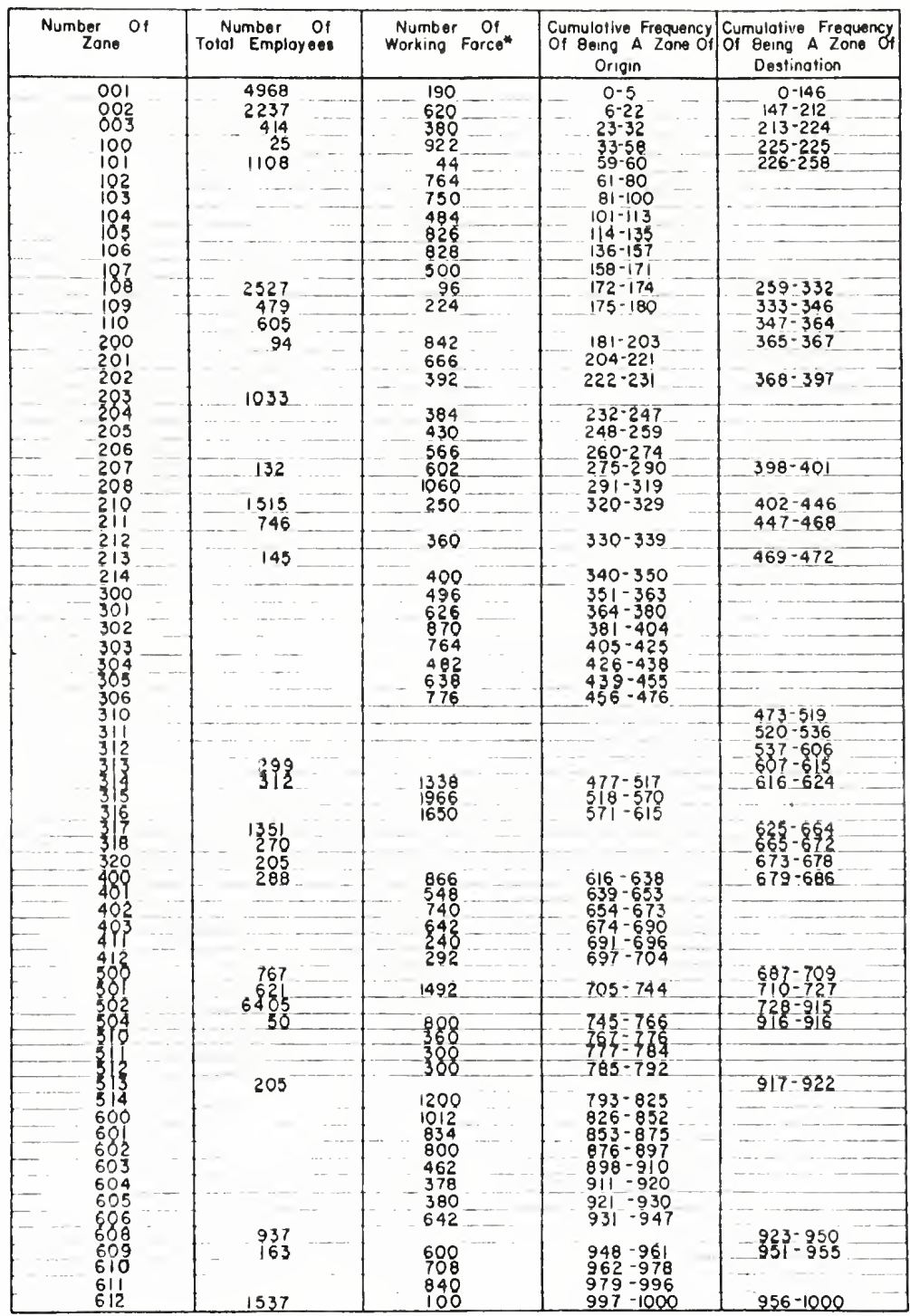

- Number of working force = Total population-number af peaple less than 18 years old-number of peoplo equal and greoter thon 62 years ald. 
TABLE A-2 LEVEL OF SERVICE OF THE FIXED-ROUTE BUS SYSTEM

\begin{tabular}{|c|c|c|c|c|c|c|c|c|c|}
\hline $\begin{array}{c}\text { Number of } \\
\text { Event }\end{array}$ & $\begin{array}{l}\text { Origin } \\
\text { Zone }\end{array}$ & $\begin{array}{c}\text { Destination } \\
\text { Zone }\end{array}$ & $\begin{array}{c}\text { Trovel Time } \\
\text { By Bue }\end{array}$ & $\begin{array}{c}\text { Travel Time } \\
\text { By Auto }\end{array}$ & $\begin{array}{l}\text { Trovel Time } \\
\text { 8y Auto } \\
+40 \text { Minute } \\
\text { Access Time }\end{array}$ & $\begin{array}{l}\text { Travel Time } \\
\text { By 8us } \\
+15 \text { Minute } \\
\text { Wolking 8 } \\
\text { Woiting Time }\end{array}$ & $\begin{array}{l}\text { Lovel of } \\
\text { Service }\end{array}$ & $\begin{array}{c}\text { Travel TIme } \\
\text { By Bus } \\
+20 \text { Minute } \\
\text { Walking } 8 \\
\text { Wating Time }\end{array}$ & $\begin{array}{l}\text { Lovel of } \\
\text { Service }\end{array}$ \\
\hline 1 & 609 & 002 & 30 & 1430 & 1830 & 45 & 246 & 50 & 273 \\
\hline 2 & 511 & 312 & 35 & 16.90 & 2090 & 50 & 2.39 & 55 & 2.63 \\
\hline 3 & 104 & 211 & 22 & 7.80 & 11.80 & 37 & 3.13 & 42 & 3.55 \\
\hline 4 & 316 & 312 & 7 & 3.90 & 7.90 & 22 & 2.78 & 27 & 3.41 \\
\hline 3 & 501 & 320 & 30 & 16.90 & 20.90 & 45 & 2.15 & 50 & 2.39 \\
\hline 6 & 212 & 502 & 30 & 16.90 & 20.90 & 45 & 2.15 & 50 & 239 \\
\hline 7 & 100 & 312 & 18 & 9.10 & 13.10 & 33 & 2.51 & 38 & 2.90 \\
\hline$\theta$ & 200 & 210 & 10 & 6.50 & 10.50 & 25 & 2.38 & 30 & 2.85 \\
\hline 9 & 106 & 002 & 15 & 7.80 & 11.80 & 30 & 2.54 & 35 & 2.96 \\
\hline 10 & 603 & 001 & 15 & 7.80 & 11.80 & 30 & 2.54 & 35 & 2.96 \\
\hline 11 & 610 & 310 & 32 & 18.20 & 22.20 & 47 & 2.11 & 52 & 2.34 \\
\hline 12 & 316 & 002 & 22 & 9.62 & 13.62 & 37 & 2.76 & 42 & 3.14 \\
\hline 13 & 610 & 001 & 20 & 13.00 & $=17.00$ & 35 & 2.05 & 40 & 2.35 \\
\hline 14 & 316 & 502 & 33 & 16.64 & 20.64 & 48 & 2.32 & 53 & 256 \\
\hline 15 & 315 & 001 & 23 & 13.00 & 17.00 & 38 & 2.23 & 43 & 2.53 \\
\hline 16 & 206 & 501 & 17 & 10.92 & 14.92 & 32 & 2.14 & 37 & 2.48 \\
\hline 17 & 305 & 200 & 10 & 5.20 & 9.20 & 25 & 2.71 & 30 & 326 \\
\hline 18 & 612 & 210 & 40 & 21.32 & 25.32 & 55 & 2.17 & 60 & 2.37 \\
\hline 19 & 202 & 312 & 18 & 7.80 & ii. $\overline{8} 0$ & 33 & 2.79 & 38 & 3.22 \\
\hline 20 & 603 & 310 & 32 & 15.60 & 19.60 & 47 & 2.39 & 52 & 265 \\
\hline 21 & 400 & 612 & -30 & 16.90 & 20.90 & 45 & 2.15 & 50 & 239 \\
\hline 22 & 314 & 502 & 22 & 14.56 & 18.56 & 37 & 1.99 & 42 & 2.26 \\
\hline 23 & 402 & 001 & 6 & 5.20 & 9.20 & 21 & 2.28 & 26 & 2.82 \\
\hline 24 & 304 & 608 & 17 & 11.44 & 15.44 & 32 & 2.07 & 37 & 2.39 \\
\hline 25 & 107 & 311 & 27 & 1248 & 16.48 & 42 & 2.54 & 47 & 2.85 \\
\hline 26 & 315 & 500 & 25 & 14.30 & 18.30 & 40 & 2.18 & 45 & 2.46 \\
\hline 27 & 303 & 108 & 23 & 11.70 & 15.70 & 38 & 242 & 43 & 2.73 \\
\hline 28 & 316 & 502 & 33 & 16.64 & 20.64 & 48 & 2.32 & 53 & 256 \\
\hline 29 & 600 & 211 & 22 & 10.92 & 14.92 & 37 & 2.47 & 42 & 2.81 \\
\hline 30 & 105 & 001 & -10 & 6.50 & 10.50 & 25 & 2.38 & 30 & 2.85 \\
\hline 31 & 306 & 001 & 10 & 7.80 & 1180 & 25 & 2.11 & 30 & 2.54 \\
\hline 32 & 600 & 101 & 15 & 3.90 & 7.90 & 28 & 3.54 & 33 & 4.45 \\
\hline 33 & 402 & 109 & 18 & 13.00 & 17.00 & 33 & 1.94 & 38 & 2.23 \\
\hline 34 & 107 & 317 & 38 & 16.90 & 20.90 & 53 & 253 & 58 & 277 \\
\hline 35 & 303 & 002 & 6 & 5.20 & 9.20 & 21 & 2.28 & 26 & 2.82 \\
\hline 36 & 306 & 101 & 15 & 10.40 & 14.40 & 30 & 2.08 & 35 & 2.43 \\
\hline 37 & 400 & 108 & 16 & 10.40 & 14.40 & 31 & 2.15 & 36 & 2.50 \\
\hline 38 & 403 & 502 & 16 & 10.40 & 1440 & 31 & 2.15 & 36 & 250 \\
\hline 39 & 511 & 001 & 12 & 7.80 & 11.80 & 27 & 228 & 32 & 2.71 \\
\hline 40 & 602 & 203 & 16 & 910 & 13.10 & 31 & 236 & 36 & 2.74 \\
\hline 41 & 102 & 108 & 6 & 5.20 & 9.20 & 21 & 228 & 26 & 2.82 \\
\hline 42 & 303 & 608 & 30 & 1820 & 22.20 & 45 & 2.02 & 50 & 2.25 \\
\hline 43 & 203 & 502 & 18 & 11.70 & 15.70 & 33 & 2.10 & 38 & 2.42 \\
\hline 44 & 401 & 302 & 13 & 6.76 & 10.76 & 28 & 2.60 & 33 & 3.06 \\
\hline 45 & 602 & 002 & 10 & 630 & 10.50 & 25 & 2.38 & 30 & 2.85 \\
\hline 46 & 315 & 210 & 30 & 13.00 & 17.00 & 45 & 2.64 & 50 & 2.94 \\
\hline 47 & 100 & 302 & 13 & 7.80 & 11.80 & 28 & 2.37 & 33 & 279 \\
\hline 48 & 400 & 310 & 13 & 884 & 1284 & 28 & 2.18 & 33 & 2.57 \\
\hline 49 & 602 & 608 & 11 & 780 & 11.80 & 26 & 2.20 & 31 & 2.62 \\
\hline 50 & 202 & 502 & 15 & 10.40 & 14.49 & 30 & 2.08 & 35 & 2.43 \\
\hline
\end{tabular}




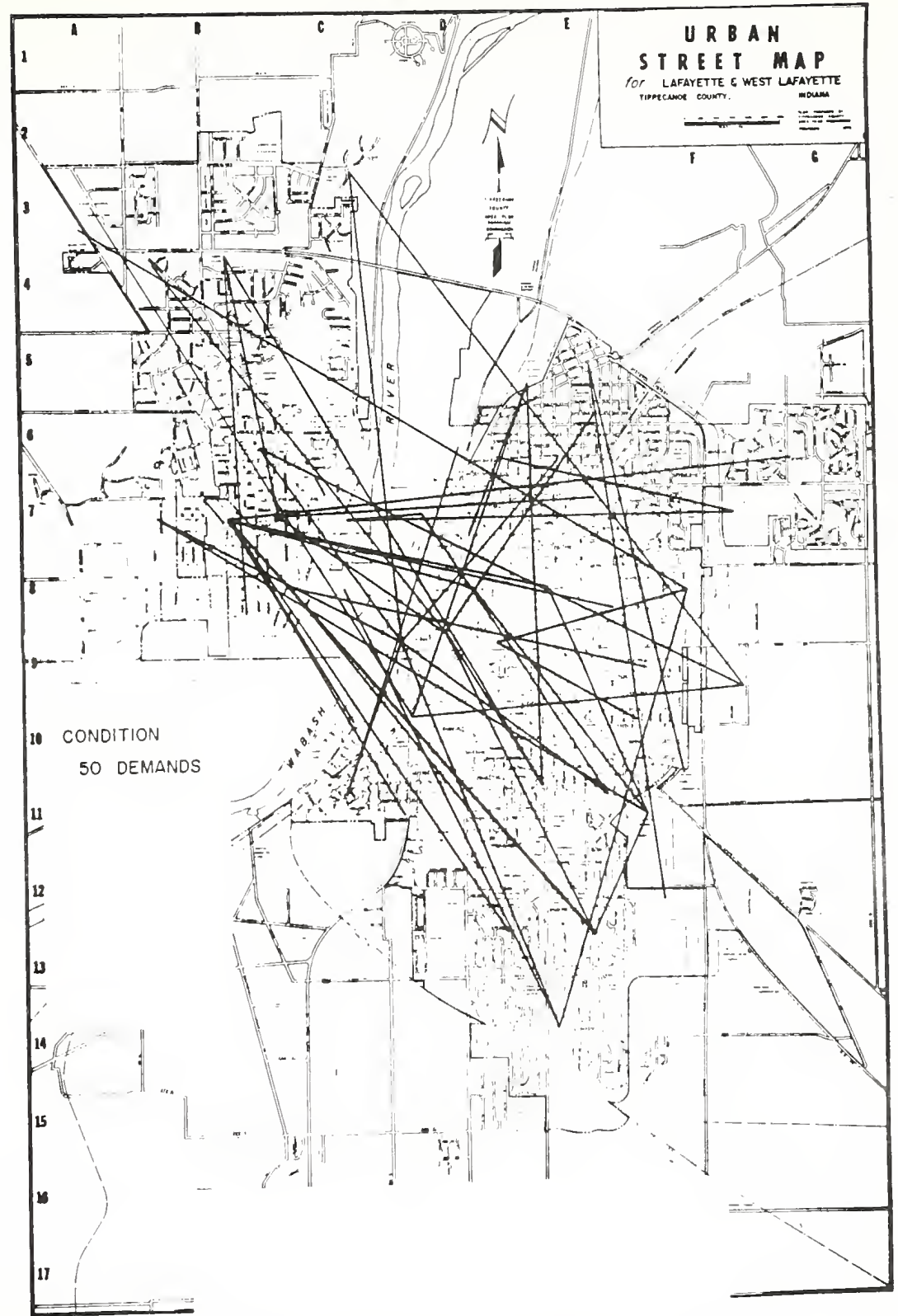

FIGURE A-I DESIRE LINES OF TRAVEL OF THE FIXED-ROUTE SIMULATION 


\section{APPENDIX B}

This appendix shows a sample of the input and output data of the Dial-A-Ride computer simulation. Explanatory information on the output data is provided and has been taken from the Basic Program Implementation and User's Guide of the computer simulation package. 


\section{TABLE B-I A SAMPLE OF INPUT DATA}

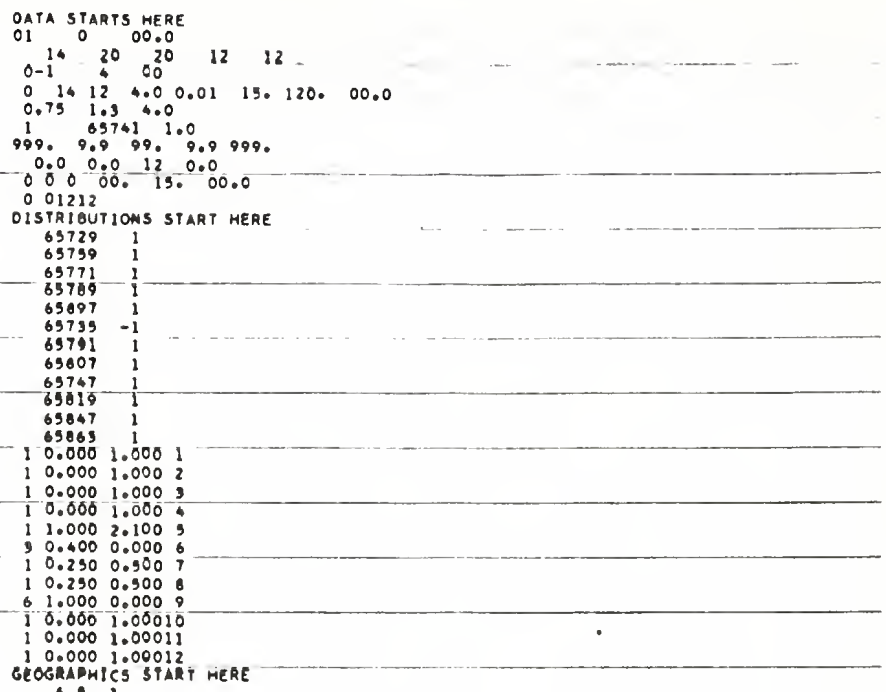

$$
1 \text { - }
$$

$0.00 \quad 2.79 \quad 0.50 \quad 3.20 \quad 1510$

$0.902 .790 .813 .20 \quad 0 \quad 0$

0.183 .491 .323 .20193

1.322 .751 .652 .9700

$1.073 .201 .45-3.652510$

0.793 .201 .073 .6925140

0.003 .200 .793 .794020

0.001 .790 .194 .9300

0.353 .790 .794 .1500

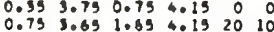

$0.554 .151 .65 \quad .0 \% 330-13$

$0.004 .930 .393 .0510 \%$

0.954 .931 .259 .1320 .0

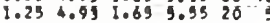

0.003 .090 .393 .9939

0.393 .131 .293 .9520 ,

0.001 .781 .322 .75000

0.000 .891 .791 .7800

$0.00 \quad 0.00 \quad 2.22 \quad 0.85 \quad 0 \quad 0$

$1.322 .491 .692 .79-00$

1.75 0.09 2.0221 .782010

1.051 .451 .851 .45 is 20

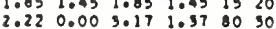

$2.220 .00 \quad 3.17 \quad 1.378090$

$3.17 \quad 0.0004 .600 .89 \quad 00$

$3.170 .859 .75 \quad 1.76$ s 9

$3.801 .373 .80 \quad 1.37 \quad 3060$

$2.22 \quad 1.37 \quad 3.17 \quad 1.76 \quad 2020$

$3.051 .493 .05 \quad 1.45 \quad 1040$

$2.22 \quad .783 .50 \quad 3.6023070$

$3.00 \quad 3.593 .00 \quad 3.531060$

$3.501 .703 .75 \quad 3.55 \quad 20 \quad 60$

1.631 .702 .222 .794015

1.692 .792 .009 .1040200

$2.00 \quad 2.792 .22 \quad 3.1020 \quad 15$

$1.693 .10 \quad 2.22 \quad 9.33 \quad 20 \quad 15$

1.653 .332 .003 .780

2.003 .332 .223 .7620 ,

1.693 .762 .224 .2000

$2.223 .63^{-5.79} 6.209525$

1.654 .202 .604 .630

$2.604 .202 .804 .63,5$,

$2.80 \quad 4.20 \quad 3.304 .6320$

$3.30 \quad 4.20 \quad 4.60 \quad 3.590$

$\begin{array}{llllll}3.65 & 4.83 & 3.30 & 9.55 & 0 & 0 \\ 3.75 & 3.20 & 4.60 & 4.20 & 20 & 10\end{array}$ 
OUTPUT DATA

a) FULL STATISTICAL OUTPUT

Most of the information provided in a full statistical output is self explanatory. The "normalized" quantities are calculated by dividing the quantity by its corresponding constraint and then averaging over all demands (or passengers).

The "weighted normalized" mean times are obtained by summing the total times and dividing by the sum of the total time constraints for all demands (or passengers).

Note that the "weighted normalized" quantities weight the longer trips more heavily than the shorter trips while the "normalized" quantities weight them all equally.

Level of service is defined in the context of this basic program as the total system time (waiting time plus travel time) divided by the direct automobile travel time. The Measure of Service is defined as the total system time divided by the sum of the direct automobile travel time and the variable ACCESS that is read in on Line 6.

Vehicle productivity is the average number of passengers served per hour over the entire run for all vehicles.

If the number of passengers/demand is not 1 , statistics taken "by demand" should be different than those taken. "by passenger". 
b) SYSTEM STATUS DUMP

This is easily interpreted once the abbreviations are understood. In the active demand list:

DN - demand number (becomes negative when a demand is delivered)

OX,OY - coordinates of the origin of the demand DX,DY - coordinates of the destiation of the demand $P C$ - number of passengers ("passenger content") in the demand PRTY - priority class of the demand DTIME - time that the demand arose DPTIME - time that the demand was picked up (if DPTIME $=0.0$, the demand has not yet been picked up) In the vehicle tour list:

DN - demand associated with this stop TX, TY - coordinates of this stop $p$ - if stop is a pickup, this is the pointer to the corresponding delivery stop. If stop is a delivery, pointer is set to -1 .

TIME - expected arrival time at this stop CONST - link constraint (negative if a constraint on this link, or further down the route, is violated). 


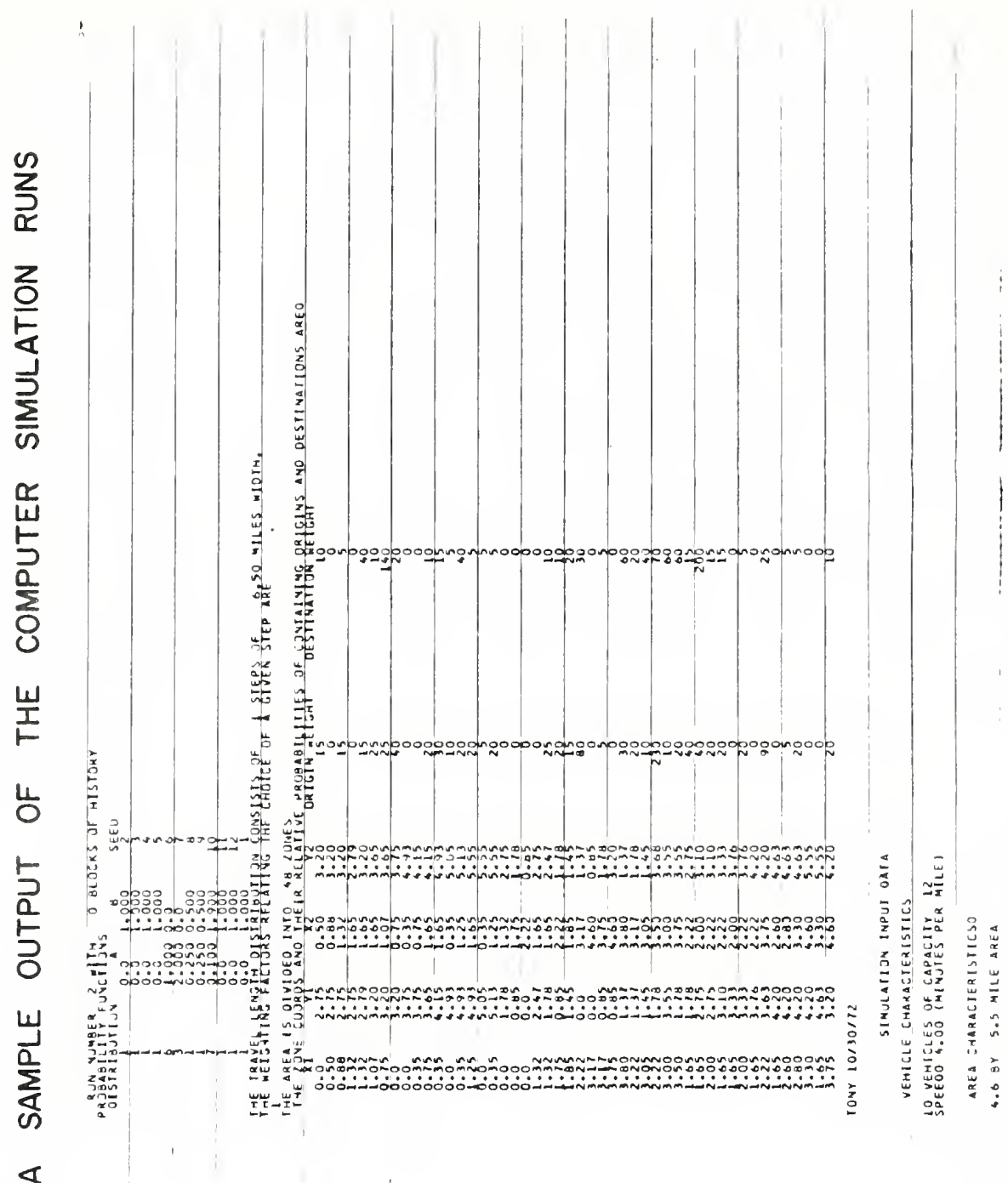

d 


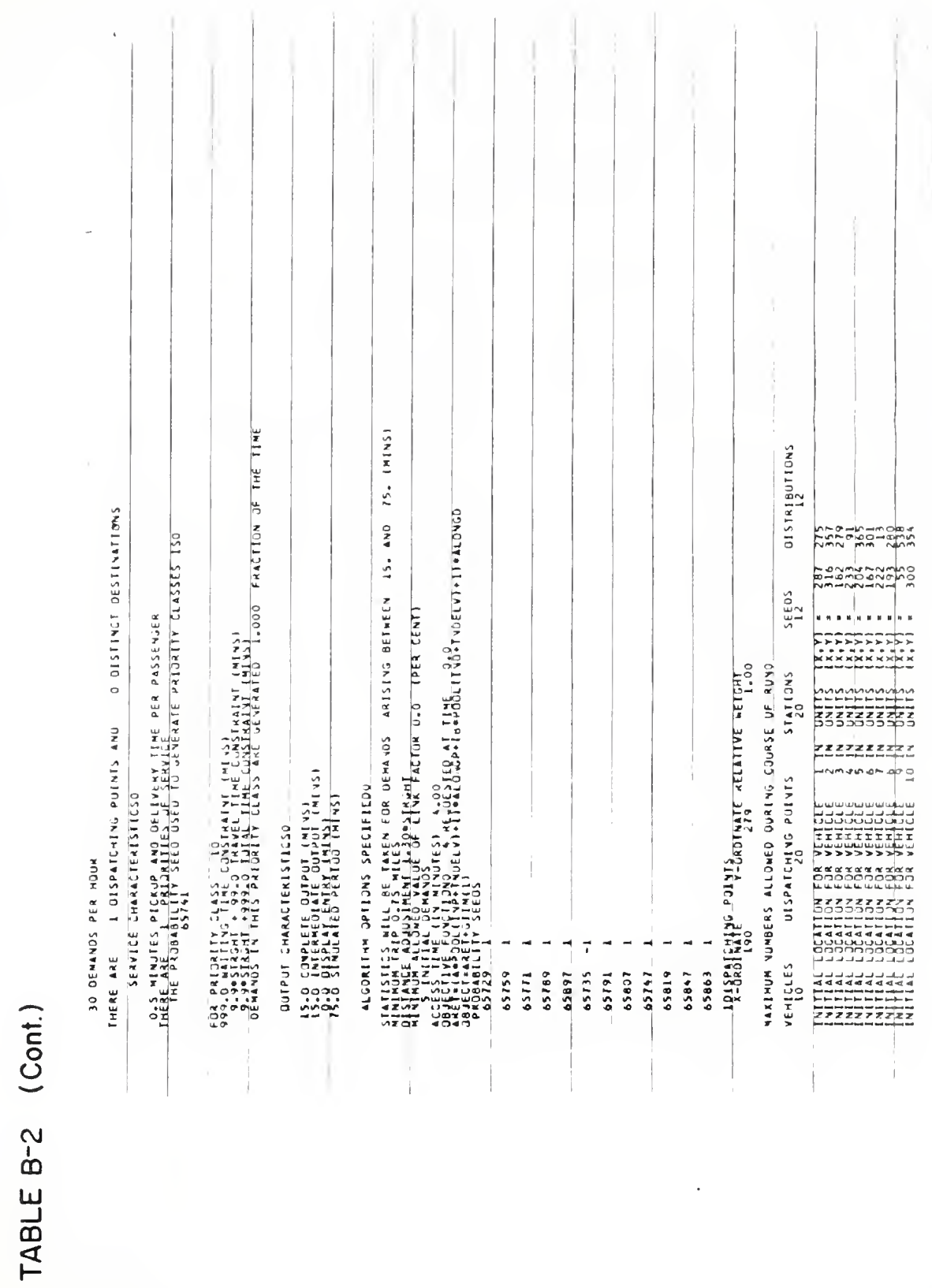




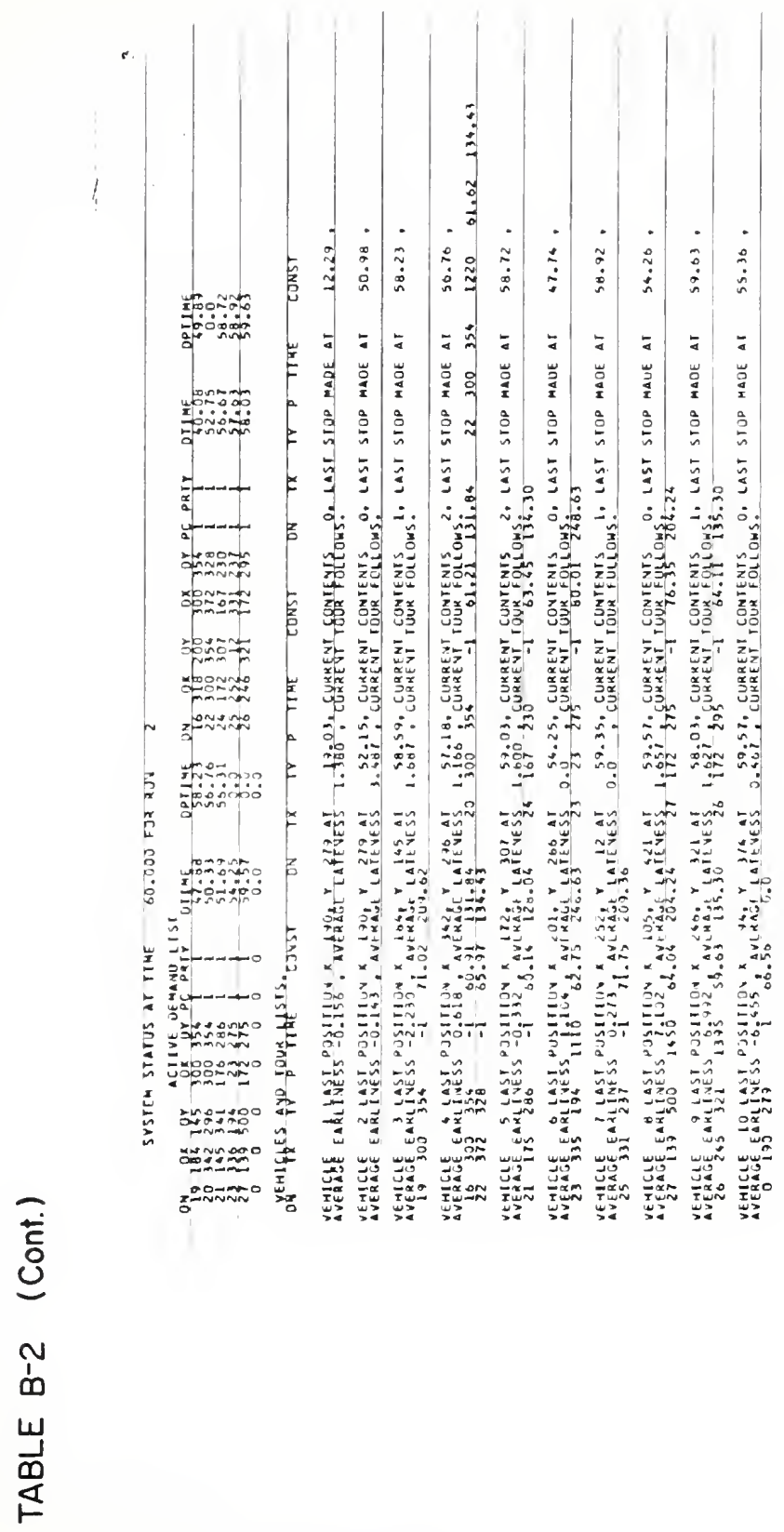




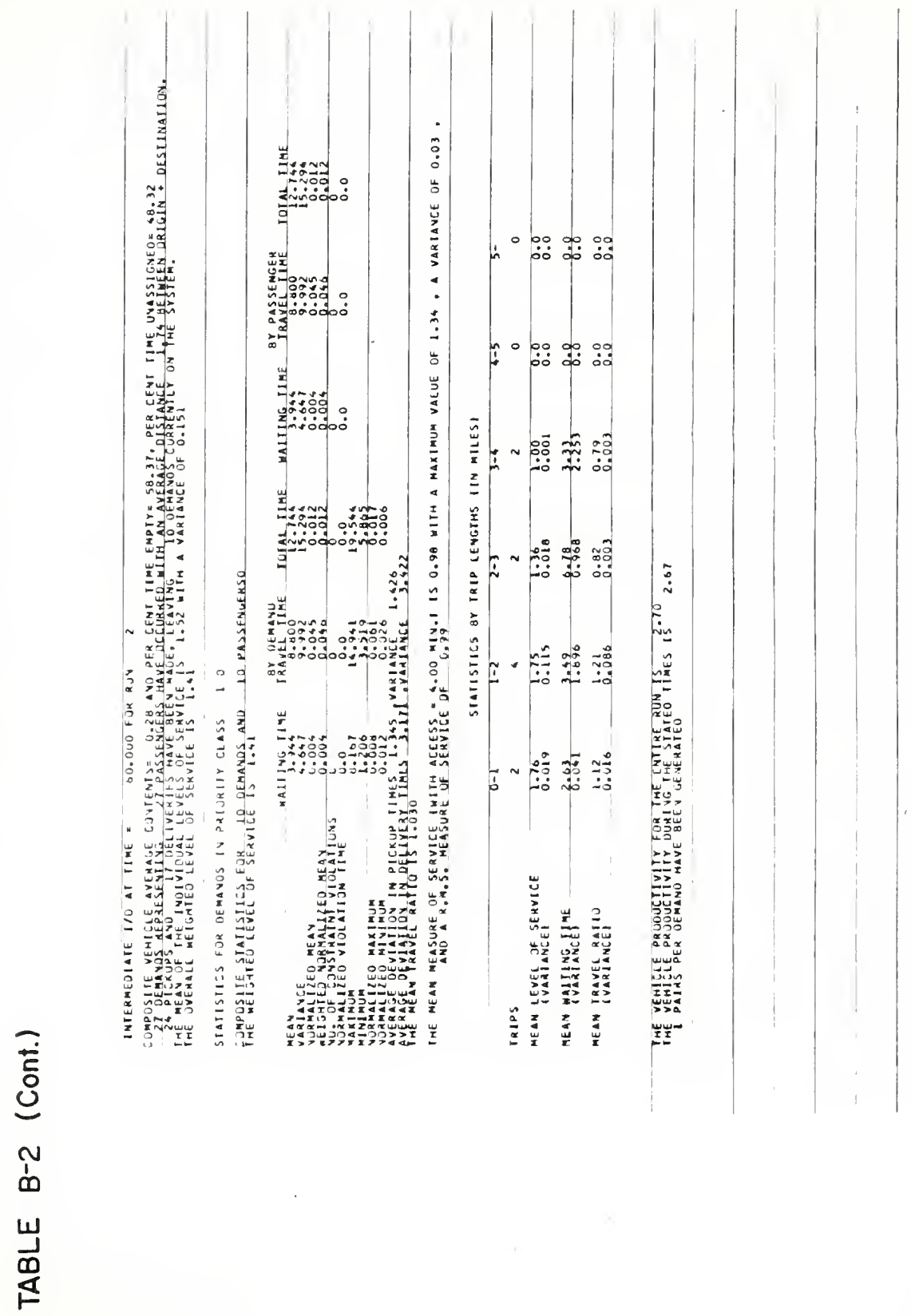




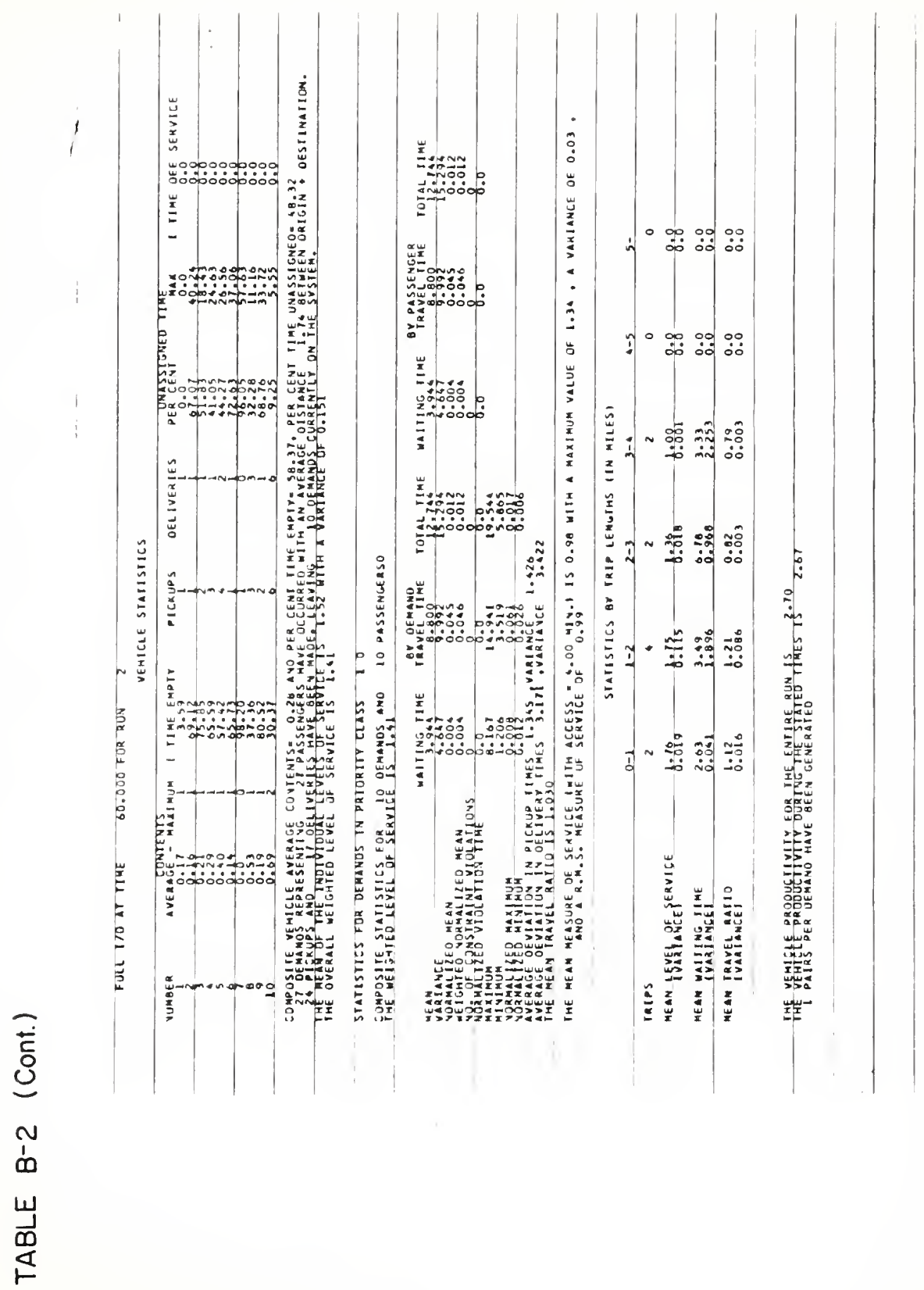




\section{APPENDIX C}

This appendix shows the Dial-A-Ride simulation zones, their demographic characteristics, their coordinates, their relative probability weights of containing origins and destinations, and the desire lines of travel for 60 demands per hour for the different simulation runs. 


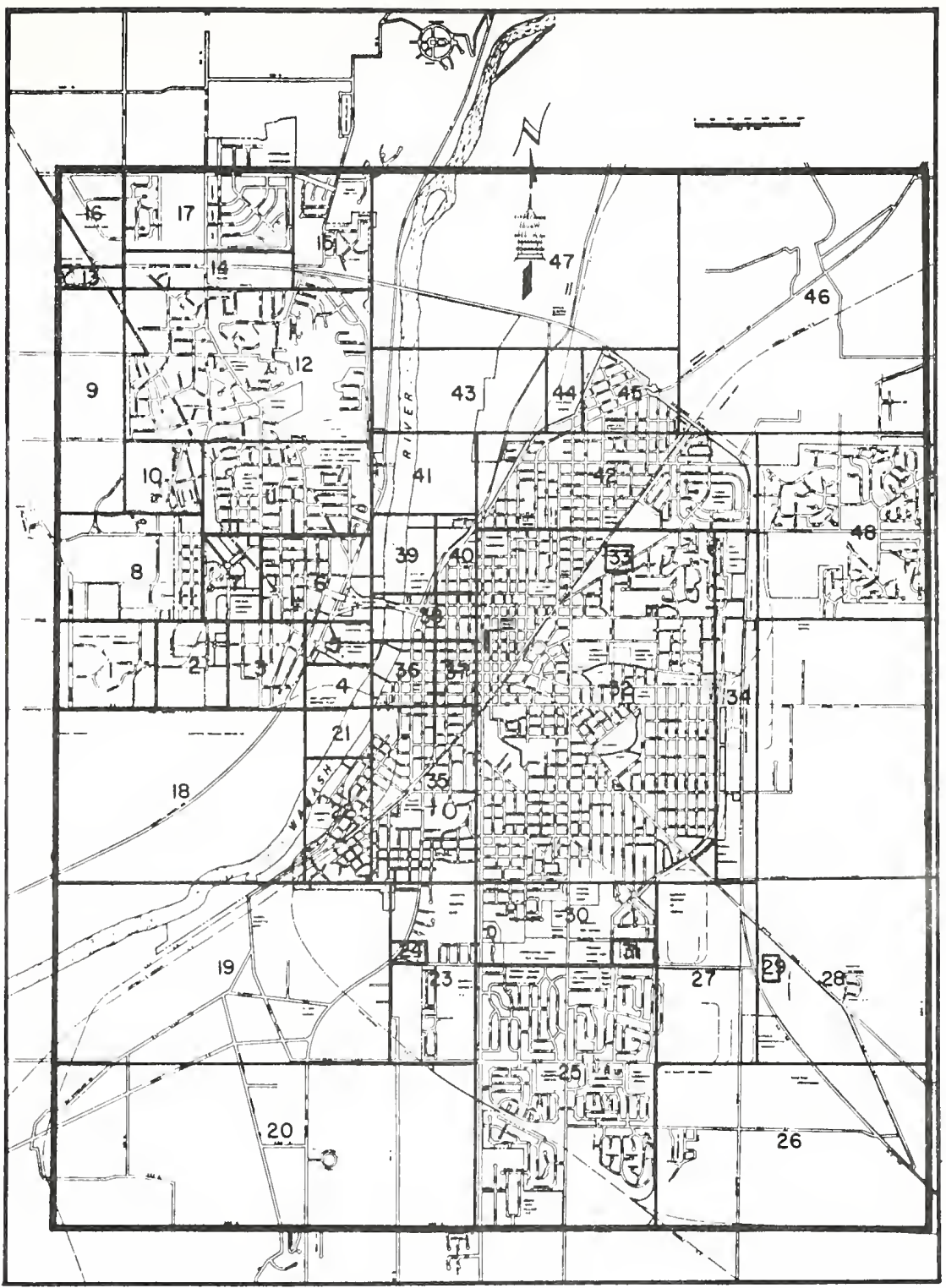

FIGURE C-I DIAL-A-RIDE SIMULATION ZONES 


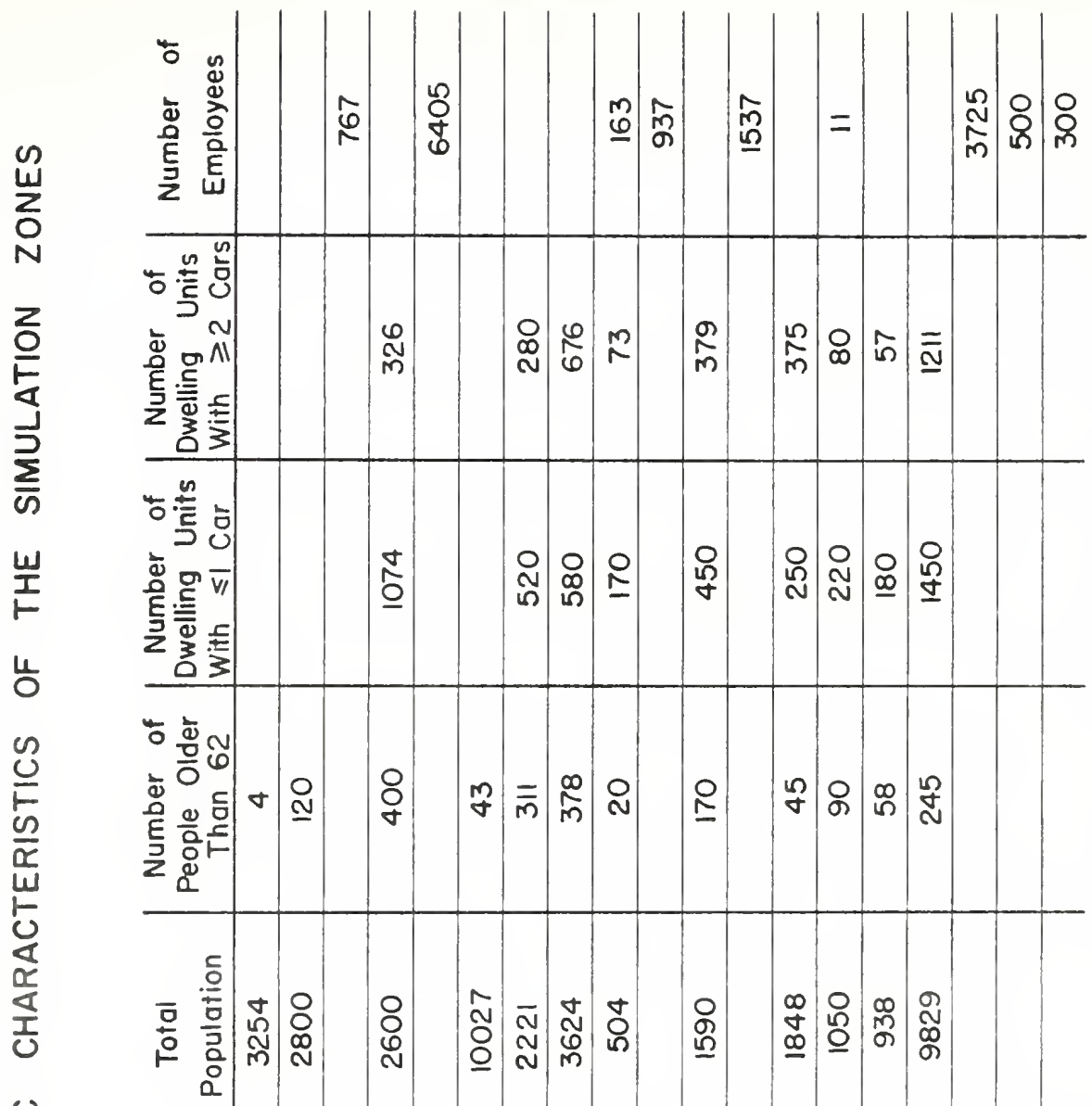

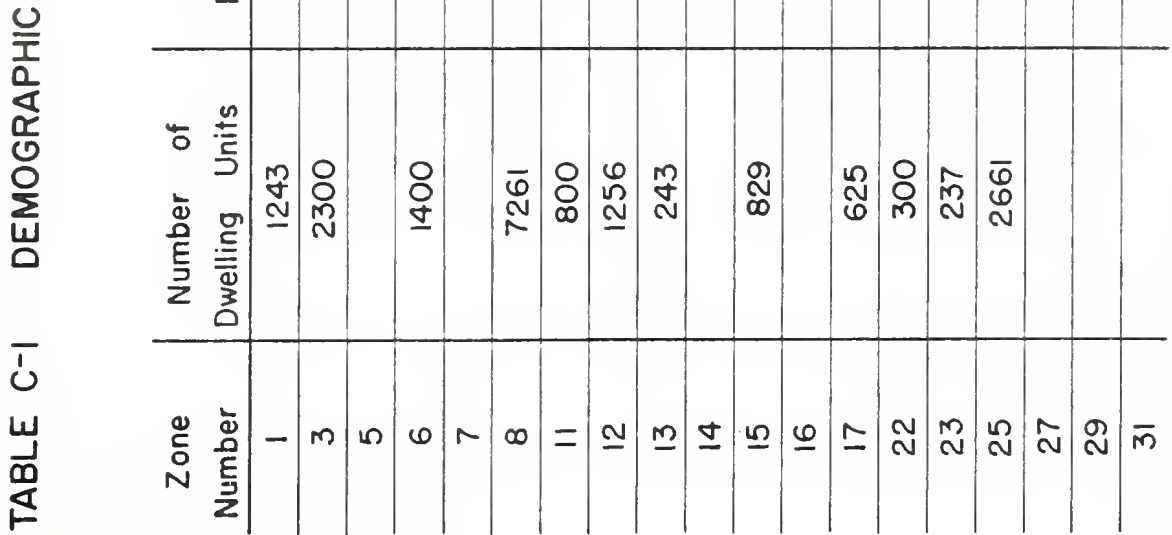




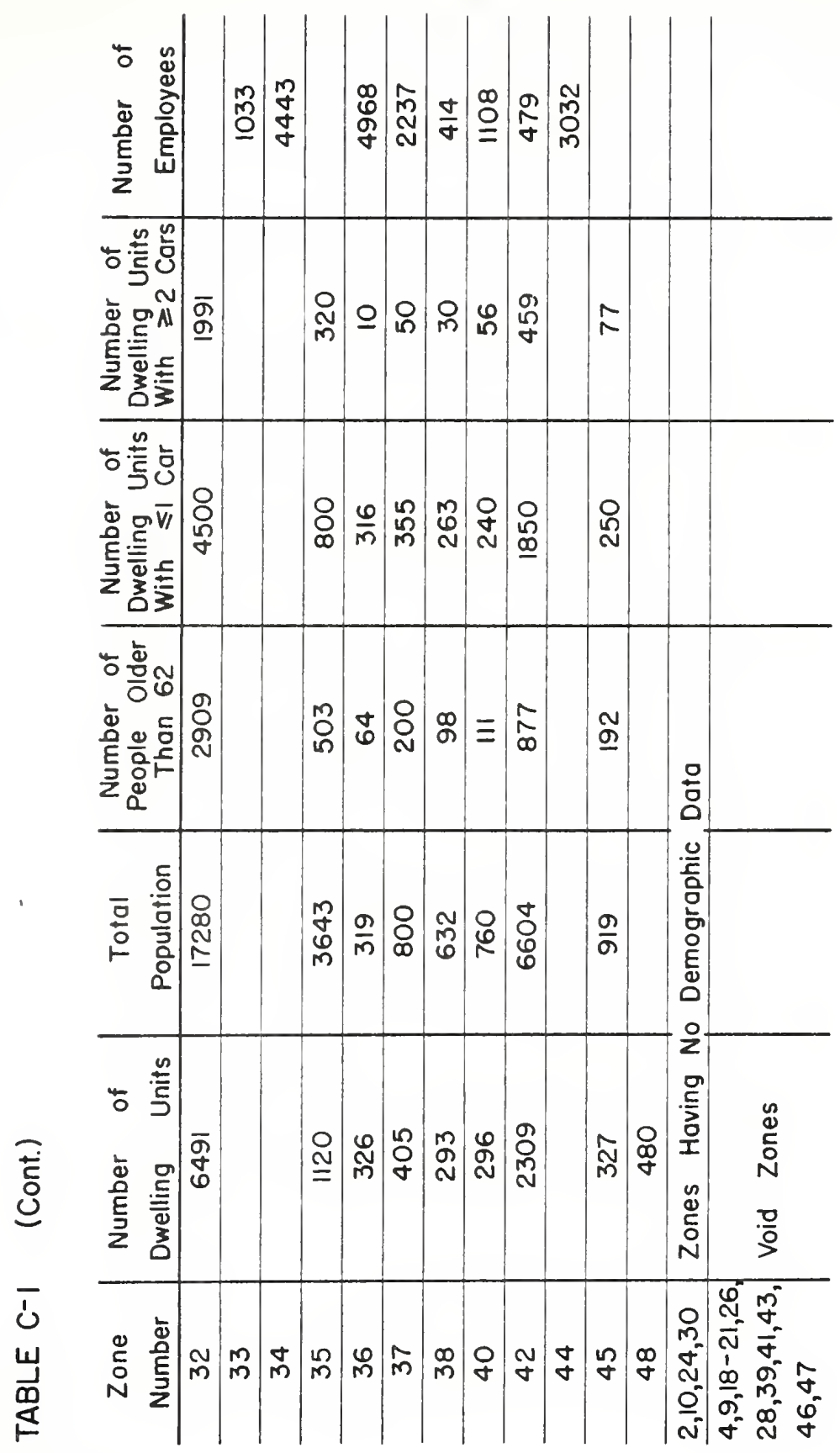




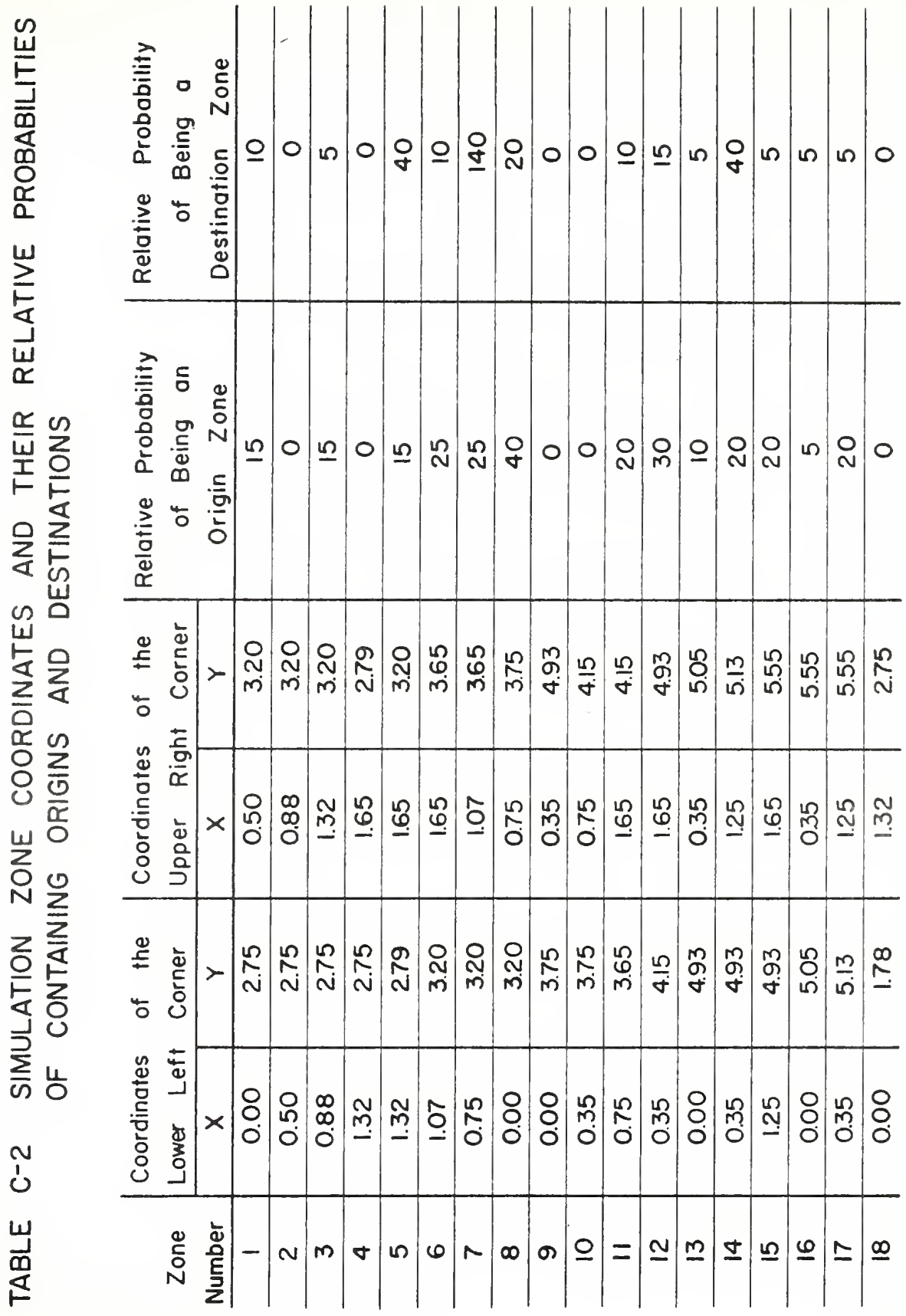




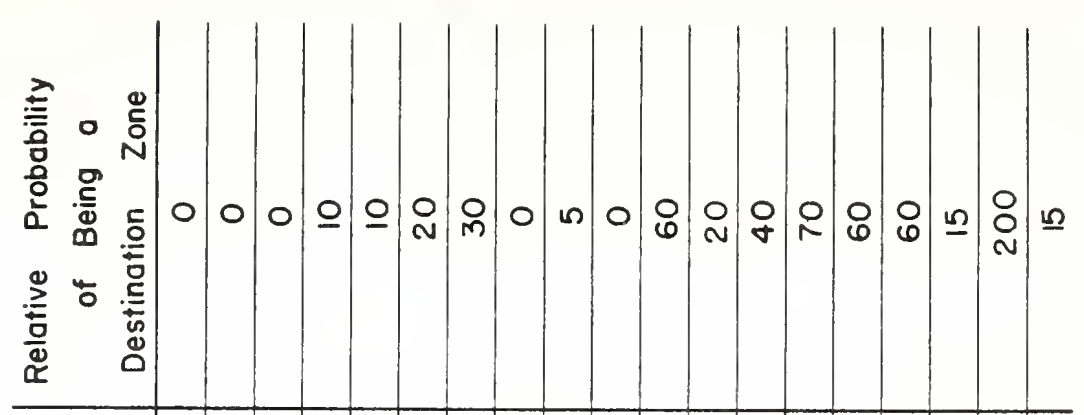

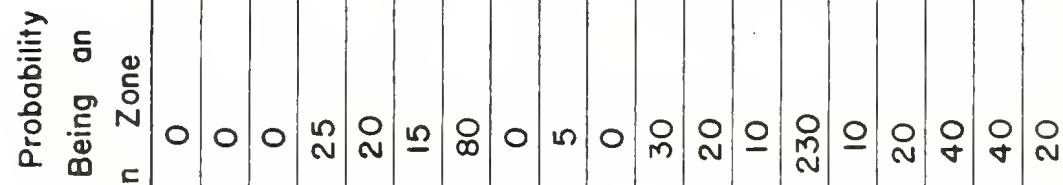
妾立

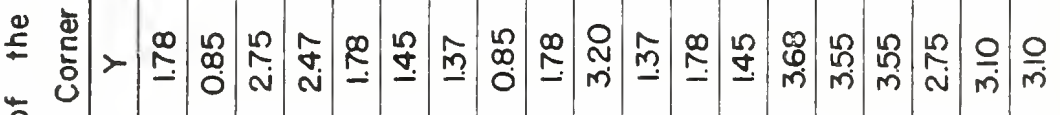

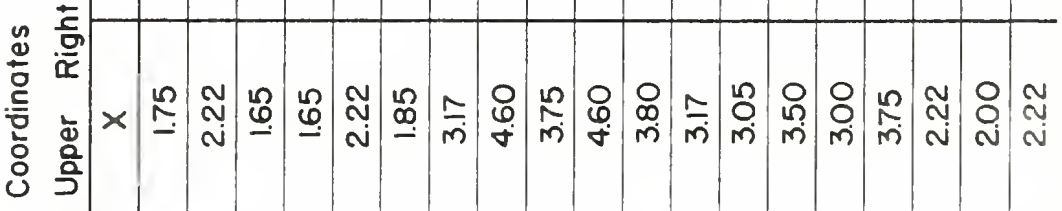

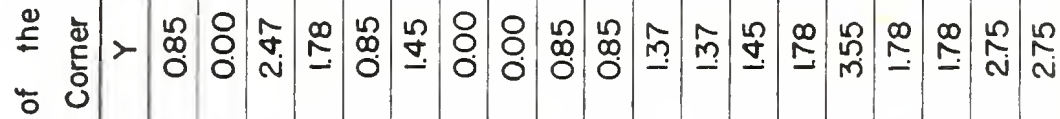

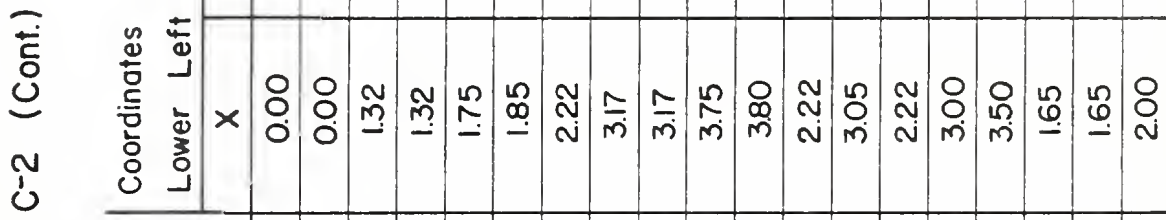

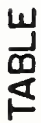

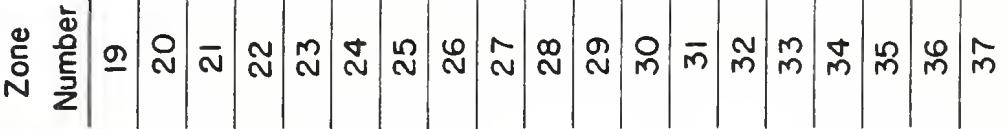




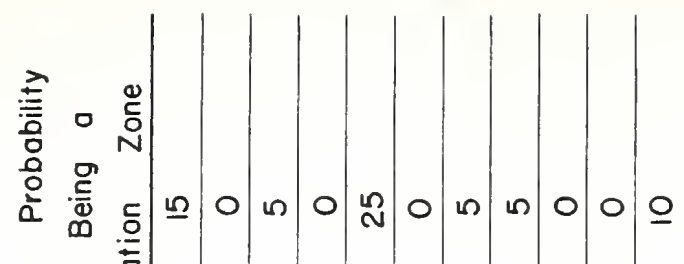

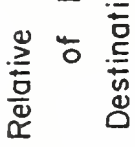

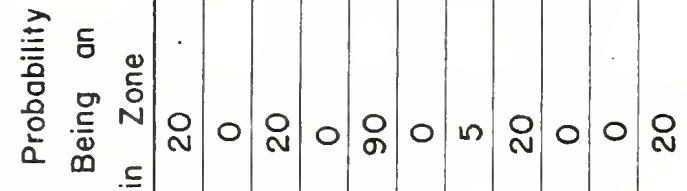

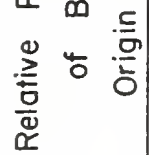

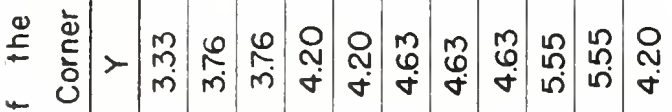

당

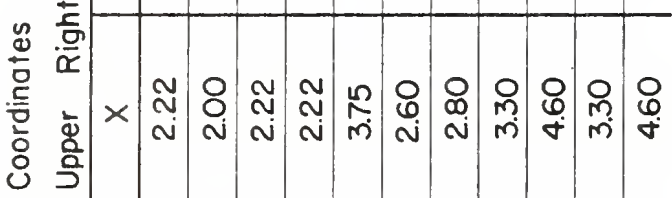

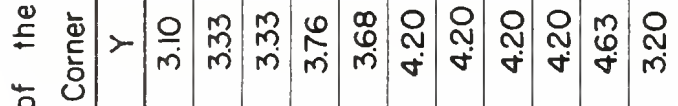

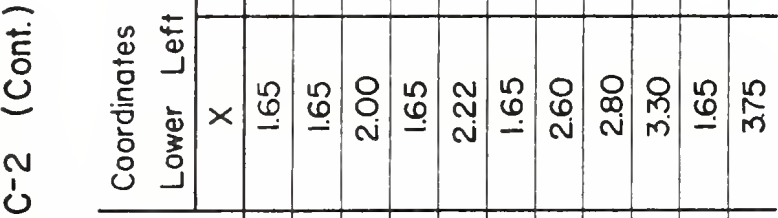

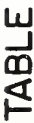

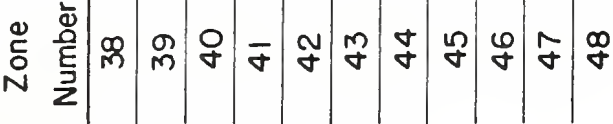




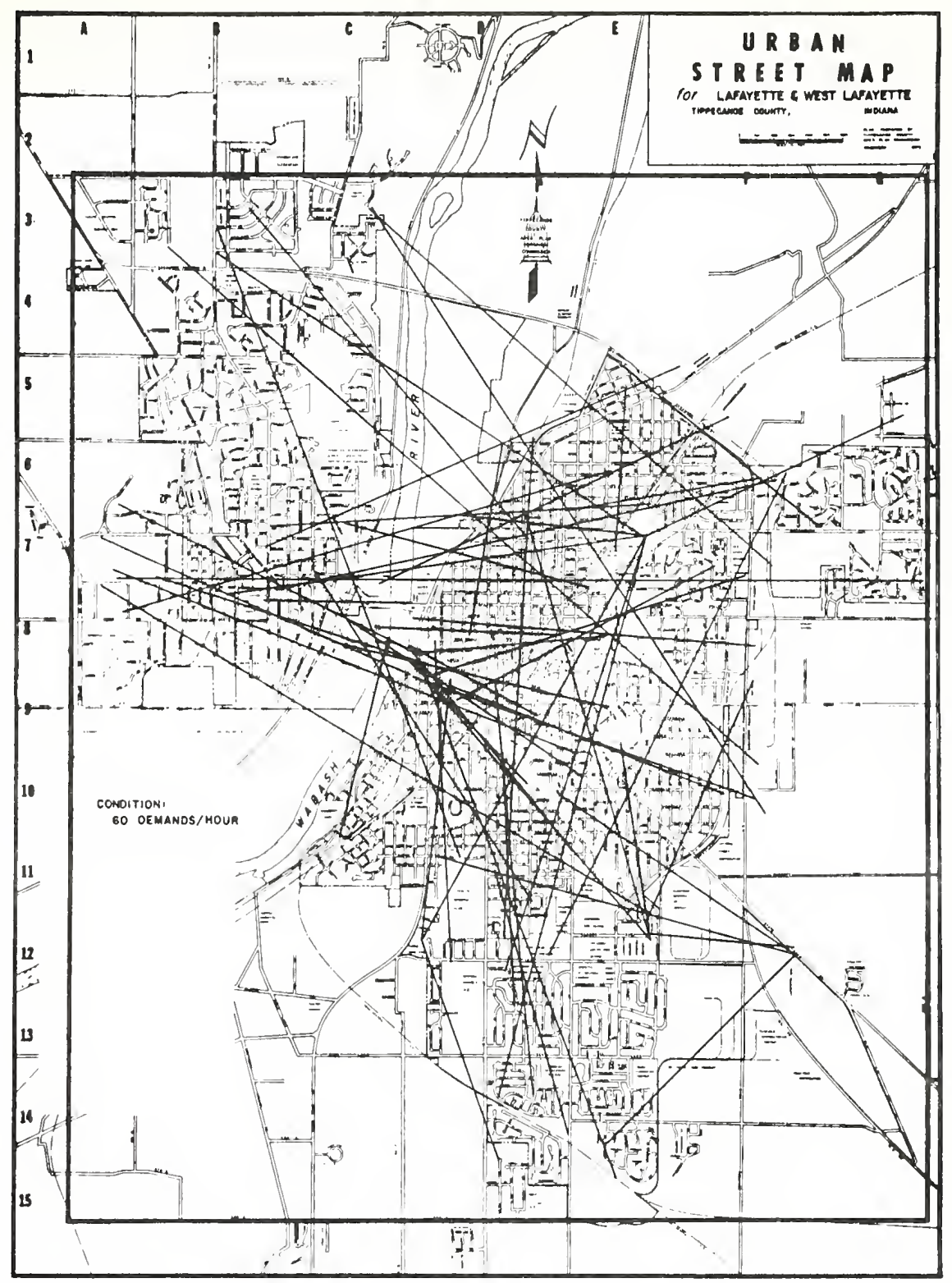

FIGURE C-2 DESIRE LINES OF TRAVEL OF SIMULATION RUN NUMBER I 


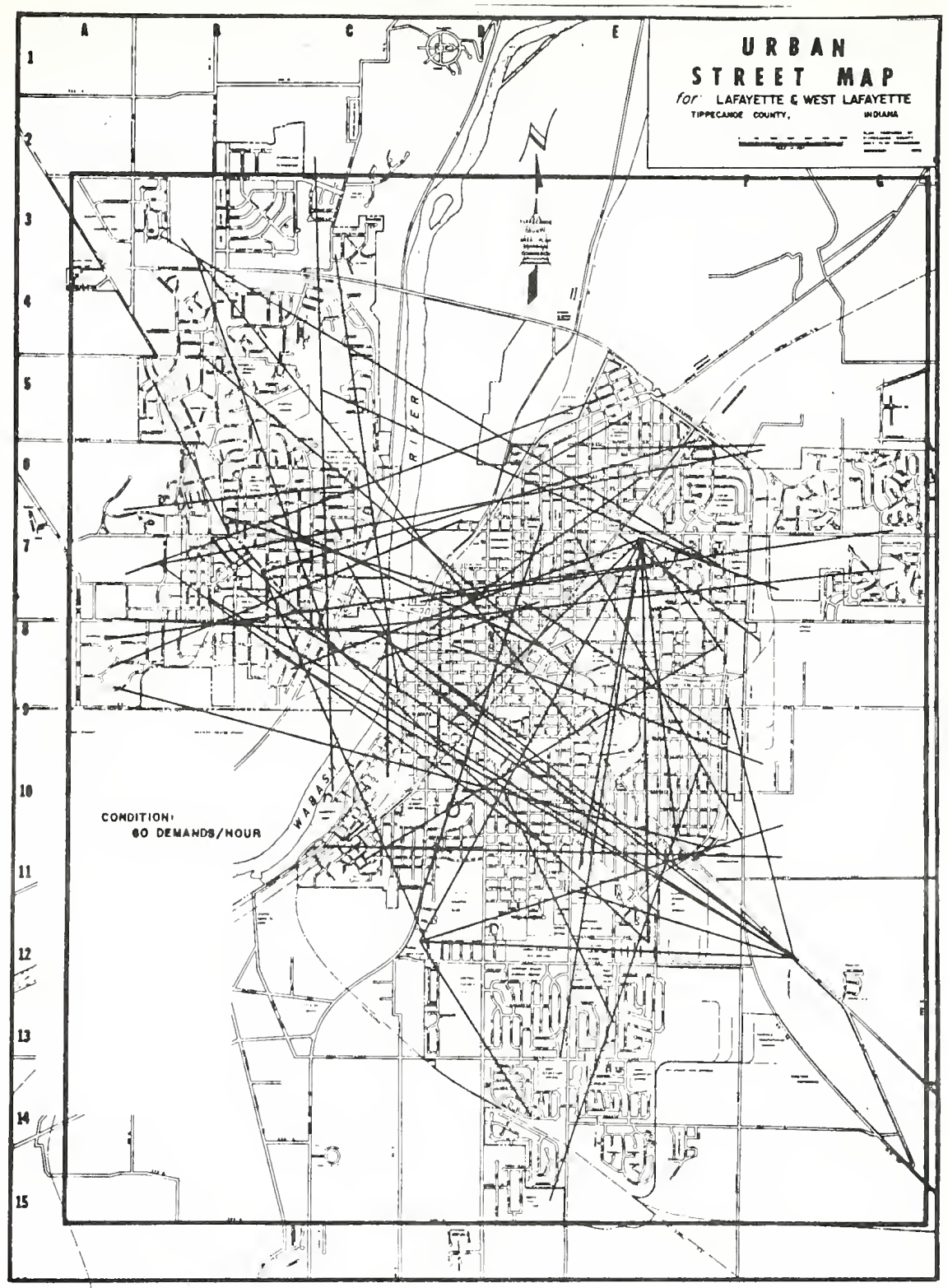

FIGURE C-3 DESIRE LINES OF TRAVEL OF SIMULATION RUN NUMBER 2 


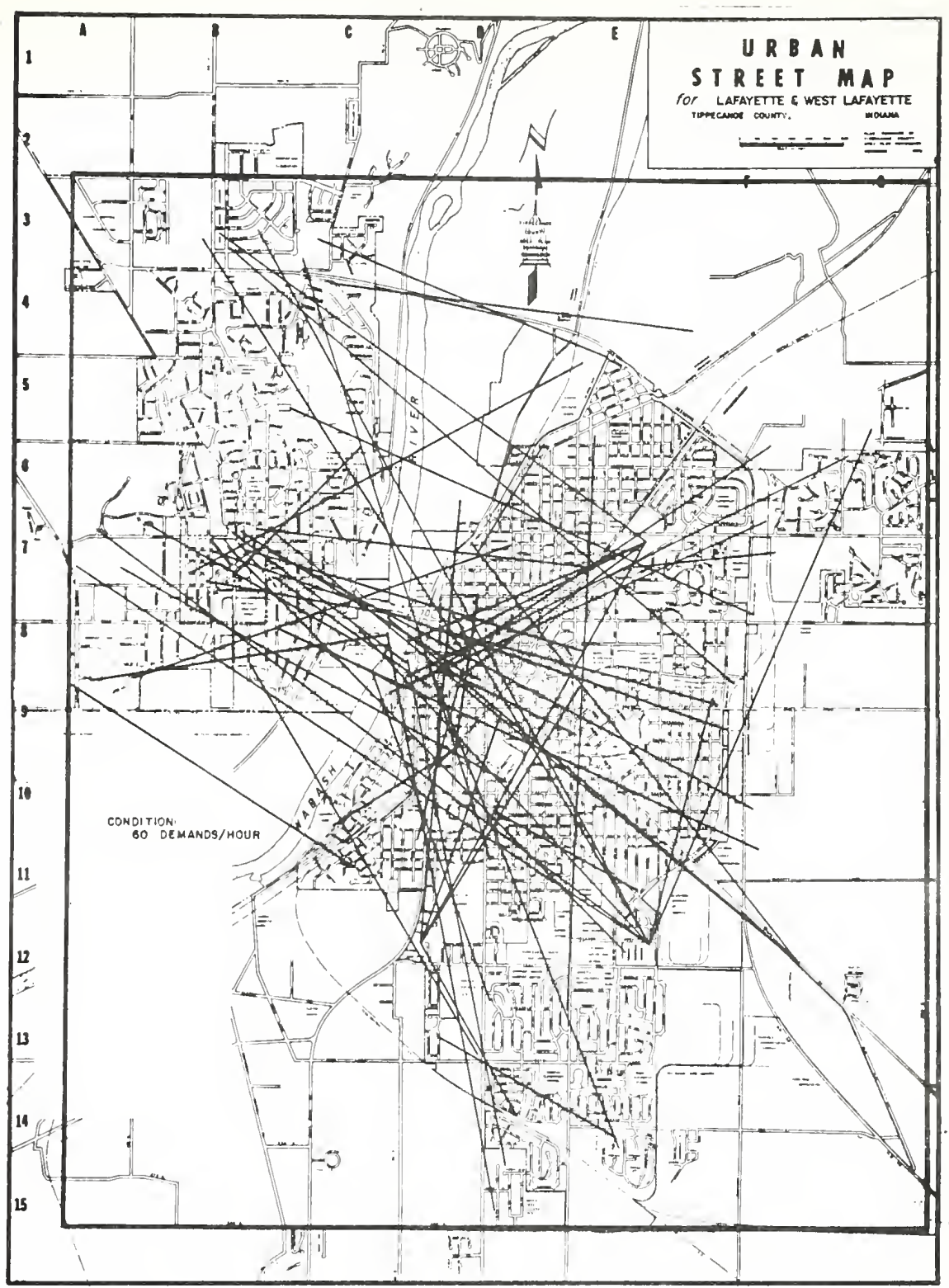

FIGURE C-4 DESIRE LINES OF TRAVEL OF SIMULATION RUN NUMBER 3 


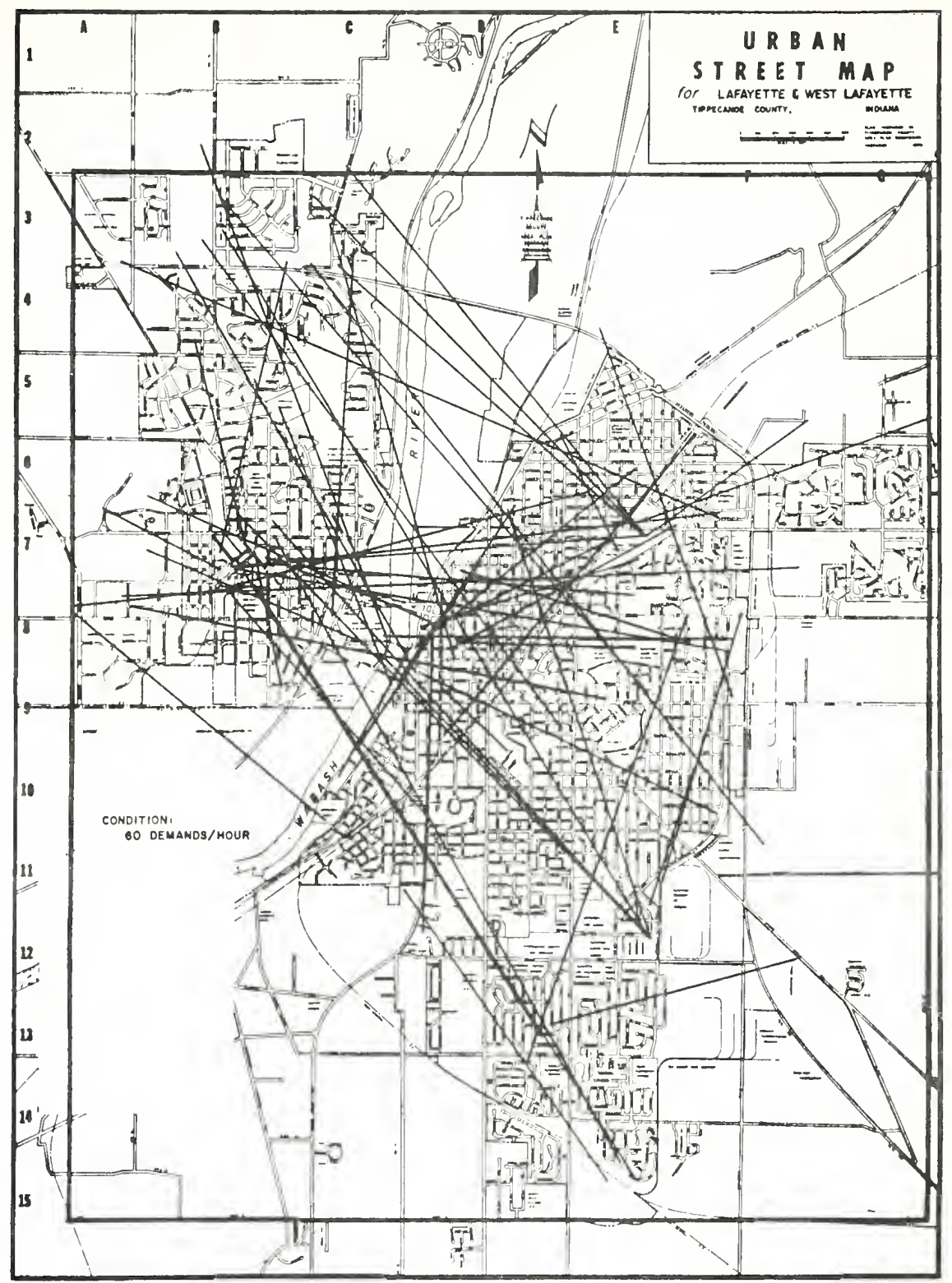

FIGURE C-5 DESIRE LINES OF TRAVEL OF SIMULATION RUN NUMBER 4 
APPENDIX D

Appendix $D$ tabulates the results of the different simulation experiments. 


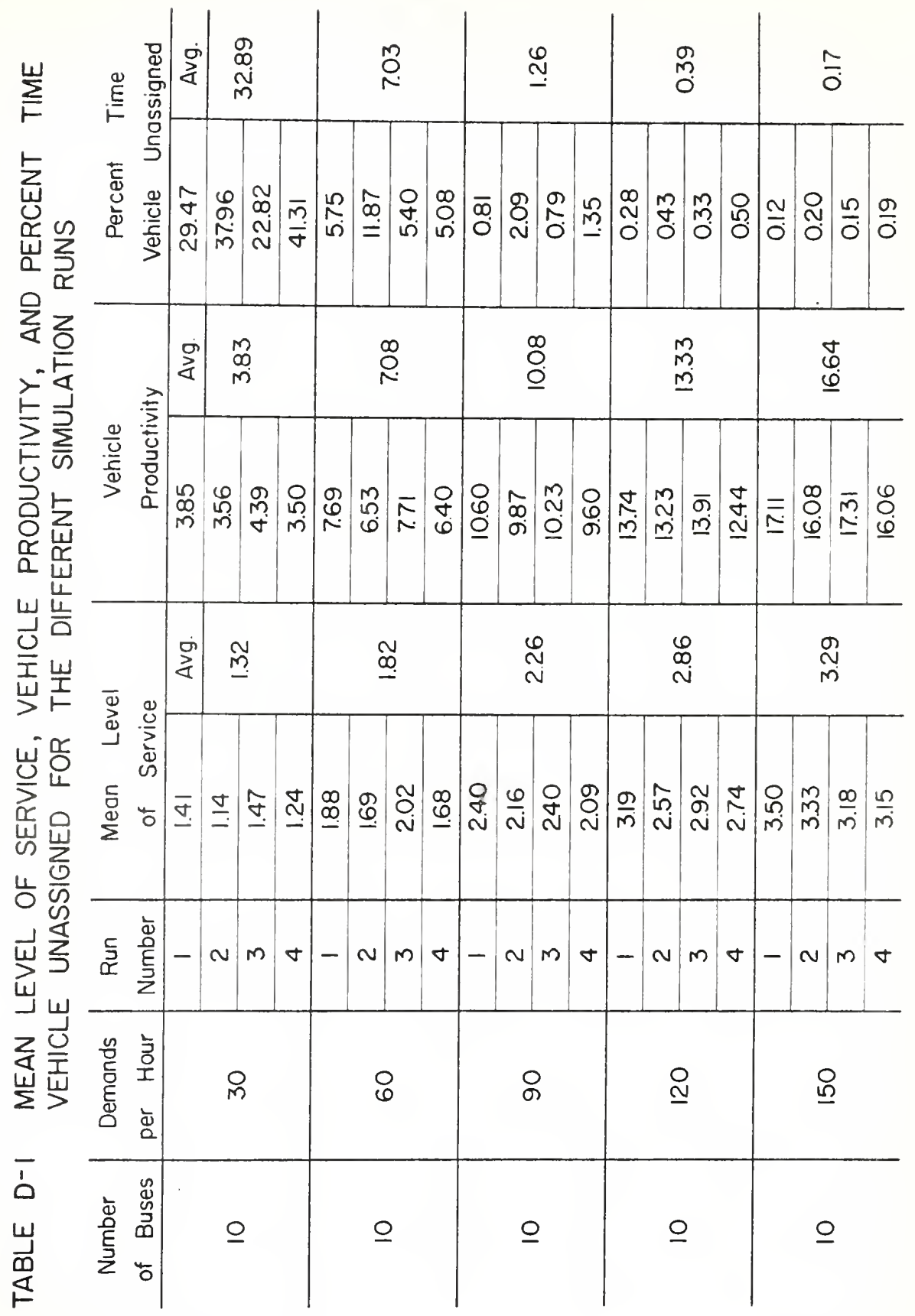




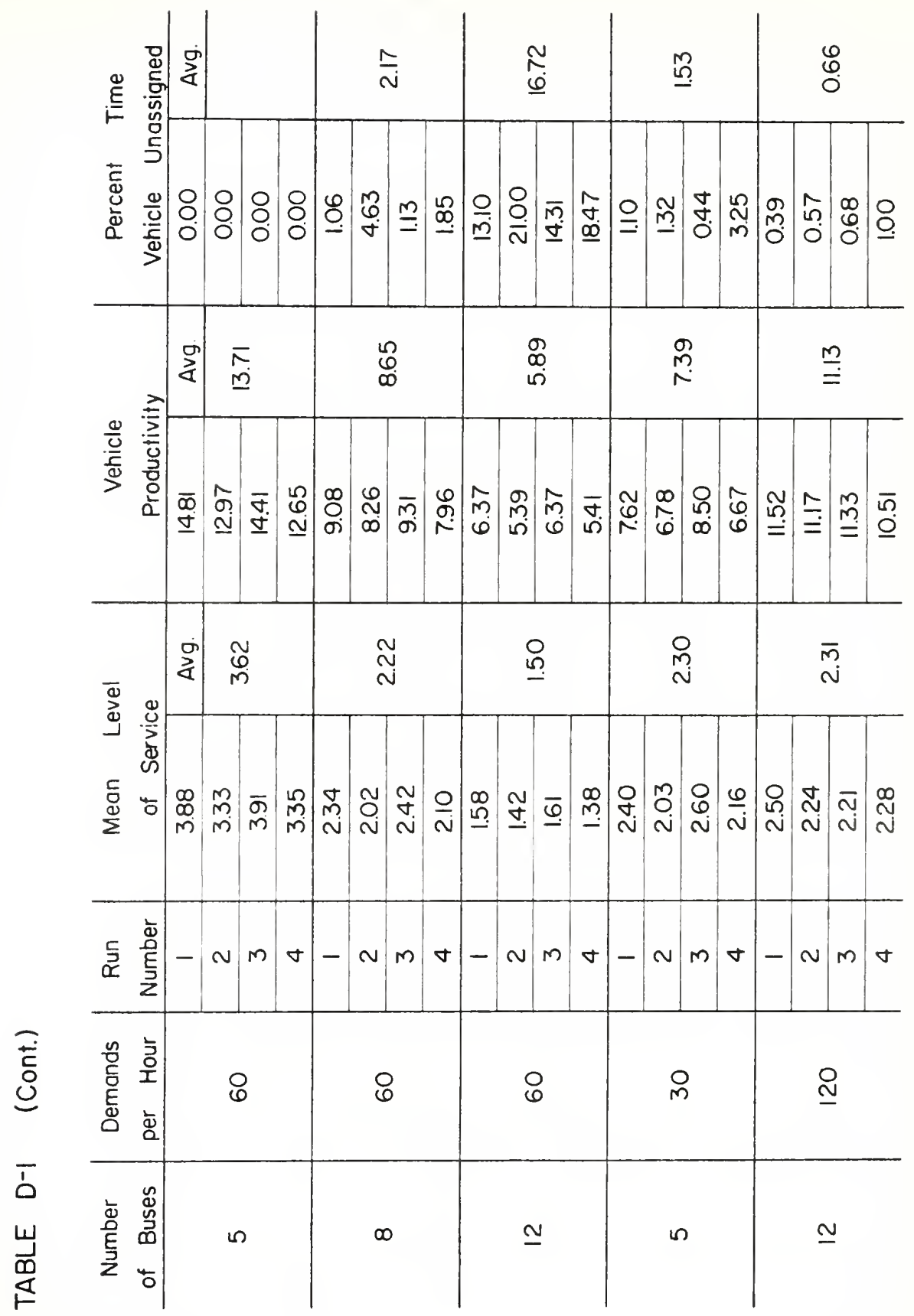




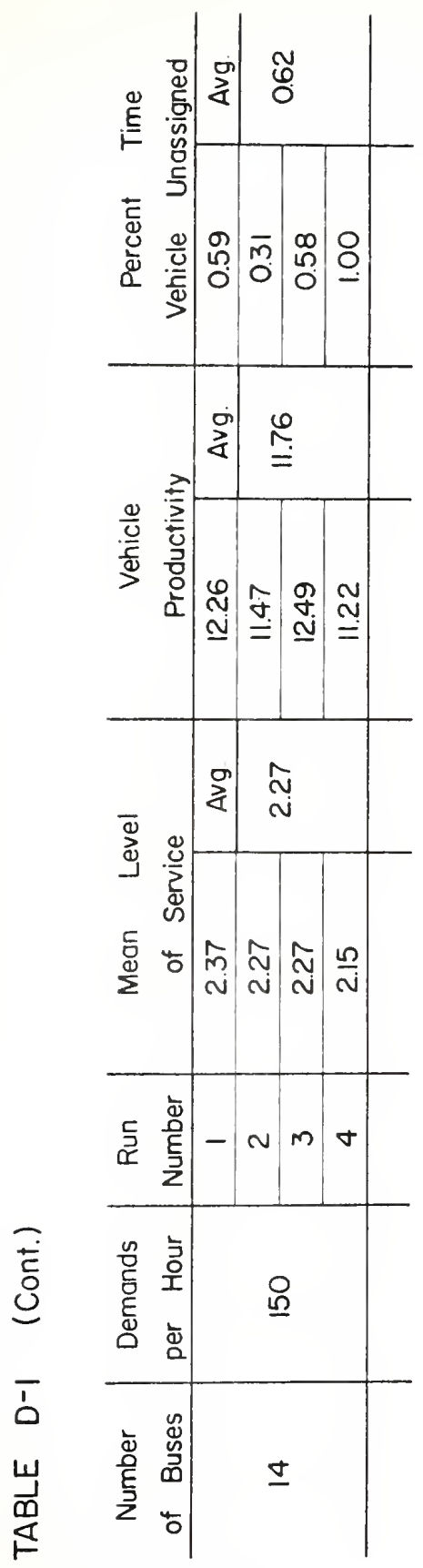




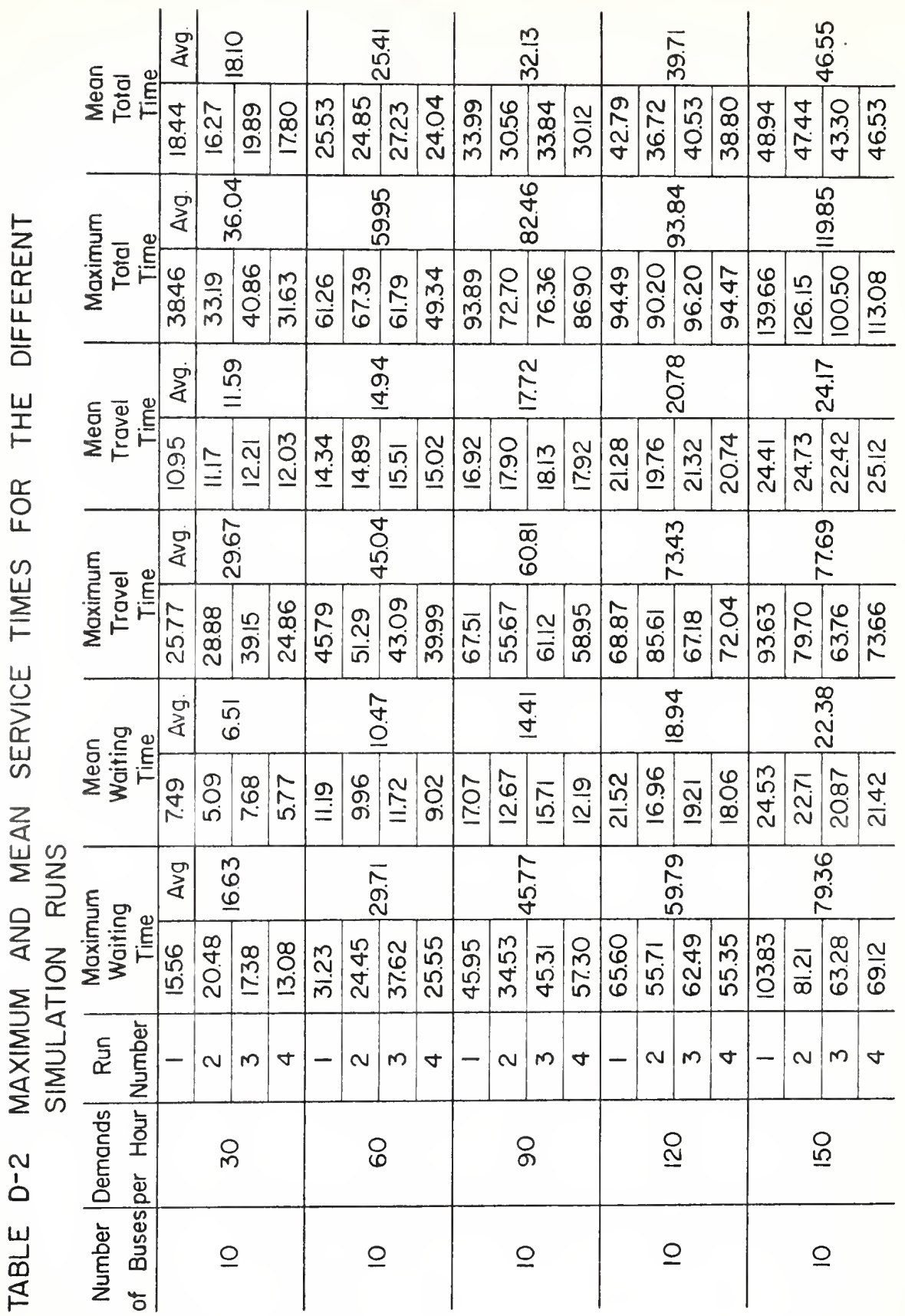




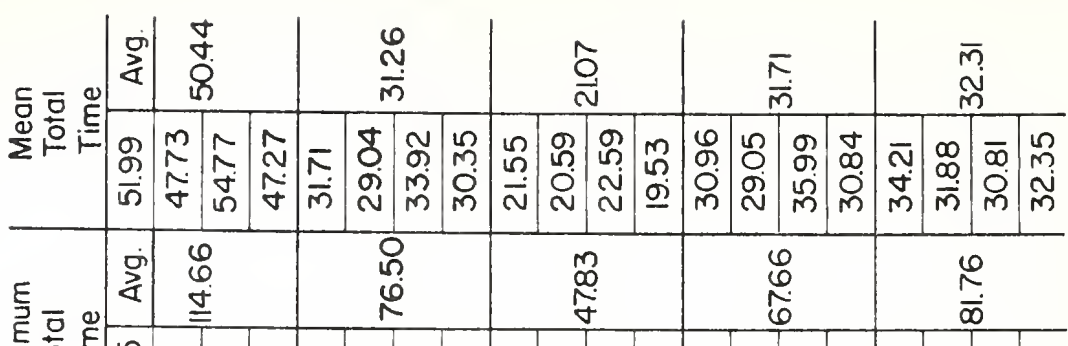

\begin{tabular}{|c|c|c|c|c|c|c|c|c|c|c|c|c|c|}
\hline 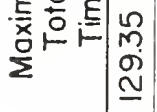 & $\begin{array}{ll}\dot{\sigma} & m \\
\dot{\sigma} & \Omega \\
\underline{D} & \underline{D}\end{array}$ & $\begin{array}{l}\mathfrak{N} \\
\sigma \\
\overline{\overline{0}}\end{array}$ & $\left|\begin{array}{l}0 \\
\sigma \\
\mathfrak{R} \\
\end{array}\right|$ & \begin{tabular}{|c|c}
0 & $\alpha$ \\
0 & $\alpha$ \\
0 & $\alpha$ \\
0
\end{tabular} & \begin{tabular}{l|l}
0 & 0 \\
& $\infty$ \\
0 & $\infty$ \\
0
\end{tabular} & $\frac{0}{0}$ & 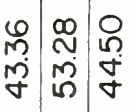 & 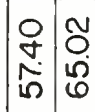 & 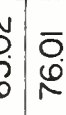 & $\frac{a}{N}$ & $\left|\begin{array}{l}0 \\
i \\
\sim \\
\infty \\
\infty\end{array}\right|$ & \begin{tabular}{l|l}
$\omega$ & $r$ \\
$n$ & \multicolumn{1}{c}{} \\
$\infty$ & \multicolumn{1}{c}{} \\
$\infty$ & $n$ \\
$\sigma$ & $n$
\end{tabular} & 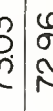 \\
\hline$\frac{9}{4}$ & 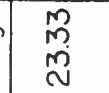 & & & $\begin{array}{l}\mathscr{M} \\
\infty \\
\underline{\varphi}\end{array}$ & & & $\underline{\underline{m}}$ & & $\begin{array}{l}m \\
\stackrel{m}{0} \\
\underline{n}\end{array}$ & & & 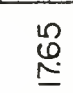 & \\
\hline
\end{tabular}

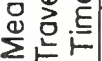

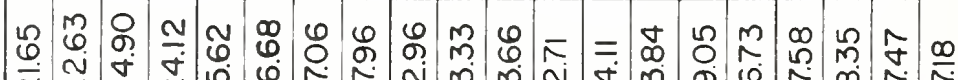

\begin{tabular}{|c|c|c|c|c|c|c|c|c|c|c|c|c|c|c|c|c|}
\hline \multirow[b]{2}{*}{ 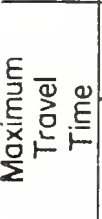 } & 㲾 & \multicolumn{2}{|l|}{$\bar{m}$} & \multicolumn{4}{|c|}{$\begin{array}{l}\tilde{N} \\
0 \\
0\end{array}$} & \multicolumn{3}{|c|}{ 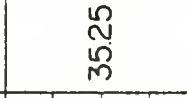 } & \multicolumn{3}{|c|}{$\begin{array}{l}\hat{\infty} \\
\stackrel{\mathcal{J}}{\mathcal{Y}} \\
\end{array}$} & \multicolumn{3}{|c|}{$\begin{array}{l}\hat{0} \\
\infty \\
0 \\
0\end{array}$} \\
\hline & $\begin{array}{ll}\stackrel{N}{n} \\
\stackrel{n}{=} \\
\end{array}$ & 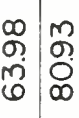 & 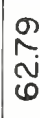 & 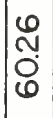 & $\begin{array}{l}O \\
N \\
m \\
n\end{array}$ & $\underset{n}{n}$ & 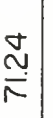 & \begin{tabular}{l}
\multirow{2}{0}{} \\
ஸे.
\end{tabular} & 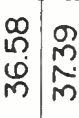 & న్ & 胥 & \begin{tabular}{l|l}
$\infty$ & 0 \\
$n$ & $n$ \\
$\sim$ & $\alpha$ \\
$m$ & $\alpha$
\end{tabular} & $\left\{\begin{array}{l}\hat{\infty} \\
\sim \\
\sim\end{array}\right.$ & $\begin{array}{l}\mathscr{W} \\
\sigma \\
\omega \\
R\end{array}$ & 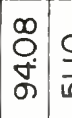 & $\frac{7}{5}$ \\
\hline & गे & $\frac{N}{N}$ & & & $\begin{array}{l}\stackrel{m}{+} \\
\dot{I}\end{array}$ & & & & 옷 & & & $\begin{array}{l}\stackrel{\infty}{\stackrel{n}{\underline{n}}} \\
\end{array}$ & & & & \\
\hline
\end{tabular}

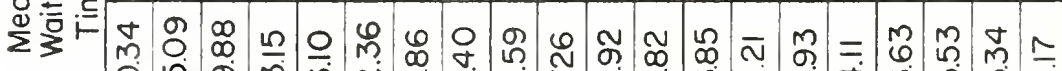

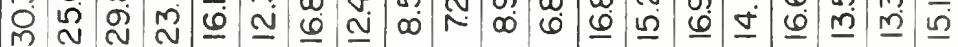

\begin{tabular}{|c|c|c|c|c|c|}
\hline \begin{tabular}{l|l} 
\\
0
\end{tabular} & $\begin{array}{l}\hat{0} \\
\infty \\
\end{array}$ & $\begin{array}{l}m \\
\sigma \\
\sigma\end{array}$ & $\begin{array}{l}\stackrel{\infty}{\infty} \\
\stackrel{n}{N}\end{array}$ & $\begin{array}{l}\stackrel{\sim}{N} \\
\tilde{\sigma} \\
\tilde{\sigma}\end{array}$ & $\stackrel{\bar{n}}{\stackrel{\sim}{\sigma}}$ \\
\hline
\end{tabular}

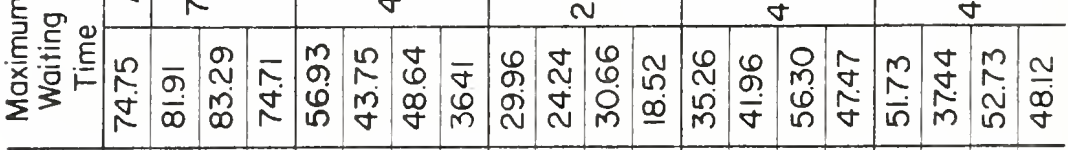

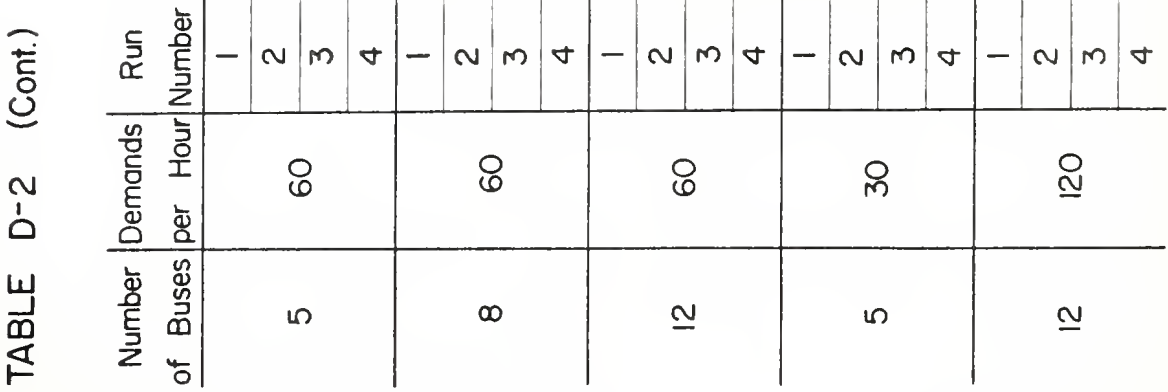




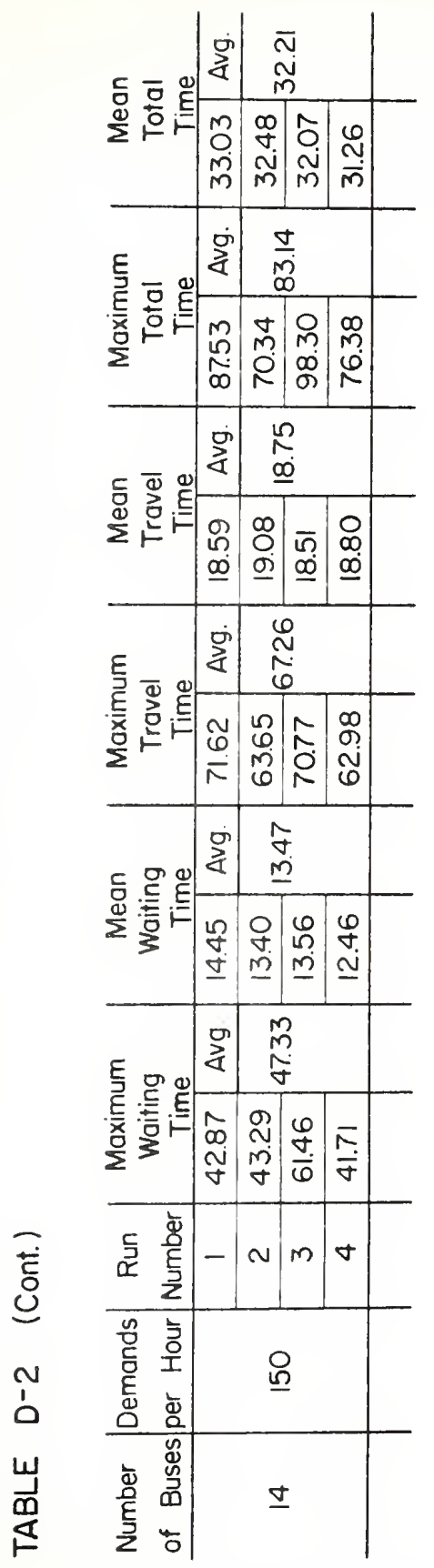




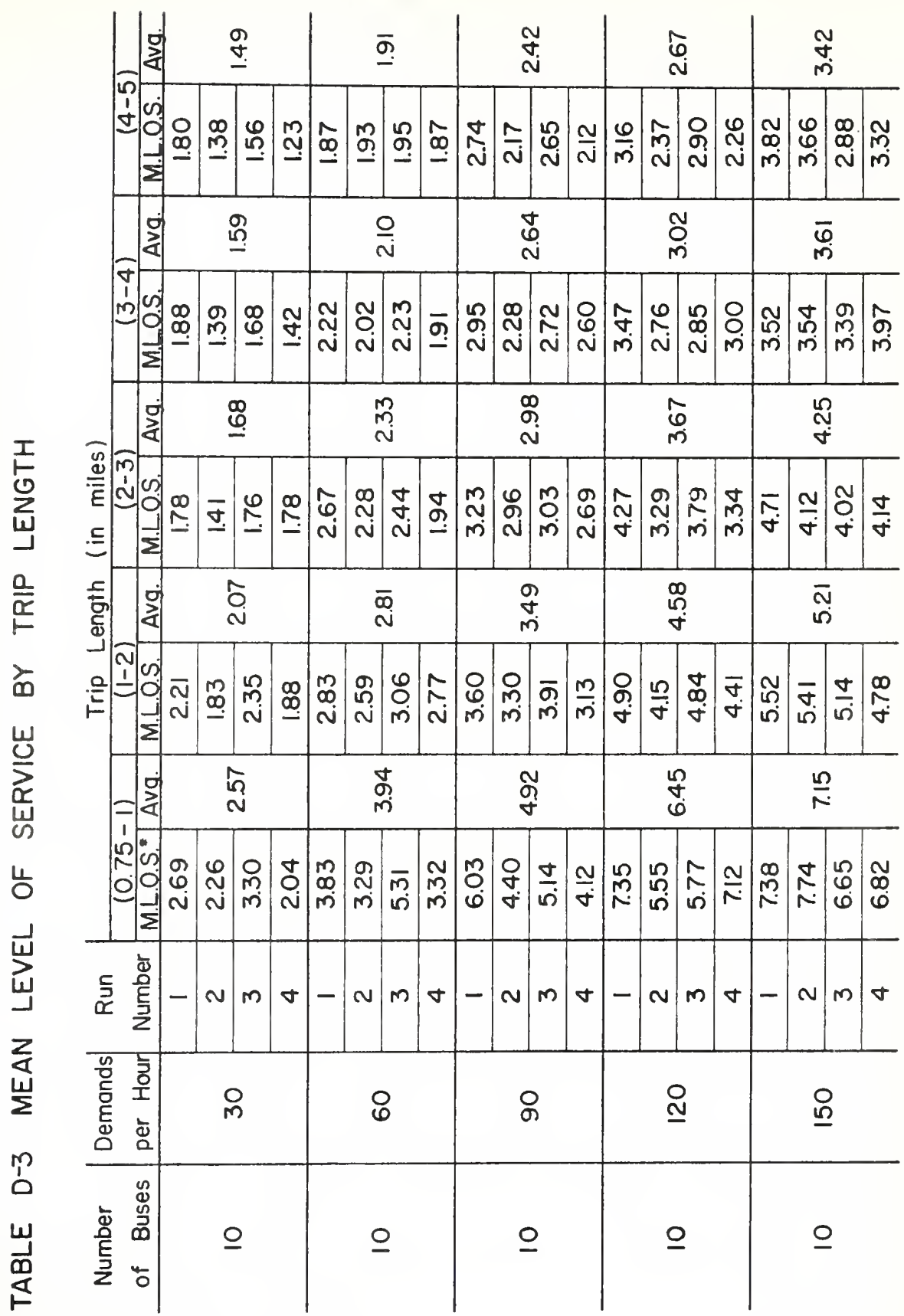




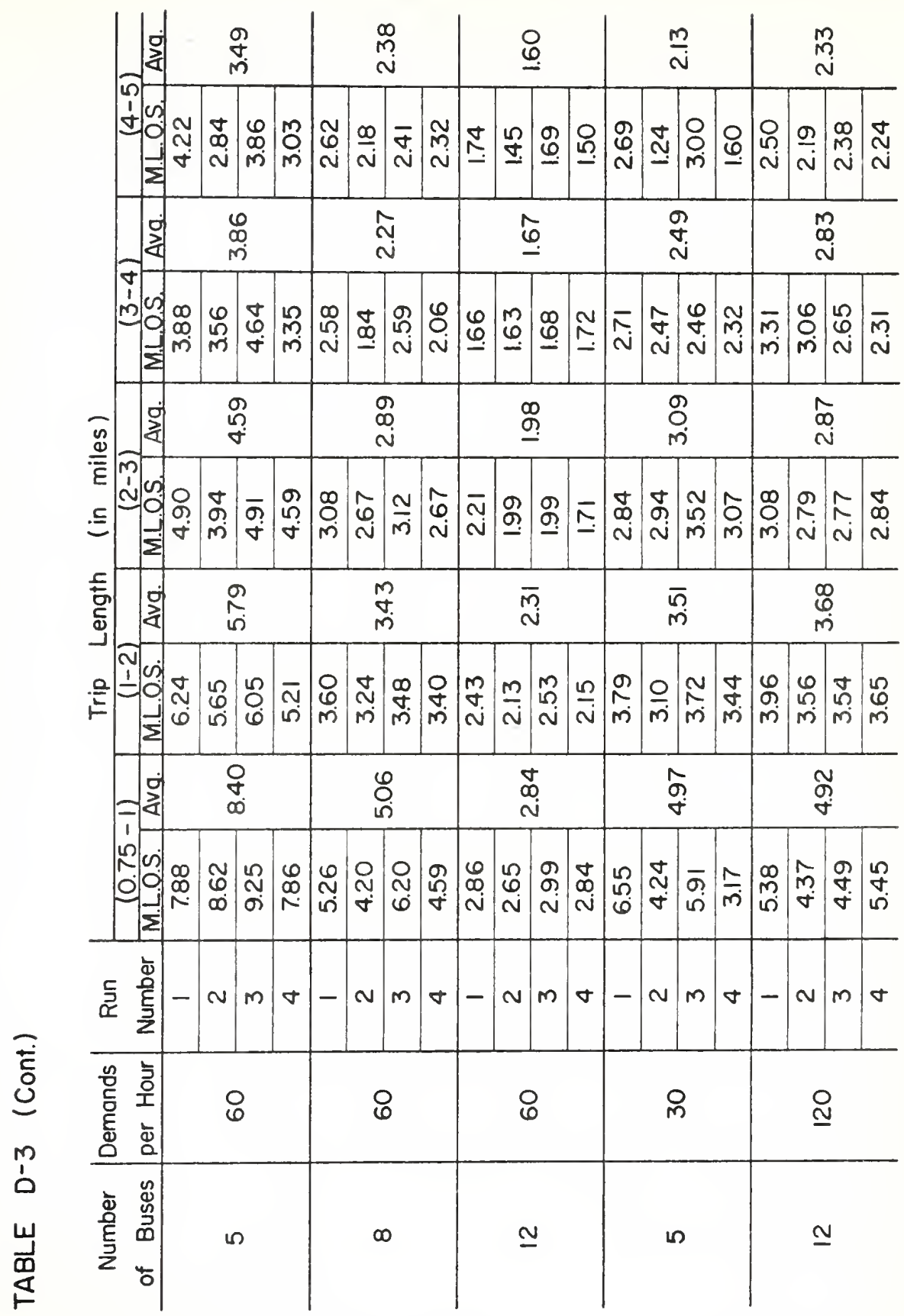




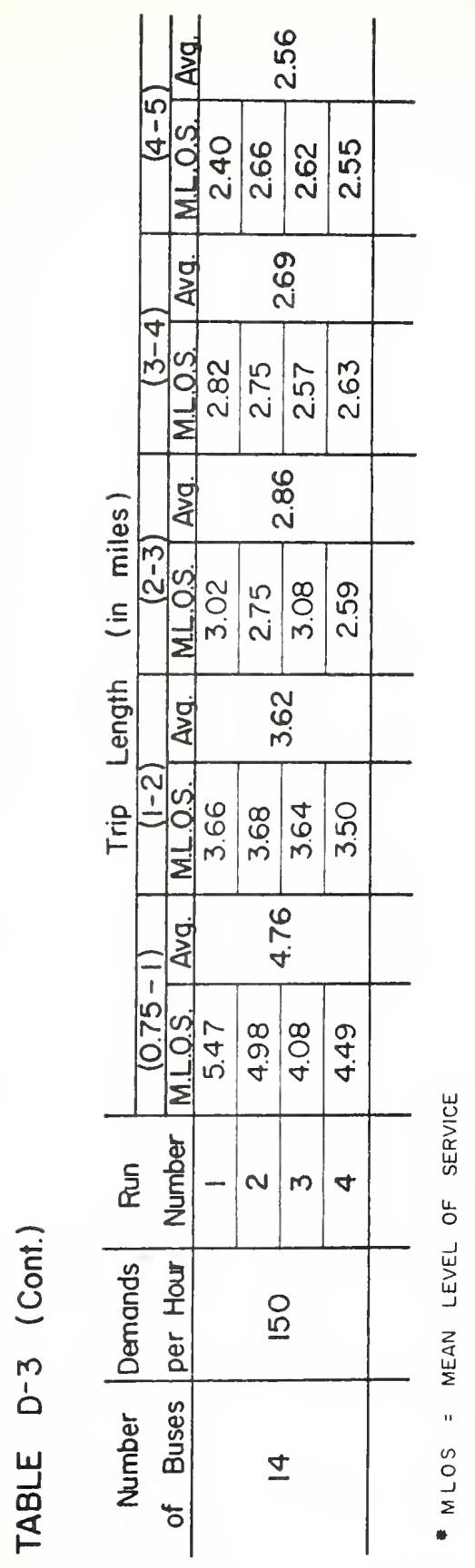


VITA 
VITA

Antoine G. Hobeika was born September 1943 in Homsieh, Lebanon. He completed his secondary education at the International College of Beirut and received his Lebanese Baccalaureate Part II (Mathematics) in 1963.

He entered the American University of Beirut and received his Bachelor of Engineering (Major: Civil) in 1967. He was also awarded Engineering Honors.

In 1967, he worked as a site engineer for Salem Brothers in the ESSO Gas Liquification Plant at Morsa-Brega, Libya. In 1968 he was appointed a graduate assistant at the American University of Befrut and received his M.E. (liajor: Civil) in 1970. During that period, he also worked as a design engineer for the office of Reconstruction, Ministry of Public Works, Lebanon. In 1970-71 he received the International Road Federation Fellowship to study at Purdue University. Since then he has been appointed as a research assistant.

He is a member of Lebanese Order of Engineers, a member of Lebanese Society of Environmental Engineers, a student member of Institute of Traffic Engineers, and an associate member of Sigma $X_{i}$. 
